the Total Environment

Elsevier Editorial system(tm) for Science of

Manuscript Draft

Manuscript Number: STOTEN-D-18-06314R1

Title: Long-term monitoring of drug consumption patterns in a large-sized European city using wastewater-based epidemiology: Comparison of two sampling schemes for the assessment of multiannual trends

Article Type: Research Paper

Keywords: illicit drugs, opioids, multiannual trends, wastewater-based epidemiology, Zagreb, LC-MS/MS

Corresponding Author: Dr. Senka Terzic,

Corresponding Author's Institution: Rudjer Boskovic Institute

First Author: Ivona Krizman-Matasic, PhD

Order of Authors: Ivona Krizman-Matasic, PhD; Ivan Senta, PhD; Petra Kostanjevecki, BSc; Marijan Ahel, PhD; Senka Terzic

Abstract: A comprehensive study aimed at monitoring of temporal variability of illicit drugs (heroin, cocaine, amphetamine, MDMA, methamphetamine and cannabis) and therapeutic opiate methadone in a large-sized European city using wastewater-based epidemiology (WBE) was conducted in the city of Zagreb, Croatia, during an 8-year period (20092016). The study addressed the impact of different sampling schemes on the assessment of temporal drug consumption patterns, in particular multiannual consumption trends and documented the possible errors associated with the one-week sampling scheme. The highest drug consumption prevalence was determined for cannabis (from $59 \pm 18$ to $156 \pm$ 37 doses/day/1000 inhabitants 15-64 years), followed by heroin (from $11 \pm$ 10 to $71 \pm 19$ doses/day/1000 inhabitants 15-64 years), cocaine (from 8.3 \pm 0.9 to $23 \pm 4.0$ doses/day/1000 inhabitants $15-64$ years) and amphetamine (from $1.3 \pm 0.9$ to $21 \pm 6.1$ doses/day/1000 inhabitants $15-64$ years) whereas the consumption of MDMA was comparatively lower (from $0.18 \pm 0.08$ to 2.7 doses \pm 0.7 doses/day/1000 inhabitants $15-64$ years). The drug consumption patterns were characterized by clearly enhanced weekend and Christmas season consumption of stimulating drugs (cocaine, MDMA and amphetamine) and somewhat lower summer consumption of almost all drugs. Pronounced multiannual consumption trends were determined for most of the illicit drugs. The investigated 8-year period was characterized by a marked increase of the consumption of pure cocaine (1.6-fold), THC (2.7fold), amphetamine (16-fold) and MDMA (15-fold) and a concomitant decrease (2.3-fold) of the consumption of pure heroin. The heroin consumption decrease was associated with an increase of methadone consumption (1.4-fold), which can be linked to its use in the heroin substitution therapy. The estimated number of average methadone doses consumed in the city of Zagreb was in a good agreement with the prescription data on treated opioid addicts in Croatia.

Response to Reviewers: Reviewer \#1: The authors report a WBE study in which they monitor temporal variability in biomarkers of heroin, cocaine, amphetamine, MDMA, methamphetamine and cannabis and the therapeutic 
opiate methadone in the waste water of Zagreb, Croatia over an 8-year period (2009-2016). The study assessed the reliability of one week vs annual sampling strategies on estimated temporal drug consumption patterns, weekday variations in the use of these drugs, and trends over time in the use of these drugs.

Their main findings were similar to those of studies in other European and high income countries in that:

* the drug with the highest consumption prevalence of use was for cannabis, followed by heroin, cocaine and amphetamine, with MDMA use much lower;

* There were enhanced weekend and holiday consumption of cocaine, MDMA, and amphetamine;

* Consumptions was marginally lower in summer for almost all drugs, reflecting population movements;

* Over the 8-year study period there was increases in the consumption of cocaine and THC and a more marked increase in use of amphetamine (16fold) and MDMA (15-fold). There was a large decrease in the consumption of heroin over the study period and an increase in the last year of study.

* The decline in heroin use was associated with an increase in methadone consumption that was linked to its increased use as a substitution treatment for heroin.

* The estimated average daily methadone dose in the city of Zagreb agreed well with the prescription data on the number of opioid addicts in Croatia enrolled in methadone treatment.

The last two findings are major novelties that have not been previously reported so far as I am aware, namely, a decline in indicators of heroin use occurring as there was increased use of methadone; and showing that methadone consumption estimated from waste water biomarkers closely agreed with data on the amount of methadone dispensed.

Q: I had one minor issue: what was the justification for the "arbitrary" definition of a significant ratio of weekend to weekly use of a drug, i.e. 1 plus or minus -0.2 ?

R: The criterion was selected based on the initial insight into the dayto-day variability of various non-stimulating drugs (in particular morphine, codeine and methadone) in the city of Zagreb with moderate relative standard deviations (RSD) of average daily loads being in the range up to 11 to $17 \%$, which indicated robustness of the collective excretion rates as an indicator of drug abuse in larger populations. Moreover, this criterion is well above the possible limitations posed by mere repeatability of the analytical method.

\section{Reviewer \#2: General Comments}

The manuscript presents a 7-year monitoring of selected drug consumption patterns in the city of Zagreb. The study presents an extensive monitoring data and is within the scope of STOTEN. Although similar studies have published before, the authors have tried to give a new perspective to the study by comparing monitoring data for different sampling periods and look for specific trends. I recommend this manuscript for publication following some major corrections. 
Major comments:

* It appears that the Authors have tried to make relatively generalized conclusions about any "large-sized European city" using the example of Zagreb with limited number of drugs considered. However, EMCDDA reports have shown the trends of drug use is very region-dependent and different for each drug. I suggest the authors to be more moderate and corroborate their outcomes with the studies in the same region and cities with similar population size.

R: We do not agree with this comment. As it was clearly emphasized in the title, one of the primary goals of the paper was testing different sampling strategies (sampling schemes) and estimation of the robustness of the applied sampling schemes to assess relatively small changes in consumption rates by taking into account possible sources of temporal variability (weekly dynamics, seasonal variability and impact of special events). These are important methodological issues of general character applicable to any large sized city. Our study did not intend to make any generalization regarding the drug consumption trends in other large-sized European cities based on the data from the city of Zagreb. We rather demonstrated that considering the proper sampling schemes can significantly improve the reliability of the trend monitoring making possible detection of relatively small changes.

* Using the term "sampling strategies", especially in the title is misleading. In fact, the study does not consider different sampling strategies (e.g. flow, volume, time proportional with different sampling intervals) but it rather considers different "sampling periods".

R: The term "sampling strategy" was systematically replaced with the term "sampling scheme(s)".

* The impact of in-sewer transformations was neglected in the manuscript. Number of studies (including previous author's studies) have shown that 6-AM, BE, THC-COOH are subject to transformation or formation in the sewer. How do the results would change if the authors consider such transformations? If these in-sewer processes are not included in the estimation of consumption rates (e.g. not through correction factors), at least the possible impacts should be discussed.

R: The impact of possible in-sewer transformations was not taken into account when estimating drug consumption. A model experiments which were performed at $100 \mathrm{C}$ and $200 \mathrm{C}$, with the wastewater from the city of Zagreb, indicated rather higher stability of all urinary biomarkers within the wastewater in-sewer residence time $(<5 \mathrm{~h})$ in the city of Zagreb. Our study (Senta et al., 2016. Sci Tot Environ, 487, 659-665), showed that even the most labile biomarkers such as 6-AM, BE, THC-COOH are not expected to be transformed more than 10\% (which we accepted as a margin of error). Furthermore, the study was performed within the same city (the same sewer system). Consequently, possible in-sewer transformations is not expected to have a significant effect either on the determined weekday/workday and holiday consumption patterns or on multiannual consumption trends.

A possible impact of in-sewer transformations is now briefly discussed in the revised version (Section 3.2.3.). 
* Devault et al. 2017 has shown that the stability of 6-AM and THC$\mathrm{COOH}$ is greatly influenced by temperature. Since this manuscript presents results related to March and August how does the temperature difference can explain the difference between the results presented in Fig. 4. Unfortunately the temperature is not reported in the manuscript and the impact is not discussed.

R: The typical in-sewer temperature in the city of Zagreb in March and Jul/Aug periods is $120 \mathrm{C}$ and $20.50 \mathrm{C}$, respectively. Our model experiments which were performed at $100 \mathrm{C}$ and $200 \mathrm{C}$, with the wastewater from the city of Zagreb, indicated rather higher stability of all urinary biomarkers presented in Fig. 4 at both investigated temperature conditions (Senta et al., 2016. Sci Tot Environ, 487, 659-665). Since the in-sewer wastewater residence time in the city of Zagreb is relatively short $(<5 \mathrm{~h})$, a significant impact of in-sewer degradation on the results presented on Figure 4 is not very likely.

A possible impact of in-sewer transformations is now briefly discussed in the revised version (Section 3.2.3.) and the reference Devault et al., 2017 is included.

* As compared to the actual outcomes, the conclusion section is rather short and incomplete. This can be supplemented with some details as outlined in the objectives (Lines 110-114) together with some recommendations for future monitoring campaigns.

R: The suggestion has been accepted. The conclusion section has been modified.

Detailed comments:

Line 142-144: When was the beginning and ending sampling in each day?

R: The samples were collected from 8 a.m. of the previous day to 8 a.m. of the sample collection day. This info was added to the manuscript (Section 2.3.)

Line 147-149: Are there any data that presented here but published before e.g. Krizman et al. 2016, Senta et al. 2015 or SCORE monitoring? This should be clarified in the manuscript.

R: The sentence: "Since the study covers a rather long time-period, some of the data, resulting from the sampling campaigns described above, were partially used in previously published studies (e.g. Krizman et al., 2016; Ort et al., 2014b; Terzic et al., 2010; Thomas et al., 2014)." has been added to the manuscript.

Line 153: "The total number of samples per year varied from 21 to 46". These numbers do not much with the "number of analyzed samples" in Table 2 (7 to 72). Is there any difference between number of samples and number of analyzed samples?

R: The total number of samples per year collected within the whole-year sampling scheme was 21-46. However, the total number of the samples presented in the Table 2 includes all samples collected and analyzed within a specified year (e.g. the number of samples collected within the one-week sample scheme plus the number of samples collected within the whole-year sample scheme, plus the number of samples collected within the Christmas-New Year period). 
Line 173 - 188: This is entirely a copy-paste from Krizman et al. 2016 (STOTEN 566-567 (2016) 454-462).

R: The applied methodology for the estimation of drug abuse is the same as described in Krizman et al (2016). We did our best to change the sentences of this part of the section 2.4. The changes are clearly marked in the revised version.

Line 195-197: What about correction factor for heroin?

R: The following text was added to the last sentence of the Section 2.4.: "whereas heroin consumption was calculated from 6-AM mass loads, using a correction factor of 86.9 (van Nuijs et al. 2011)

Line 209: 213: This seems to belong to Materials and Methods

R: This sentence was omitted from the revised version of the manuscript.

Line 210: what does the age of registered drug addicts (15-64) relate to your wastewater data? As you keep mentioning this range of age in your results, how can you make sure that people with age not included in the range did not contribute to your collected samples? I suggest you bring a strong evidence or remove it from the manuscript and Fig. 6.

R: We do not agree with this comment and suggestion. The epidemiological data (e.g. number of registered drug users are frequently normalized on the population of age 15-64 years. It does not mean that all users are in that age group. Consequently, the WBE data are frequently normalized on the population of age 15-64 years old and it does not mean that only the population of the age $15-64$ years contributed to the sample.

250-251: this is a repeated sentence (Line 156-157), suggest to remove

R: Suggestion accepted. Removed.

Line 269: "higher than" instead of "higher then"

$\mathrm{R}:$ Corrected

Line 325-331: Ort et al. 2014b, only assessed the back-calculation of COC using $\mathrm{BE}$. So the relative error of $60 \%$ was for this specific chemicals. Whereas in this manuscript the chemicals are completely different and the error varies a lot as shown in Figure 5. So this comparison and generalization is not entirely valid.

R: We do not agree with this comment. Ort and coworkers (2014b) addressed the challenges of surveying wastewater drug loads of small populations and generalizable aspects on optimizing monitoring design by comparing the results obtained for cocaine biomarker mass loads (BE and COC) using different sampling schemes in one small city (7160 inhabitants). Fig. 5 contains the data for $\mathrm{BE}$ as well. The variability for $\mathrm{BE}$ for both sampling schemes (one-week and whole-year) was lower then $20 \%$ in all investigated years. Therefore, we think that the performed comparison is appropriate. 
Line 340: please check with the formatting standard of the journal when you refer to supplementary material.

R: The expression "Electronic Supplementary Material" was replaced by "Supplementary Material".

Line 351: "... in some other WBE studies". This is very general. In which regions where those studies conducted? what population size? Which chemicals?

R: The following text was added to the revised manuscript:

"In principle, the determined drug consumption patterns and rates were rather similar to those determined in some other Mediterranean countries, like Spain and Italy (Mastroianni et al., 2017; Zuccato et al., 2016), although some differences regarding the prevalence of individual drugs as well as regarding the temporal trends were observed. For example, cannabis and cocaine were the most prevalently consumed illicit drugs in Barcelona (Spain) and investigated Italian cities, whereas a heroin consumption was reported to be much lower (Mastroianni et al., 2017; Zuccato et al., 2016)."

Line 410: "... are much smaller than those for the small communities". Based on which comparison this conclusion is made? This statement requires detailed comparison.

R: The sentence was slightly changed as follows:

"The errors associated with day-to-day and intra-annual variability of $\mathrm{BE}$ $(<20 \%)$ determined in the city of Zagreb (>500 000 inhabitants) study were much smaller from those reported for small communities (Ort et al. 2914b), which indicated enhanced robustness of the estimates obtained for large sized cities."

Figures: Please define in the figure captions what do error bars mean.

R: Defined. Error bars represent standard deviations.

Reviewer \#3: The manuscript presents the monitoring of drug consumption in Zagreb using wastewater-based epidemiology from 2009-2016.

The manuscript is fairly well written and cover a range of topics. I think this work is of relevance for readers of Science of the Total Environment and only have minor comments for the authors to remedy: * Despite an apparently comprehensive literature search, I believe the authors are missing some references that could strengthen the introduction. A group from South Australia have been performing bimonthly (every two months) sampling and it would be pertinent to include this somewhere in the introduction to show that there are other groups who don't just do one-week sampling. References could be Bade et al Analytical and Bioanalytical Chemistry 2018, $529-542$ and Tscharke et al Science of the Total Environment 2016, 384-391. Furthermore, Jiang et al (Environmental Science and Technology 2015, 792-799) also present the use of wastewater-based epidemiology for analyzing drug consumption during a festival. I encourage the authors to cite these articles within the introduction.

R: The suggested references are included in the revised manuscript. 
* The authors should be consistent with nomenclature. E.g. Line 231 (Figure 1) then all subsequent references to figures are (Fig. 2 etc.) The authors should stick with one.

\section{R: Corrected.}

* Line 277-279 is not needed. It is replicated at the beginning of the next section.

Removed from the revised version.

* Line 304: Why were Sunday and Tuesday chosen as sampling says for the year-long campaign? By only sampling one weekend day, the majority of the stimulants would be underestimated as described later in the section.

R: Sunday and Tuesday were selected as representatives of weekend day and week-day, respectively, for practical reasons. However, we don't think that we underestimated stimulants by sampling only one weekend day. Namely, as clearly described in our methodology we calculated representative average mass loads using the weight factors of 2 and 5 for weekend and weekday, respectively.

* The authors should replace "bimonthly" with "fortnightly" as bimonthly can be confused with "every two months".

R: Replaced.

* Line 407: The authors state in the conclusion that whole-year sampling showed a clear advantage over the seven-consecutive-day sampling scheme. However, in line 323, the authors state that one-week sampling may provide a reliable base the estimate of the annual consumption if most classical illicit drugs. These two sentences seem contrasting. In my opinion, there is no clear opinion voiced by the authors in section 3.3 as to which sampling scheme should be used. If the authors do believe that year-long sampling is advantageous, they should state that in section 3.3 .

R: We agree with the reviewer's comment. To avoid misinterpretations, the sentence in the section 3.3. was rephrased as follows:

"Nevertheless, although some previous studies, addressing the issue of multiannual changes, demonstrated the applicability of one-week sampling scheme (Ort et al. 2014; Mastroianni et al. 2017), our data show that such a scheme is insufficiently reliable for the drugs exhibiting high day-to-day and/or intra-annual variability, even in case of larger cities like the city of Zagreb."

* Figure 6: Why was methamphetamine not included in this figure?

$\mathrm{R}$ : Concentration of methamphetamine in most of the samples was below MQL and quantifiable concentrations appeared only sporadically. Therefore, its consumption was not included in Fig 6 which illustrates multiannual trends in Zagreb since, under the circumstances, no reliable trends could be observed 
* Figure 7: What are "stimulants" in the epidemiological figure? Within the manuscript, stimulants are described as the cocaine, methamphetamine, amphetamine and MDMA. However, cocaine is separate in this figure. The authors should specify precisely what these stimulants cover to ensure comparability with the wastewater data.

R: Stimulants in the epidemiological figure include amphetamine-type drugs. The explanation is added to the Figure captions.

Reviewer \#4: The manuscript entitled, "Long-term monitoring of drug consumption patterns in a large-sized European city using wastewaterbased epidemiology: comparison of sampling strategies for the assessment of multiannual trends" provides an interesting study for estimating drugs consumption in a European city. The paper is relevant, well written and logically constructed. The paper is of general interest. Even though the research is not novel as back-calculation methods have been use in many papers to estimate illicit drugs in untreated wastewater. I would like to recommend acceptance of this manuscript however there are important sections of data which should be explained in more detail before publication to ensure the results and methodologies applied are transparent and adequately quality assessed.

Comments

1. In my opinion the graphical abstract is not attractive. It could be improved.

R: This comment is not very informative. It is difficult to know what the reviewer means by "not attractive". However, we hope the reviewer is going to find the graphical abstract being more attractive in its revised form.

2. Line 30 and 42: According to the data, a 7-year period was conducted. Therefore, change 8-year period to 7-year period.

R: The study was performed within an 8-year period (2009-2016) but the data set includes data from 7 years $(2009,2011,2012,2013,2014,2015$, $2016)$.

3. Line 39-40. Please, specify that "holiday" refers to Christmas time.

R: "holiday" replaced with "the Christmas season"

4. Line 106: To be consistent with the rest of the paper, replace WBA by WBE.

R: Corrected

5. Line 134. MQ = Milli-Q water, I guess

$R:$ Corrected

6. Line 128. Which deuterated standards did you use? 
R: All analytes had their deuterated analogues. The analytical details are given in the analytical method (Senta et al, Analytical and Bioanalytical Chemistry, 405, 3255-3268).

7. Sampling data is confusing. I suggest adding the exact dates for sampling regarding lines 150 to 157 .

R: The Section 2.3. is changed in the revised version.

8. Specify the exact total number of samples you analyzed.

R: A following sentence was included in the revised manuscript: "A total number of 282 samples with an average pH of $7.6 \pm 0.2$ was collected."

9. Which was the pH sample?

R: A following sentence was included in the revised manuscript: "A total number of 282 samples with an average $\mathrm{pH}$ of $7.6 \pm 0.2$ was collected."

10. Brief information about liquid-chromatography as well as MS/MS conditions should be mentioned in the text

R: Some additional information on HPLC and MS conditions was added. We think that this should suffice considering the word count limitations. According to the Journal instructions, the methods which are already published should be summarized, and indicated by a reference, which is done.

11. Lines 186-189: "The population normalized daily mass loads were obtained by dividing the representative average mass loads with the number of inhabitants (in thousands) served by the investigated WWTP, which was based on 2011 Census data". However, data are referred to population

15-64 years along the text. Please, clarify.

R: Some of the published WBE data available in the literature are normalized to the total population (e.g. Zuccato et al. Drug Alcohol Depend 2016), whereas some of them are normalized to the population of age 15-64 years (e.g. Mastroianni et al. 2017). To facilitate the comparison with the literature, the drug consumption data in the Table S2 (Supplementary Material) are expressed in 8 different units (mg/day/1000 inh.; mg/day/1000 inh. 15-64 years; doses/day/1000 inh.; doses/day/1000 inh. 15-64 years; g/day; kg/year; kg/year - street purity). Only the Fig. 7 includes consumption data normalized to the population (in thousands) of age 15-64 years since the epidemiological data which are included in this figure are normalized to the population 15-64 years old.

Both the total population number served by the WWTP and the population number of age 15-64 years served by the WWTP are based on 2011 Census data.

12. For the back-calculation of heroin from MOR, did you take into account the contribution of therapeutic MOR? It should be subtracted when back-calculating heroin consumption 
R: Heroin consumption was calculated from 6-AM. Please, check the Table 1 .

13. Line 259-262. Is there any explanation about the increase of MOR?

R: No, currently we do not know the reason.

14. Line 262 and 378: Typing error: replace "concomittant" by

"concomitant"

R: Corrected.

15. Line 269: Change then for than in sentence "Christmas holiday season were 2 - 3.9-fold higher then during the average weekday"

R: Corrected.

16. Line 287-289. I partially agree with the authors because in summer there is a decrease of residential population but many tourists visit the city.

R: Even in summer, the contribution of tourists to the city population is negligible (<1\%; official data), whereas at the peak of summer season (25.7-15.8.) a significant percentage of residential population (unfortunately, official data are not available) leave Zagreb. This information was included in the revised section 3.2.3.

17. Lines 292-294. This statement should be explained in more detailed.

R: The discussion in the Section 3.2.3. has been amended to address possible reasons for lower summer biomarker mass loads.

18. Line 298: "was based" should be replace by "were based"

R: Corrected.

19. Line 311. There is a typing error. Replace "occasional" by

"occasional"

$\mathrm{R}:$ Corrected

20. Line 366. Add a reference for official data on the purity of seized drugs in the same period

R: The data on the purity of seized drugs were provided by the office for Combating Narcotic Drug Abuse of the Government of the Republic of Croatia. This info was added to the revised manuscript.

21. Please, explain how you calculated the amounts of the street-purity drugs (line 367-368).

R: Following sentence was added to the manuscript (Section 2.4.): "The amounts of street-purity drugs which circulated on the illegal market in Zagreb were calculated from the estimated annual consumption of pure 
drugs (expressed in $\mathrm{kg} /$ year), which were divided by the corresponding drug purity presented in Table S1."

22. Conclusions: As you have not compared errors in large cities vs small communities, this sentence should be modified

R: This section was thoroughly modified.

23. Table 1. Put a space in "Castiglioniet al" between Castiglioni and et

$\mathrm{R}$ : Corrected.

24. Table 1. Refined correction factors have been recently proposed for the back-calculation of the illicit drugs considered in this work. I suggest the authors to check the most recently published works (for instance, Gracia-Lor et al. 2016)

R: The refined correction factors proposed by Gracia-Lor et al. (2016) are applied in the revised version.

25. Figure 2. A legend about the meaning of the horizontal lines should be included.

R: The following text was added to the figure caption: "Horizontal lines represent arbitrarily assumed weekend to workday mass load ratio of $1.0 \pm$ 0.2 ".

26. In Figure 2, 7 and $\mathrm{S} 1$ it is difficult to distinguish among data due to similar coloured bars. Kindly, use a different means for identifying each analyte.

$\mathrm{R}$ : Corrected.

27. References: line 479, change Horder to Hordern

$\mathrm{R}:$ Corrected.

28. Table S2. Typing error: Change "wastwater" to wastewater

$R:$ Corrected

Reviewer \#5: This manuscript presents a long-term monitoring study of drug consumption in Zagreb - Croatia using wastewater-based epidemiology. In addition to 1 week of samples per year which is common in other multiannual wastewater-based epidemiology studies, the authors have also looked at higher sampling frequencies for a couple of years and compared this with the results they would have otherwise got based on only 1 week of sampling. The authors have also looked at drug consumption during holiday periods. My only major concern is that the authors appear to have used a static population size when the study has been conducted over an 8 year period and thus the data may not be truly population normalised and thus I think this needs to be addressed or at the very minimum discussed. My minor comment is that there are numerous grammatical errors throughout the text which would have been addressed from proper editing prior to submission. 
R: We do not expect that the population in Zagreb changed significantly over the investigated period. For example, the difference in the number of city inhabitants obtained by CENSUS 2001 and CENSUS 2011 was lower than $2 \%$. The number of tourists visiting Zagreb never exceeds $1 \%$ of the total population (official data). The only period with a significant change in population number might be summer vacation season (25th July 15th August.) due to the outward migrations of residential population (official data not available). Therefore, the mass loads determined during summer might be somewhat underestimated, which was discussed in Section 3.2.3.

Individual points:

Abstract

Line 30 - grammar "an 8-year"

R: Corrected

Line 66 - grammar "of the WBE approach"

$R$ : Corrected

Line 67 - grammar "of the WBE approach"

R: Corrected

Introduction

Line 106 - grammar and spelling "an initial WBE"

$\mathrm{R}$ : Corrected

Line 107 - grammar "of the other"

$R:$ Corrected

Chemicals and materials

Line 135 - grammar "purifying with an Elix-Mili-Q-system"

R: Corrected

Line 136 - grammar "were purchased from Waters"

R: Corrected

Line 138 - grammar "were purchased from Phenomenex"

$\mathrm{R}$ : Corrected

Line 139 - grammar "were purchased from Whatman"

R: Corrected

Wastewater sampling and analysis

Lines 144 to 149 - the way this is written is unclear

R: This part of the Section 2.3. is rewritten. We hope it is clear now. Line 162 - grammar "where performance" 


\section{$R:$ Corrected}

Lines 186 to 189 - This is a long time to normalize to a static population size. Did the population change over this period? What about for the holiday period comparison? Were population markers assessed?

R: We do not expect that the population in Zagreb changed significantly over the investigated period. For example, the difference in the number of city inhabitants obtained by CENSUS 2001 and CENSUS 2011 was < 2\%. The number of tourists visiting Zagreb never exceeds 1\% of the total population (official data). The only period with a significant change in population number might be summer vacation season (25th July - 15th August.) due to the outward migrations of residential population (official data not available). Therefore, the mass loads determined during summer might be somewhat underestimated, which was discussed in Section 3.2.3.

Line 197 - grammar "using the later"

R: Corrected

Line 213 - grammar "in the treatment"

$\mathrm{R}$ : Corrected

The impact of holiday season on drug consumption patterns

Line 252 - grammar "load"

$R$ : Corrected

Line 255 - grammar "seasons"

$R:$ Corrected

Line 262 - grammar - remove "a" before "holiday-related"

$\mathrm{R}$ : Corrected

Line 264 - be consistent with "holiday season" and "holiday-season"

R: Corrected

Lines 264 to 267 - without using de facto population sizes it seems like these differences might not be due to higher "per capita consumption" or may only be increased to a lesser extent

R: We do not agree with this comment. It is not likely that the data presented in Fig 3 can be significantly affected by the changes in population in the city of Zagreb.

Line 277 - grammar "on a one-week"

R: The sentence was omitted from the revised manuscript. 
Lines 287 to 294 - Other studies have shown numerous markers of population in wastewater which even without a thorough calibration for the investigated catchments would at least reflect relative change in population size. Why have the authors ignored this aspect?

R: As indicated in our response above, the official data on the population of the city of Zagreb do not suggest any significant changes during the period covered by this study.

Impact of sampling strategy on the estimation of drug consumption in multiannual studies

Line 298 -replace "was" with "previously conducted were"

$\mathrm{R}:$ Corrected.

Line 301 - replace "the" with "an"

$\mathrm{R}$ : Corrected.

Multiannual trends in drug consumption patterns and comparison with available epidemiological data

Line 379 - spelling "substitution therapy"

$\mathrm{R}$ : Corrected.

Line 395 - grammar "the outcome"

R: Corrected.

Line 396 - grammar "surveys"

$\mathrm{R}:$ Corrected.

Line 412 - too many uses of "moreover"

$\mathrm{R}$ : Corrected.

Reviewer \#6: Dear Editor,

Thank you for your invitation to review manuscript STOTEN-D-18-06314 entitled "Long-term monitoring of drug consumption patterns in a largesized European city using wastewater-based epidemiology: Comparison of sampling strategies for the assessment of multiannual trends."

Monitoring studies are useful and the topic is of interest, so I consider this paper is interesting to be published in STOTEN after some minor changes.

General comments

- Why do you write sometimes 7-year study (highlights, page 6, line 114) and sometimes 8-year period (page 2, line 30 and 42; page 18, line 355)?

R: The study was performed within an 8-year period (2009-2016) but the data set includes data from 7 years $(2009,2011,2012,2013,2014,2015$, 
2016). To be more consistent, the corrections were made in the text wherever needed.

- Page 4, lines 62-65, 68-70: Some references are quite old. There are a lot of monitoring research studies on wastewater-based epidemiology in the last 5 years so I recommend to authors to update references.

R: Some additional references are included in the revised version. However, the literature on WBE of illicit drugs has become rather large and, since this is not a review paper, there has to be some selection.

- Page 6, line 106: I think you want to say 'WBE'.

$\mathrm{R}:$ Corrected.

- I suggest extending the discussion in sections 3.1 Occurrence of drug biomarkers in municipal wastewater of the city of Zagreb and 3.2 Drug consumption patterns. Please, compare your results with other European countries.

R: In our opinion there is no need for the extensive comparison of the results from Zagreb with the results from other European cities in these 2 sections. According to the Journal's instructions, extensive citations and discussion of published literature should be avoided.

- Table 2. Delete vertical line between Mass load and Average (first line of AMP data).

R: Corrected.

- Figure 1 and 5. Exchange decimals in commas for decimal points.

$\mathrm{R}:$ Corrected.

Reviewer \#7: The article titled "Long-term monitoring of drug consumption patterns in a large-sized European city using wastewater-based epidemiology: Comparison of sampling strategies for the assessment of multiannual trends" is based on the analysis of WBE data over an eightyear period. Their study analyses trends revealed by the longitudinal data and compares sampling techniques currently used in many WBE studies. Based on their results, the authors propose a different sampling strategy different from what has been currently used in many WBE studies.

With more regions implementing WBE for community drug monitoring, the results from this study could prove significant to improving regional and multi-regional sampling. I believe this study will be of interest to many STOTEN readers and even more the WBE scientists. I recommend the article for publication.

I have only few comments and suggest a thorough read-through to correct some typos.

1. Line 183-184 authors used daily flow rates for mass load calculation, as such I assume you have all the flow rate data. Line 290292. Do the seasonal changes in population affect the WWTP flow rates? 
$\mathrm{R}$ : Yes, the data on wastewater mass flow expressed in m3/day were obtained from the Central WWTP of the city of Zagreb. However, the sewer system of the city of Zagreb receives either municipal and industrial wastewater as well as rain water and even some stream waters. The flow rates are therefore more influenced by precipitations than by changes in population size and cannot be used as indicators of population size changes.

2. Additionally, though the proposed multiannual and seasonal sampling techniques applied in this study were useful in providing insight on drug use dynamics and better drug use estimations for Zagreb. It is difficult without a comparison site to tell if the same sampling technique would apply as well or have significant impact on a different city (smaller vs bigger; rural vs urban) even in Croatia.

R: We believe that the improvements achieved through the use the wholeyear sampling scheme described in this paper strongly suggest that, in spite of possible variations in weekly and seasonal dynamics, large sized cities provide a robust systems for multiannual monitoring of illicit drugs. 


\section{Cover Letter}

$\begin{array}{lllllllllllllllllllll}I & n & s & t & i & t & u & t & R & u & d & e & r & B & o & s & k & o & v & i & c\end{array}$

Adresa: Bijenička cesta 54, 10000 Zagreb | Tel: +385 (0)1 4561111 | Fax: +385 (0)1 4680084 | www.irb.hr

\section{Dr. Senka Terzic}

Division of the marine and environmental research

Bijenička cesta 54

P.O. BOX 180

1000 Zagreb

Croatia

Tel: ++ 38514560940

Fax: ++38514680242

terzic@irb.hr

Zagreb, 30 July 2018

Dear dr. Pico,

please find enclosed the revised version of the manuscript entitled "Long-term monitoring of drug consumption patterns in a large-sized European city using wastewater-based epidemiology: Comparison of two sampling schemes for the assessment of multiannual trends". We carefully considered all reviewers' comments and provided an itemized list of responses. The changes made to the manuscript are clearly marked in the revised version of the manuscript using the track changes option. The version of the revised manuscript with the accepted changes is also submitted. We are very grateful to all 7 reviewers whose valuable comments, suggestions and questions helped us to improve the manuscript.

We hope that the revised manuscript is now acceptable for the publication in the Science of the Total Environment.

Please send all further correspondence to me (terzic@irb.hr).

Sincerely yours,

dr. Senka Terzic 


\title{
Long-term monitoring of drug consumption patterns in a large-sized European city using wastewater-based epidemiology: Comparison of two sampling schemes for the assessment of multiannual trends
}

\section{Division for Marine and Environmental Research, Rudjer Boskovic Institute, Bijenicka c. 54, 10000 Zagreb, Croatia}

\begin{abstract}
*Corresponding author:
\end{abstract}
Dr. Senka Terzic

Contact: terzic@irb.hr

Tel. +385-1-4560-940

Fax: +385-1-4680-242 


\section{ANSWERS TO THE REVIEWERS}

Reviewer \#1: The authors report a WBE study in which they monitor temporal variability in biomarkers of heroin, cocaine, amphetamine, MDMA, methamphetamine and cannabis and the therapeutic opiate methadone in the waste water of Zagreb, Croatia over an 8-year period (2009-2016). The study assessed the reliability of one week vs annual sampling strategies on estimated temporal drug consumption patterns, weekday variations in the use of these drugs, and trends over time in the use of these drugs.

Their main findings were similar to those of studies in other European and high income countries in that: * the drug with the highest consumption prevalence of use was for cannabis, followed by heroin, cocaine and amphetamine, with MDMA use much lower;

* There were enhanced weekend and holiday consumption of cocaine, MDMA, and amphetamine;

* $\quad$ Consumptions was marginally lower in summer for almost all drugs, reflecting population movements;

* Over the 8-year study period there was increases in the consumption of cocaine and THC and a more marked increase in use of amphetamine (16-fold) and MDMA (15-fold). There was a large decrease in the consumption of heroin over the study period and an increase in the last year of study.

* The decline in heroin use was associated with an increase in methadone consumption that was linked to its increased use as a substitution treatment for heroin.

* The estimated average daily methadone dose in the city of Zagreb agreed well with the prescription data on the number of opioid addicts in Croatia enrolled in methadone treatment.

The last two findings are major novelties that have not been previously reported so far as I am aware, namely, a decline in indicators of heroin use occurring as there was increased use of methadone; and showing that methadone consumption estimated from waste water biomarkers closely agreed with data on the amount of methadone dispensed.

Q: I had one minor issue: what was the justification for the "arbitrary" definition of a significant ratio of weekend to weekly use of a drug, i.e. 1 plus or minus -0.2 ?

R: The criterion was selected based on the initial insight into the day-to-day variability of various non-stimulating drugs (in particular morphine, codeine and methadone) in the city of Zagreb with moderate relative standard deviations (RSD) of average daily loads being in the range up to 11 to $17 \%$, which indicated robustness of the collective excretion rates as an indicator of drug abuse in larger populations. Moreover, this criterion is well above the possible limitations posed by mere repeatability of the analytical method.

\section{Reviewer \#2: General Comments}

The manuscript presents a 7-year monitoring of selected drug consumption patterns in the city of Zagreb. The study presents an extensive monitoring data and is within the scope of STOTEN. Although similar studies have published before, the authors have tried to give a new perspective to the study by comparing monitoring data for different sampling periods and look for specific trends. I recommend this manuscript for publication following some major corrections.

\section{Major comments:}

* It appears that the Authors have tried to make relatively generalized conclusions about any "large-sized European city" using the example of Zagreb with limited number of drugs considered. However, EMCDDA reports have shown the trends of drug use is very region-dependent and different for each drug. I suggest the authors to be more moderate and corroborate their outcomes with the studies in the same region and cities with similar population size. 
R: We do not agree with this comment. As it was clearly emphasized in the title, one of the primary goals of the paper was testing different sampling strategies (sampling schemes) and estimation of the robustness of the applied sampling schemes to assess relatively small changes in consumption rates by taking into account possible sources of temporal variability (weekly dynamics, seasonal variability and impact of special events). These are important methodological issues of general character applicable to any large sized city. Our study did not intend to make any generalization regarding the drug consumption trends in other large-sized European cities based on the data from the city of Zagreb. We rather demonstrated that considering the proper sampling schemes can significantly improve the reliability of the trend monitoring making possible detection of relatively small changes.

* $\quad$ Using the term "sampling strategies", especially in the title is misleading. In fact, the study does not consider different sampling strategies (e.g. flow, volume, time proportional with different sampling intervals) but it rather considers different "sampling periods".

R: The term "sampling strategy" was systematically replaced with the term "sampling scheme(s)".

* The impact of in-sewer transformations was neglected in the manuscript. Number of studies (including previous author's studies) have shown that 6-AM, BE, THC-COOH are subject to transformation or formation in the sewer. How do the results would change if the authors consider such transformations? If these in-sewer processes are not included in the estimation of consumption rates (e.g. not through correction factors), at least the possible impacts should be discussed.

R: The impact of possible in-sewer transformations was not taken into account when estimating drug consumption. A model experiments which were performed at $10^{\circ} \mathrm{C}$ and $20^{\circ} \mathrm{C}$, with the wastewater from the city of Zagreb, indicated rather higher stability of all urinary biomarkers within the wastewater in-sewer residence time $(<5 \mathrm{~h}$ ) in the city of Zagreb. Our study (Senta et al., 2016. Sci Tot Environ, 487, 659-665), showed that even the most labile biomarkers such as 6-AM, BE, THC-COOH are not expected to be transformed more than $10 \%$ (which we accepted as a margin of error). Furthermore, the study was performed within the same city (the same sewer system). Consequently, possible in-sewer transformations is not expected to have a significant effect either on the determined weekday/workday and holiday consumption patterns or on multiannual consumption trends.

A possible impact of in-sewer transformations is now briefly discussed in the revised version (Section 3.2.3.).

* Devault et al. 2017 has shown that the stability of 6-AM and THC-COOH is greatly influenced by temperature. Since this manuscript presents results related to March and August how does the temperature difference can explain the difference between the results presented in Fig. 4. Unfortunately the temperature is not reported in the manuscript and the impact is not discussed.

R: The typical in-sewer temperature in the city of Zagreb in March and Jul/Aug periods is $12^{\circ} \mathrm{C}$ and $20.5^{\circ} \mathrm{C}$, respectively. Our model experiments which were performed at $10^{\circ} \mathrm{C}$ and $20^{\circ} \mathrm{C}$, with the wastewater from the city of Zagreb, indicated rather higher stability of all urinary biomarkers presented in Fig. 4 at both investigated temperature conditions (Senta et al., 2016. Sci Tot Environ, 487, 659-665). Since the in-sewer wastewater residence time in the city of Zagreb is relatively short ( $<5 \mathrm{~h}$ ), a significant impact of in-sewer degradation on the results presented on Figure 4 is not very likely.

A possible impact of in-sewer transformations is now briefly discussed in the revised version (Section 3.2.3.) and the reference Devault et al., 2017 is included.

* As compared to the actual outcomes, the conclusion section is rather short and incomplete. This can be supplemented with some details as outlined in the objectives (Lines 110-114) together with some recommendations for future monitoring campaigns. 
R: The suggestion has been accepted. The conclusion section has been modified.

Detailed comments:

Line 142-144: When was the beginning and ending sampling in each day?

R: The samples were collected from 8 a.m. of the previous day to 8 a.m. of the sample collection day. This info was added to the manuscript (Section 2.3.)

Line 147-149: Are there any data that presented here but published before e.g. Krizman et al. 2016, Senta et al. 2015 or SCORE monitoring? This should be clarified in the manuscript.

R: The sentence: "Since the study covers a rather long time-period, some of the data, resulting from the sampling campaigns described above, were partially used in previously published studies (e.g. Krizman et al., 2016; Ort et al., 2014b; Terzic et al., 2010; Thomas et al., 2014)." has been added to the manuscript.

Line 153: "The total number of samples per year varied from 21 to 46 ". These numbers do not much with the "number of analyzed samples" in Table 2 ( 7 to 72 ). Is there any difference between number of samples and number of analyzed samples?

R: The total number of samples per year collected within the whole-year sampling scheme was 21-46. However, the total number of the samples presented in the Table $\mathbf{2}$ includes all samples collected and analyzed within a specified year (e.g. the number of samples collected within the one-week sample scheme plus the number of samples collected within the whole-year sample scheme, plus the number of samples collected within the Christmas-New Year period).

Line 173 - 188: This is entirely a copy-paste from Krizman et al. 2016 (STOTEN 566-567 (2016) 454-462).

R: The applied methodology for the estimation of drug abuse is the same as described in Krizman et al (2016). We did our best to change the sentences of this part of the Section 2.4. The changes are clearly marked in the revised version.

Line 195-197: What about correction factor for heroin?

R: The following text was added to the last sentence of the Section 2.4.:

"whereas heroin consumption was calculated from 6-AM mass loads, using a correction factor of 86.9 (van Nuijs et al. 2011)

Line 209: 213: This seems to belong to Materials and Methods

R: This sentence was omitted from the revised version of the manuscript.

Line 210: what does the age of registered drug addicts (15-64) relate to your wastewater data? As you keep mentioning this range of age in your results, how can you make sure that people with age not included in the range did not contribute to your collected samples? I suggest you bring a strong evidence or remove it from the manuscript and Fig. 6.

R: We do not agree with this comment and suggestion. The epidemiological data (e.g. number of registered drug users are frequently normalized on the population of age 15-64 years. It does not mean that all users are in that age group. Consequently, the WBE data are frequently normalized on the population of age 15-64 years old and it does not mean that only the population of the age $15-64$ years contributed to the sample. 
250-251: this is a repeated sentence (Line 156-157), suggest to remove

R: Suggestion accepted. Removed.

Line 269: "higher than" instead of "higher then"

\section{R: Corrected}

Line 325-331: Ort et al. 2014b, only assessed the back-calculation of COC using BE. So the relative error of $60 \%$ was for this specific chemicals. Whereas in this manuscript the chemicals are completely different and the error varies a lot as shown in Figure 5. So this comparison and generalization is not entirely valid.

R: We do not agree with this comment. Ort and coworkers (2014b) addressed the challenges of surveying wastewater drug loads of small populations and generalizable aspects on optimizing monitoring design by comparing the results obtained for cocaine biomarker mass loads (BE and COC) using different sampling schemes in one small city (7160 inhabitants). Fig. 5 contains the data for BE as well. The variability for BE for both sampling schemes (one-week and whole-year) was lower then $\mathbf{2 0 \%}$ in all investigated years. Therefore, we think that the performed comparison is appropriate.

Line 340: please check with the formatting standard of the journal when you refer to supplementary material.

R: The expression “Electronic Supplementary Material” was replaced by "Supplementary Material”.

Line 351: "... in some other WBE studies". This is very general. In which regions where those studies conducted? what population size? Which chemicals?

R: The following text was added to the revised manuscript:

„In principle, the determined drug consumption patterns and rates were rather similar to those determined in some other Mediterranean countries, like Spain and Italy (Mastroianni et al., 2017; Zuccato et al., 2016), although some differences regarding the prevalence of individual drugs as well as regarding the temporal trends were observed. For example, cannabis and cocaine were the most prevalently consumed illicit drugs in Barcelona (Spain) and investigated Italian cities, whereas a heroin consumption was reported to be much lower (Mastroianni et al., 2017; Zuccato et al., 2016).“

Line 410: "... are much smaller than those for the small communities". Based on which comparison this conclusion is made? This statement requires detailed comparison.

R: The sentence was slightly changed as follows:

"The errors associated with day-to-day and intra-annual variability of BE $(<20 \%)$ determined in the city of Zagreb (>500 000 inhabitants) study were much smaller from those reported for small communities (Ort et al. 2914b), which indicated enhanced robustness of the estimates obtained for large sized cities."

Figures: Please define in the figure captions what do error bars mean.

R: Defined. Error bars represent standard deviations.

Reviewer \#3: The manuscript presents the monitoring of drug consumption in Zagreb using wastewater-based epidemiology from 2009-2016.

The manuscript is fairly well written and cover a range of topics. I think this work is of relevance for readers of Science of the Total Environment and only have minor comments for the authors to remedy: 
* Despite an apparently comprehensive literature search, I believe the authors are missing some references that could strengthen the introduction. A group from South Australia have been performing bimonthly (every two months) sampling and it would be pertinent to include this somewhere in the introduction to show that there are other groups who don't just do one-week sampling. References could be Bade et al Analytical and Bioanalytical Chemistry 2018, 529-542 and Tscharke et al Science of the Total Environment 2016, 384-391. Furthermore, Jiang et al (Environmental Science and Technology 2015, 792-799) also present the use of wastewater-based epidemiology for analyzing drug consumption during a festival. I encourage the authors to cite these articles within the introduction.

R: The suggested references are included in the revised manuscript.

* The authors should be consistent with nomenclature. E.g. Line 231 (Figure 1) then all subsequent references to figures are (Fig. 2 etc.) The authors should stick with one.

\section{R: Corrected.}

* $\quad$ Line $277-279$ is not needed. It is replicated at the beginning of the next section.

\section{Removed from the revised version.}

* $\quad$ Line 304: Why were Sunday and Tuesday chosen as sampling says for the year-long campaign? By only sampling one weekend day, the majority of the stimulants would be underestimated as described later in the section.

R: Sunday and Tuesday were selected as representatives of weekend day and week-day, respectively, for practical reasons. However, we don't think that we underestimated stimulants by sampling only one weekend day. Namely, as clearly described in our methodology we calculated representative average mass loads using the weight factors of $\mathbf{2}$ and $\mathbf{5}$ for weekend and weekday, respectively.

* The authors should replace "bimonthly" with "fortnightly" as bimonthly can be confused with "every two months".

R: Replaced.

* $\quad$ Line 407: The authors state in the conclusion that whole-year sampling showed a clear advantage over the seven-consecutive-day sampling scheme. However, in line 323, the authors state that one-week sampling may provide a reliable base the estimate of the annual consumption if most classical illicit drugs. These two sentences seem contrasting. In my opinion, there is no clear opinion voiced by the authors in section 3.3 as to which sampling scheme should be used. If the authors do believe that year-long sampling is advantageous, they should state that in section 3.3.

R: We agree with the reviewer's comment. To avoid misinterpretations, the sentence in the Section 3.3 . was rephrased as follows:

"Nevertheless, although some previous studies, addressing the issue of multiannual changes, demonstrated the applicability of one-week sampling scheme (Ort et al. 2014; Mastroianni et al. 2017), our data show that such a scheme is insufficiently reliable for the drugs exhibiting high day-to-day and/or intra-annual variability, even in case of larger cities like the city of Zagreb."

Figure 6: Why was methamphetamine not included in this figure? 
R: Concentration of methamphetamine in most of the samples was below MQL and quantifiable concentrations appeared only sporadically. Therefore, its consumption was not included in Fig $\mathbf{6}$ which illustrates multiannual trends in Zagreb since, under the circumstances, no reliable trends could be observed

* $\quad$ Figure 7: What are "stimulants" in the epidemiological figure? Within the manuscript, stimulants are described as the cocaine, methamphetamine, amphetamine and MDMA. However, cocaine is separate in this figure. The authors should specify precisely what these stimulants cover to ensure comparability with the wastewater data.

R: Stimulants in the epidemiological figure include amphetamine-type drugs. The explanation is added to the Figure captions.

Reviewer \#4: The manuscript entitled, "Long-term monitoring of drug consumption patterns in a large-sized European city using wastewater-based epidemiology: comparison of sampling strategies for the assessment of multiannual trends" provides an interesting study for estimating drugs consumption in a European city. The paper is relevant, well written and logically constructed. The paper is of general interest. Even though the research is not novel as back-calculation methods have been use in many papers to estimate illicit drugs in untreated wastewater. I would like to recommend acceptance of this manuscript however there are important sections of data which should be explained in more detail before publication to ensure the results and methodologies applied are transparent and adequately quality assessed.

Comments

1.In my opinion the graphical abstract is not attractive. It could be improved.

R: This comment is not very informative. It is difficult to know what the reviewer means by "not attractive". However, we hope the reviewer is going to find the graphical abstract being more attractive in its revised form.

2. Line 30 and 42: According to the data, a 7-year period was conducted. Therefore, change 8-year period to 7-year period.

R: The study was performed within an 8-year period (2009-2016) but the data set includes data from 7 years (2009, 2011, 2012, 2013, 2014, 2015, 2016).

3. Line 39-40. Please, specify that "holiday" refers to Christmas time.

R:"holiday" replaced with "the Christmas season"

4. Line 106: To be consistent with the rest of the paper, replace WBA by WBE.

\section{R: Corrected}

5. Line 134. $\mathrm{MQ}=$ Milli-Q water, $\mathrm{I}$ guess

\section{R: Corrected}

6. Line 128 . Which deuterated standards did you use? 
R: All analytes had their deuterated analogues. The analytical details are given in the analytical method (Senta et al, Analytical and Bioanalytical Chemistry, 405, 3255-3268).

7. Sampling data is confusing. I suggest adding the exact dates for sampling regarding lines 150 to 157.

R: The Section 2.3. is changed in the revised version.

8. Specify the exact total number of samples you analyzed.

R: A following sentence was included in the revised manuscript: "A total number of 282 samples with an average pH of $7.6 \pm 0.2$ was collected."

9. Which was the $\mathrm{pH}$ sample?

R: A following sentence was included in the revised manuscript: "A total number of 282 samples with an average pH of $7.6 \pm 0.2$ was collected."

10. Brief information about liquid-chromatography as well as MS/MS conditions should be mentioned in the text

R: Some additional information on HPLC and MS conditions was added. We think that this should suffice considering the word count limitations. According to the Journal instructions, the methods which are already published should be summarized, and indicated by a reference, which is done.

11. Lines 186-189: "The population normalized daily mass loads were obtained by dividing the representative average mass loads with the number of inhabitants (in thousands) served by the investigated WWTP, which was based on 2011 Census data". However, data are referred to population

15-64 years along the text. Please, clarify.

R: Some of the published WBE data available in the literature are normalized to the total population (e.g. Zuccato et al. Drug Alcohol Depend 2016), whereas some of them are normalized to the population of age 15-64 years (e.g. Mastroianni et al. 2017). To facilitate the comparison with the literature, the drug consumption data in the Table S2 (Supplementary Material) are expressed in 8 different units (mg/day/1000 inh.; mg/day/1000 inh. 15-64 years; doses/day/1000 inh.; doses/day/1000 inh. 15-64 years; g/day; kg/year; kg/year - street purity). Only the Fig. 7 includes consumption data normalized to the population (in thousands) of age 15-64 years since the epidemiological data which are included in this figure are normalized to the population 15-64 years old. Both the total population number served by the WWTP and the population number of age 15-64 years served by the WWTP are based on 2011 Census data.

12. For the back-calculation of heroin from MOR, did you take into account the contribution of therapeutic MOR? It should be subtracted when back-calculating heroin consumption

R: Heroin consumption was calculated from 6-AM. Please, check the Table 1.

13. Line 259-262. Is there any explanation about the increase of MOR?

R: No, currently we do not know the reason.

14. Line 262 and 378: Typing error: replace "concomittant" by "concomitant" 


\section{R: Corrected.}

15. Line 269: Change then for than in sentence "Christmas holiday season were 2 - 3.9-fold higher then during the average weekday"

\section{R: Corrected.}

16. Line 287-289. I partially agree with the authors because in summer there is a decrease of residential population but many tourists visit the city.

R: Even in summer, the contribution of tourists to the city population is negligible (<1\%; official data), whereas at the peak of summer season (25.7-15.8.) a significant percentage of residential population (unfortunately, official data are not available) leave Zagreb. This information was included in the revised section 3.2.3.

17. Lines 292-294. This statement should be explained in more detailed.

R: The discussion in the Section 3.2.3. has been amended to address possible reasons for lower summer biomarker mass loads.

18. Line 298: "was based" should be replace by "were based"

R: Corrected.

19. Line 311. There is a typing error. Replace "occasional" by "occasional"

\section{R: Corrected}

20. Line 366. Add a reference for official data on the purity of seized drugs in the same period

R: The data on the purity of seized drugs were provided by the Office for Combating Narcotic Drug Abuse of the Government of the Republic of Croatia. This info was added to the revised manuscript.

21. Please, explain how you calculated the amounts of the street-purity drugs (line 367-368).

R: Following sentence was added to the manuscript (Section 2.4.): "The amounts of street-purity drugs which circulated on the illegal market in Zagreb were calculated from the estimated annual consumption of pure drugs (expressed in kg/year), which were divided by the corresponding drug purity presented in Table S1."

22. Conclusions: As you have not compared errors in large cities vs small communities, this sentence should be modified

R: This section was thoroughly modified.

23. Table 1. Put a space in "Castiglioniet al" between Castiglioni and et

R: Corrected.

24. Table 1. Refined correction factors have been recently proposed for the back-calculation of the illicit drugs considered in this work. I suggest the authors to check the most recently published works (for instance, Gracia-Lor et al. 2016) 
R: The refined correction factors proposed by Gracia-Lor et al. (2016) are applied in the revised version.

25. Figure 2. A legend about the meaning of the horizontal lines should be included.

R: The following text was added to the figure caption: „Horizontal lines represent arbitrarily assumed weekend to workday mass load ratio of $1.0 \pm 0.2^{\prime \prime}$.

26. In Figure 2, 7 and S1 it is difficult to distinguish among data due to similar coloured bars. Kindly, use a different means for identifying each analyte.

\section{R: Corrected.}

27. References: line 479, change Horder to Hordern

\section{R: Corrected.}

28. Table S2. Typing error: Change "wastwater" to wastewater

\section{R: Corrected}

Reviewer \#5: This manuscript presents a long-term monitoring study of drug consumption in Zagreb - Croatia using wastewater-based epidemiology. In addition to 1 week of samples per year which is common in other multiannual wastewater-based epidemiology studies, the authors have also looked at higher sampling frequencies for a couple of years and compared this with the results they would have otherwise got based on only 1 week of sampling. The authors have also looked at drug consumption during holiday periods. My only major concern is that the authors appear to have used a static population size when the study has been conducted over an 8 year period and thus the data may not be truly population normalised and thus I think this needs to be addressed or at the very minimum discussed. My minor comment is that there are numerous grammatical errors throughout the text which would have been addressed from proper editing prior to submission.

R: We do not expect that the population in Zagreb changed significantly over the investigated period. For example, the difference in the number of city inhabitants obtained by CENSUS 2001 and CENSUS 2011 was lower than $2 \%$. The number of tourists visiting Zagreb never exceeds $1 \%$ of the total population (official data). The only period with a significant change in population number might be summer vacation season $\left(25^{\text {th }}\right.$ July $-15^{\text {th }}$ August.) due to the outward migrations of residential population (official data not available). Therefore, the mass loads determined during summer might be somewhat underestimated, which was discussed in Section 3.2.3.

Individual points:

Abstract

Line 30 - grammar "an 8-year"

\section{R: Corrected}

Line 66 - grammar "of the WBE approach"

\section{R: Corrected}

Line 67 - grammar "of the WBE approach"

\section{R: Corrected}


Introduction

Line 106 - grammar and spelling "an initial WBE"

R: Corrected

Line 107 - grammar "of the other"

R: Corrected

Chemicals and materials

Line 135 - grammar "purifying with an Elix-Mili-Q-system"

R: Corrected

Line 136 - grammar "were purchased from Waters"

R: Corrected

Line 138 - grammar "were purchased from Phenomenex"

R: Corrected

Line 139 - grammar "were purchased from Whatman"

R: Corrected

Wastewater sampling and analysis

Lines 144 to 149 - the way this is written is unclear

R: This part of the Section 2.3. is rewritten. We hope it is clear now.

Line 162 - grammar "where performance"

R: Corrected

Lines 186 to 189 - This is a long time to normalize to a static population size. Did the population change over this period? What about for the holiday period comparison? Were population markers assessed?

R: We do not expect that the population in Zagreb changed significantly over the investigated period. For example, the difference in the number of city inhabitants obtained by CENSUS 2001 and CENSUS 2011 was < 2\%. The number of tourists visiting Zagreb never exceeds $1 \%$ of the total population (official data). The only period with a significant change in population number might be summer vacation season (25th July - 15th August.) due to the outward migrations of residential population (official data not available). Therefore, the mass loads determined during summer might be somewhat underestimated, which was discussed in Section 3.2.3.

Line 197 - grammar "using the later"

\section{R: Corrected}

Line 213 - grammar "in the treatment"

\section{R: Corrected}


The impact of holiday season on drug consumption patterns

Line 252 - grammar "load"

\section{R: Corrected}

Line 255 - grammar "seasons"

R: Corrected

Line 262 - grammar - remove "a" before "holiday-related"

R: Corrected

Line 264 - be consistent with "holiday season" and "holiday-season"

\section{R: Corrected}

Lines 264 to 267 - without using de facto population sizes it seems like these differences might not be due to higher "per capita consumption" or may only be increased to a lesser extent

R: We do not agree with this comment. It is not likely that the data presented in Fig 3 can be significantly affected by the changes in population in the city of Zagreb.

Line 277 - grammar "on a one-week"

\section{R: The sentence was omitted from the revised manuscript.}

Lines 287 to 294 - Other studies have shown numerous markers of population in wastewater which even without a thorough calibration for the investigated catchments would at least reflect relative change in population size. Why have the authors ignored this aspect?

R: As indicated in our response above, the official data on the population of the city of Zagreb do not suggest any significant changes during the period covered by this study.

Impact of sampling strategy on the estimation of drug consumption in multiannual studies

Line 298 -replace "was" with "previously conducted were"

\section{R: Corrected.}

Line 301 - replace "the" with "an"

\section{R: Corrected.}

Multiannual trends in drug consumption patterns and comparison with available epidemiological data Line 379 - spelling "substitution therapy" 


\section{R: Corrected.}

Line 395 - grammar "the outcome"

\section{R: Corrected.}

Line 396 - grammar "surveys"

\section{R: Corrected.}

Line 412 - too many uses of "moreover"

\section{R: Corrected.}

Reviewer \#6: Dear Editor, Thank you for your invitation to review manuscript STOTEN-D-18-06314 entitled "Long-term monitoring of drug consumption patterns in a large-sized European city using wastewater-based epidemiology: Comparison of sampling strategies for the assessment of multiannual trends."

Monitoring studies are useful and the topic is of interest, so I consider this paper is interesting to be published in STOTEN after some minor changes.

General comments

- Why do you write sometimes 7-year study (highlights, page 6, line 114) and sometimes 8-year period (page 2, line 30 and 42 ; page 18 , line 355$)$ ?

R: The study was performed within an 8-year period (2009-2016) but the data set includes data from 7 years $(2009,2011,2012,2013,2014,2015,2016)$. To be more consistent, the corrections were made in the text wherever needed.

- Page 4, lines 62-65, 68-70: Some references are quite old. There are a lot of monitoring research studies on wastewater-based epidemiology in the last 5 years so I recommend to authors to update references.

R: Some additional references are included in the revised version. However, the literature on WBE of illicit drugs has become rather large and, since this is not a review paper, there has to be some selection.

- Page 6, line 106: I think you want to say 'WBE'.

\section{R: Corrected.}

- I suggest extending the discussion in sections 3.1 Occurrence of drug biomarkers in municipal wastewater of the city of Zagreb and 3.2 Drug consumption patterns. Please, compare your results with other European countries.

R: In our opinion there is no need for the extensive comparison of the results from Zagreb with the results from other European cities in these 2 sections. According to the Journal's instructions, extensive citations and discussion of published literature should be avoided.

- Table 2. Delete vertical line between Mass load and Average (first line of AMP data).

\section{R: Corrected.}

- Figure 1 and 5. Exchange decimals in commas for decimal points. 


\section{R: Corrected.}

Reviewer \#7: The article titled "Long-term monitoring of drug consumption patterns in a large-sized European city using wastewater-based epidemiology: Comparison of sampling strategies for the assessment of multiannual trends" is based on the analysis of WBE data over an eight-year period. Their study analyses trends revealed by the longitudinal data and compares sampling techniques currently used in many WBE studies. Based on their results, the authors propose a different sampling strategy different from what has been currently used in many WBE studies.

With more regions implementing WBE for community drug monitoring, the results from this study could prove significant to improving regional and multi-regional sampling. I believe this study will be of interest to many STOTEN readers and even more the WBE scientists. I recommend the article for publication.

I have only few comments and suggest a thorough read-through to correct some typos.

1. Line 183-184 authors used daily flow rates for mass load calculation, as such I assume you have all the flow rate data. Line 290-292. Do the seasonal changes in population affect the WWTP flow rates?

R: Yes, the data on wastewater mass flow expressed in $\mathrm{m} 3 /$ day were obtained from the Central WWTP of the city of Zagreb. However, the sewer system of the city of Zagreb receives either municipal and industrial wastewater as well as rain water and even some stream waters. The flow rates are therefore more influenced by precipitations than by changes in population size and cannot be used as indicators of population size changes.

2. Additionally, though the proposed multiannual and seasonal sampling techniques applied in this study were useful in providing insight on drug use dynamics and better drug use estimations for Zagreb. It is difficult without a comparison site to tell if the same sampling technique would apply as well or have significant impact on a different city (smaller vs bigger; rural vs urban) even in Croatia.

R: We believe that the improvements achieved through the use the whole-year sampling scheme described in this paper strongly suggest that, in spite of possible variations in weekly and seasonal dynamics, large sized cities provide a robust systems for multiannual monitoring of illicit drugs. 
1

2 3

4

5

6

7

8

9

10

11

12

$20 *$ Corresponding author:

21 Dr. Senka Terzic

22 Contact: terzic@irb.hr

23 Tel. +385-1-4560-940

24 Fax: +385-1-4680-242

25

\section{for the assessment of multiannual trends}
Division for Marine and Environmental Research, Rudjer Boskovic Institute, Bijenicka c. 54, 10000 Zagreb, Croatia




\section{Abstract}

27 A comprehensive study aimed at monitoring of temporal variability of illicit drugs (heroin, 28 cocaine, amphetamine, MDMA, methamphetamine and cannabis) and therapeutic opiate 29 methadone in a large-sized European city using wastewater-based epidemiology (WBE) was 30 conducted in the city of Zagreb, Croatia, during an 8-year period (2009-2016). The study addressed the impact of different sampling strategies-schemes on the assessment of temporal

32 drug consumption patterns, in particular multiannual consumption trends and documented the

33 possible errors associated with the one-week sampling scheme. The highest drug consumption

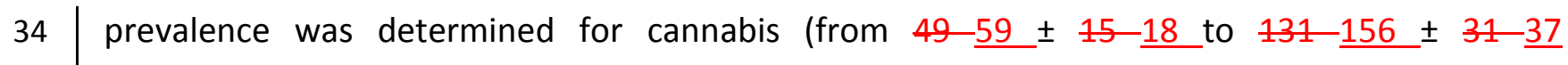
doses/day/1000 inhabitants 15-64 years), followed by heroin (from $11 \pm 10$ to $71 \pm 19$ doses/day/1000 inhabitants $15-64$ years), cocaine (from $8.3 \pm 0.9$ to $23 \pm 4.0$ doses/day/1000

37 inhabitants $15-64$ years) and amphetamine (from $1.6-\underline{3} \pm 1.0 \underline{0.9}$ to $25-\underline{21} \pm \mathbf{7} \underline{\underline{6}} . \underline{z} \underline{1}$ 38 doses/day/1000 inhabitants $15-64$ years) whereas the consumption of MDMA was 39 comparatively lower (from 0.06-18 \pm 0.03-08 to 0.9 $\underline{0.7}$ doses $\pm 0.2 \underline{7}$ doses/day/1000 inhabitants $40 \quad 15-64$ years). The drug consumption patterns were characterized by clearly enhanced weekend 41 and Christmas holiday season consumption of stimulating drugs (cocaine, MDMA; and 42 amphetamine) and somewhat lower summer consumption of almost all drugs. Pronounced 43 multiannual consumption trends were determined for most of the illicit drugs. The investigated 44 8-year period was characterized by a marked increase of the consumption of pure cocaine (1.645 fold), THC (2.7-fold), amphetamine (16-fold) and MDMA (15-fold) and a concomitant decrease 46 (2.3-fold) of the consumption of pure heroin. The heroin consumption decrease was associated 47 with an increase of methadone consumption (1.4-fold), which can be linked to its use in the 
48 heroin substitution therapy. The estimated number of average methadone doses consumed in

49 the city of Zagreb was in a good agreement with the prescription data on treated opioid addicts

50 in Croatia.

51

52 Keywords: illicit drugs, opioids, multiannual trends, wastewater-based epidemiology, Zagreb,

53 LC-MS/MS

54 


\section{Introduction}

Abuse of illicit drugs has become a major global problem with numerous negative consequences

57 including increase in crime rate, negative impacts on public health, economic damage as well as costs of treatment of drug addicts (EMCDDA, 2009). Consequently, knowing the extent and patterns of drug abuse is very important for planning timely and effective actions to mitigate these problems. The official data about illicit drug consumption usually include the information about the amount and purity of seized drugs, number of treated drug addicts and general population survey data, whose frequency in different countries may be rather different. In recent years, wastewater-based epidemiology (WBE) has been used as a complementary approach for the estimation of drug consumption across the world (e.g. Bijlsma et al., 2016;

Bones et al., 2007; Huerta-Fontela et al., 2008; Kahn et al., 2014; Kankaanpää et al., 2014;

Kasprzyk-Hordern et al., 2009; Irvine et al., 2011; Lai et al., 2013a, 2016; Metcalfe et al., 2010;

67 Postigo et al., 2010; Terzic et al., 2010; van Nuijs et al., 2009; Zuccato et al., 2008).

The main advantages of the WBE approach are objectivity and suitability for near-real-time monitoring. In order to improve and expand the WBE approach, several publications addressed the problem of uncertainties associated with sample collection (Ort et al., 2010), sample

71 stability (McCall et al., 2016; van Nuijs, 2012; Senta et al., 2014) as well as back-calculation of

72 drug consumption (Castiglioni et al., 2013; Gracia-Lor et al., 2016; Lai et al., 2011). A number of

73 studies have already demonstrated the potential of WBE to provide information about the

74 spatial (Been et al., 2016; Bijlsma et al., 2016; Kankaanpää et al., 2016; Nefau et al., 2013) and

temporal (Bade et al., 2018; Been et al., 2016; Lai et al., 2016; Mastroianni et al., 2017; Tscharke 
77 et al., 2014a; Thomas et al., 2012), which showed a pronounced regional and temporal varibility

78 of drug abuse accross the Europe. In several studies, the potential of this approach as a 79 complementary tool to support epidemiological and seizure data (Baz-Lomba et al., 2016; Been 80 et al., 2016; Zuccato et al., 2016) was demonstrated. The WBE approach was also successfully 81 applied to study the differences in drug consumption patterns between the large and small 82 cities (Krizman et al., 2016; van Nuijs et al., 2009), with a clear indication that large cities 83 represent communities with significantly enhanced drug consumption and, consequently, are 84 very suitable for the investigation of the drug consumption patterns.

85 Regarding temporal variability, a significant emphasis of existing studies was on short-term 86 consumption variability, especially regarding so-called recreational stimulating drugs. A number 87 of WBE studies performed in different countries confirmed an enhanced consumption of 88 stimulating illicit drugs during the weekend (e.g. Krizman et al., 2016; Terzic et al., 2010; Thomas 89 et al., 2012), large sport events (Gerritry et al., 2011), music festivals (Bijlsma et al., 2014; Jiang et al., 2015; Lai et al., 2013b; Mackulak et al., 2014) and the peak of tourist season in the 91 vaccation areas (Krizman et al., 2016; Lai et al., 2013c). In contrast, only few reports addressed 92 the issue of multiannual changes in drug consumption patterns within the selected population 93 (e.g. Kankaanpää et al., 2016; Mastroianni et al., 2017; Ort et al., 2014a; Tscharke at al., 2016; Zuccato et al. 2016). Most of the The published multiannual studies were based on the comparison of one-week wastewater sampling campaigns in a given time-period (Kankaanpää et al., 2016; Mastroianni et al., 2017; Ort et al., 2014a; Zuccato et al. 2016.). In such cases,

97 possible week-to-week variability during the particular year was not taken into account, which might increase the uncertainties related to the annual consumption estimates. In order to get a 
more accurate estimate, representative of average annual drug consumption, a recent study by

100 Ort et al. (2014b) recommended the use of stratified annual sampling to minimize the errors 101 associated with day-to-day varibility. The importance of sampling scheme for the assessment of 102 consumption was also discussed in Humphries et al. (2016).

103 In this study we investigated the multiannual trends in the consumption of 6 illicit drugs 104 (cannabis, cocaine, heroin, MDMA, amphetamine, methamphetamine) and one therapeutic 105 opioid (methadone) in the city of Zagreb in the period 2009-2016, by applying two different 106 sampling schemes (one-week sampling scheme and a whole-year sampling scheme). The city of 107 Zagreb is the capital and the largest Croatian city, representing almost 20\% of Croatia's 108 population. AoreoverFurthermore, an initial WBA WBE study conducted in Zagreb (Terzic et al., 109 2010) indicated specific drug consumption patterns which were different from those reported 110 for most of the other European cities, in particular regarding comparatively higher prevalence of 111 heroin consumption and lower prevalence of cocaine and amphetamine drug consumption.

112 The specific goals of the present study included: a) long-term study of the weekday-related drug 113 consumption patterns; b) impact of the holiday season on drug consumption patterns; c) 114 seasonal changes in drug consumption patterns; d) testing different sampling strategies 115 schemes for the assessment of multiannual trends; e) tracking the multiannual changes of the 116 drug consumption over a period of $7 \underline{8}$ years and comparison with the available epidemiological 117 data.

\section{2. Materials and methods}




\subsection{Selection of target compounds}

121 The selection of target compounds was made-based on the available data on drug consumption 122 patterns in Croatia (Glavak Tkalic et al., 2013) and in the city of Zagreb (Krizman et al., 2016;

123 Terzic et al., 2010). Selected analytes included morphine (MOR), morphine-3-glucuronide (M3G)

124 and 6-acetylmorphine (6-AM) as principal heroin-derived substances as well as benzoylecgonine

$125(B E)$, amphetamine (AMP), methamphetamine (MAMP), 3,4-methylendioximethamphetamine

126 (MDMA), 11-nor-9-carboxy-tetrahydrocannabinol (THC-COOH) and 2-ethylidene-1,5-dimethyl-

127 3,3-diphenylpyrrolidine (EDDP) as principal biomarkers of cocaine, amphetamine, 128 methamphetamine, MDMA, cannabis and methadone consumption, respectively.

\subsection{Chemicals and materials}

131 Standard solutions of all target analytes $(1 \mathrm{~g} / \mathrm{L})$ and their deuterated analogues $(0.1 \mathrm{~g} / \mathrm{L})$ were 132 purchased from Lipomed AG (Switzerland). Mixed standard solutions of the analytes and their 133 deuterated analogues, used as surrogate standards, were prepared in methanol $(\mathrm{MeOH})$ at concentrations of $10 \mathrm{mg} / \mathrm{L}$ and $2 \mathrm{mg} / \mathrm{L}$, respectively, and kept in the dark at $-20{ }^{\circ} \mathrm{C}$. Aqueous 135 ammonia solution $\left(\mathrm{NH}_{3}, 25 \%\right)$ and $\mathrm{LC}-\mathrm{MS}$ grade $\mathrm{MeOH}$ were purchased from Merck AG 136 (Darmstadt, Germany). Acetic acid $\left(\mathrm{CH}_{3} \mathrm{COOH}\right)$, also LC-MS grade, formic acid (HCOOH) and 137 phosphoric acid $\left(\mathrm{H}_{3} \mathrm{PO}_{4}\right)$ were purchased from Fluka (Switzerland). Milli-QMQ water was 138 obtained by purifying in with an Elix-Mili-Q-system (Millipore, Bedford, USA). Oasis MCX cartridges (150 mg / $6 \mathrm{~mL}$ ) were produced-purchased by-from Waters (Milford, MA, SAD) whereas Strata $\mathrm{NH}_{2}$ (200 mg / $3 \mathrm{~mL}$ ) cartridges as well as HPLC columns used for the 141 chromatographic separation (Synergi Polar; $4 \mu \mathrm{m}, 150 \mathrm{~mm} \times 3 \mathrm{~mm}$, Kinetex PFP; $2.6 \mu \mathrm{m}, 100$ 
142

143

144

\section{2.3. Wastewater sampling and analysis}

$\mathrm{mm} \times 2.1 \mathrm{~mm}$ ) were manufactured-purchased by from Phenomenex (Torrance, California, USA). Glass-fiber filters (GF/C) were delivered purchased by from Whatman (USA).

The 24-h composite samples (from 8 a.m. of the previous day to 8 a.m. of the sample collection day) of untreated wastewater were collected at the inlet of the central WWTP of the city of Zagreb in the period 2009-2016, except in 2010. All collected samples were time-proportional, with the sampling time interval of $15 \mathrm{~min}$. A total number of 282 samples, having an average $\mathrm{pH}$ of $7.6 \pm 0.2$, was collected. Depending on the specific research goals, different sampling schemes were applied to cover both short-time and long-term variability: one-week sample scheme, a whole-year sampling-scheme and Christmas season sampling scheme. All investigated years included at least one one-week sampling period (25 March - 2 April 2009; 26 August - 3 September 2009, 9-15 March 2011, 17-24 March 2012, 6-12 March 2013, 24 July 31 August 2013, 11-18 March 2014, 17-23 March 2015, 9-15 March 2016). In addition, in 2009 and further throughout the period 2012-2016, samples were also collected over the whole year, two to four times per month, and uniformly covered all seasons (wholeyear sampling scheme). In principle, a whole-year sampling scheme included a collection of equal number of weekend (Sunday) and weekday (Tuesday) samples. The total number of samples collected within one whole-year sampling scheme varied from 21 to 46. Special timeperiods such as Christmas holiday season and major festivals were avoided within the one-week and whole-year sampling schemes. Christmas season sampling scheme included two Christmas holiday seasons in the period: 21 December 2012 - 4 January $2013(n=15)$ and 20 December 
2013 - 3 January $2014(n=14)$. Depending on the specific research goals, different sampling strategies were applied to cover both short-time and long-term variability. All investigated years included at least one period of seven to nine consecutive days (25 March-2 April 2009; 26 August - 3 September 2009, 9-15 March 2011, 17-24 March 2012, 6-12 March 2013, 24-31 July 2013, 11-18 March 2014, 17-23 March 2015, 9-15 March 2016).

In addition, in 2009 and throughout the period 2012-2016, samples were collected over the whole year, two to four times per month, and uniformly covered all seasons. The sampling scheme included collection of a weekend sample followed by collection of a subsequent weekday (Tuesday) sample. The total number of samples per year varied from 21 to 46 samples. Special time-periods such as Christmas holiday season and major festivals were avoided during the regular sampling. To investigate the impact of special events on drug consumption, samples were collected during two holiday seasons in the period: 21 December 2012 - 4 January 2013 (A $=15)$ and 20 December $2013-3$ January $2014(n-14)$.

The samples collected during-within the one-week sampling periods-scheme as well as the samples collected during the holiday periods wereand the Christmas holiday sampling scheme were frozen immediately after collection and kept frozen until analyses, whereas all other samples were processed within a few hours after collection. Since the study covers a rather long time-period, some of the data, resulting from the sampling campaigns described above, were partially used in previously published studies (e.g. Krizman et al., 2016; Ort et al., 2014b; Terzic et al., 2010; Thomas et al., 2014).

The sample preparation and LC-MS/MS analysis were performed by applying already published and validated analytical method (Senta et al., 2013). The, which-performance of the method was 
repetitively confirmed in $7 \underline{6}$ international intercalibration studies performed during the period 2011-2016 (van Nuijs et al., 2018). Briefly, samples of wastewater (125 mL) were spiked with 188 surrogate standards (120 ng/L) and after equilibration filtered using GF/C filters. After filtration, 189 samples were enriched on Oasis MCX cartridges. The basic drugs were eluted with $6 \mathrm{~mL}$ of $0.5 \%$ $190 \mathrm{NH}_{3}$ in $\mathrm{MeOH}$ whereas THC-COOH was eluted with methanol and additionally cleaned-up using 191 Strata $\mathrm{NH}_{2}$ cartridges. These two fractions were analyzed separately by triple-quadrupole liquid 192 chromatography tandem mass spectrometry (Quantum AM, Thermo Electron, USA). 193 Chromatographic separation of basic drug biomarkers was performed using a gradient elution on Synergy $4 \mu$ POLAR-RP $80 \AA$ column (Phenomenex, $150 \times 3 \mathrm{~mm}$ ), whereas for the analyses of

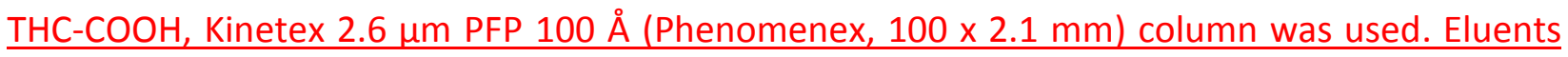
used for the separation of basic analytes included $0.1 \%$ acetic acid in $\mathrm{H}_{2} \mathrm{O}(\mathrm{v} / \mathrm{v})$ and $0.1 \%$ acetic acid in $\mathrm{MeOH}(v / v)$, whereas $\mathrm{THC}-\mathrm{COOH}$ analyses were performed using $\mathrm{H}_{2} \underline{\mathrm{O}}$ and $\mathrm{MeOH}$ as eluents. THC-COOH was analyzed in negative ionization mode (NI) whereas the analyses of all other analytes were performed in positive ionization mode (PI). Identification and quantification was performed using two characteristic transitions for each analyzed compound (MRM mode). for all analytes.

\subsection{Estimation of drug consumption}


The assessment of drugEstimation of drug consumption was performed as described earlier by Krizman et al. (2016), applying the methodology originally proposed by Zuccato et al. (2008). To minimize possible weekday-related differences in drug consumption patterns (e.g. Terzic et al., 2010), $r$ The representative average mass loads $\left(X_{\mathrm{rp}}\right)$ and their corresponding standard deviations $\left(S_{R P}\right)$ used for the assessment of drug consumption were calculated using the as following equationss: 
The number of inhabitants as well as the number of inhabitants of age 15-64 years, served by the WWTP, was based on 2011 Census data. The consumption of individual drugs expressed as the number of average doses per 1000 inhabitants was calculated by dividing the population normalized drug consumption of individual drugs, expressed as the number of doses per 1000 inhabitants, was calculated using the corresponding with the corresponding average dose size listed in fTable 17.

The amounts of street-purity drugs which circulated on the illegal market in Zagreb were calculated from the estimated annual consumption of pure drugs (expressed in $\mathrm{kg} / \mathrm{year}$ ), which were divided by the corresponding drug purity presented in Table S1.Annual consumption of so ealled street-purity illicit drugs was calculated considering the data on the average purity of the drugs seized in Croatia in investigated years (Table S1) and WBE-based estimates of pure drug consumption.

Apart from some exceptionsMost of , the correction factors used in the calculation of drug consumption were taken from the paper published by Zuccato-Gracia-Lor et al. et al. (20082016). The estimation of cocaine consumption was made by using the later proposed correction factor of 3.6 (Castiglioni et al., 2013), whereas heroin consumption was calculated from 6-AM mass loads, using a correction factor of 86.9 (van Nuijs et al. 2011).

\subsection{Statistical evaluation}

Statistical analysis of the data was performed using Sigma Plot 12.0 (Systat software Inc., SAD). Depending on data distribution, parametric ( $t$-test, One-way ANOVA) and non-parametric tests (Mann-Whitney, Kruskal-Wallis test) were applied. In order to examine differences among 
250 multiple groups $\_$One-way ANOVA and Kruskal-Wallis tests were used (with follow-up Holm-

251 Sidak and Dunn's method post-hoc testing, respectively) while for testing the differences

252 between two groups, $t$-test and Mann-Whitney test were used.

253

254 3. Results and discussion

255 3.1. Occurrence of drug biomarkers in municipal wastewater of the city of Zagreb

256 The study was performed in a city of Zagreb, with the population size of approximately 780000

inhabitants and 3.82 registered drug addicts/1000 inhabitants of age 15-64 (data for 2016,

Katalinic and Huskic 2017). The analyses included selected drug biomarkers which are excreted

after the consumption of 6 illegal drugs (cannabis, heroin, cocaine, amphetamine, MDMA and

methamphetamine) and methadone which is primarily used in the treatment of heroin users.

The analyses performed between 2009 and 2016 showed that most of the investigated drug

262 biomarkers were rather common constituents in the wastewater of the city of Zagreb (Table 2).

263 The most frequently detected biomarkers were MOR, BE, THC-COOH and EDDP, which were

264 determined in all analyzed wastewater samples $(n=270-282)$. Very high frequency of detection

265 was obtained also for 6-AM (98\%), M3G (97\%), AMP (96\%) and MDMA (99\%; $n=282)$, whereas

266 MAMP was the least frequently detected drug biomarker (83\%). Regarding abundances, the

267 highest average annual concentrations were determined for MOR (from $74 \pm 29 \mathrm{ng} / \mathrm{L}$ to $294 \pm$

$26883 \mathrm{ng} / \mathrm{L}$ ), BE (from $143 \pm 34 \mathrm{ng} / \mathrm{L}$ to $273 \pm 101 \mathrm{ng} / \mathrm{L}$ ) and EDDP (from $121 \pm 41 \mathrm{ng} / \mathrm{L}$ to $190 \pm 67$

$269 \mathrm{ng} / \mathrm{L}$ ) followed by AMP (from $7.5 \pm 7.5 \mathrm{ng} / \mathrm{L}$ to $109 \pm 58 \mathrm{ng} / \mathrm{L}$ ) and MDMA (from $6.8 \pm 7.7 \mathrm{ng} / \mathrm{L}$ to 270

$92 \pm 58 \mathrm{ng} / \mathrm{L}$ ). The lowest concentrations were determined for MAMP (from $0.6 \pm 0.6 \mathrm{ng} / \mathrm{L}$ to 1.4 
$271 \pm 1.8 \mathrm{ng} / \mathrm{L}$ ), M3G (from $1.6 \pm 2.2 \mathrm{ng} / \mathrm{L}$ to $9.9 \pm 6.7 \mathrm{ng} / \mathrm{L}$ ) and 6-AM (from $2.0 \pm 2.4 \mathrm{ng} / \mathrm{L}$ to $12 \pm$ $2724.7 \mathrm{ng} / \mathrm{L})$.

\subsubsection{Workday/weekend drug consumption patterns}

276 Possible differences in workday to weekend consumption patterns of individual drugs have 277 been evaluated based on the ratios of weekend and workday daily mass loads of selected drug 278 biomarkers for individual years (Fig_ture 1). It was arbitrarily assumed that a ratio significantly 279 different from $1.0 \pm 0.2$ was a confirmation of some specific weekday-related consumption 280 pattern. It should be stressed that the ratio for MOR consumption was calculated from the 281 corresponding mass loads of the total morphine $\left(M O R_{t o t}\right)$. The $M O R_{\text {tot }}$ mass loads were obtained 282 by summing up the daily mass loads of MOR and M3G (taking into account the molar ratio to 283 MOR of 1.62).

284 Almost all ratios of the weekend and workday average daily mass load of stimulating drug 285 biomarkers, $\mathrm{BE}(1.5 \pm 0.3$ to $1.7 \pm 0.5)$, MDMA ( $-2.3 \pm 0.5$ to $4.3 \pm 3.6)$ and $\mathrm{AMP}(1.0 \pm 1.0$ to 2.2 $286 \pm 1.3$ ), were significantly ( $t$-test) different from $1.0 \pm 0.2$. By contrast, most of the ratios for $287 \mathrm{MOR}_{\text {tot }}(0.95 \pm 0.4$ to $1.1 \pm 0.3), 6-\mathrm{AM}(0.6 \pm 0.8$ to $1.2 \pm 0.3), \mathrm{THC}-\mathrm{COOH}(0.9 \pm 0.4$ to $1.2 \pm 0.4)$ 288 and EDDP $(0.9 \pm 0.3$ to $1.1 \pm 0.3)$ indicated a rather uniform consumption of heroin, cannabis 289 and methadone throughout the week. The observed weekend-related drug consumption 290 patterns of stimulating drugs (MDMA, cocaine and AMP) documented in this study not only fully 291 support the results obtained in a number of previous studies based on 7 consecutive days 
292

293

294

295

296

297

298

299

300

301

302

303

304

305

306

307

308

309

310

311

312

sampling scheme (e.g. Krizman et al., 2015; Ort et al., 2014a; Terzic et al., 2010; Thomas et al 2012), but also confirm the robustness of the applied whole-year sampling scheme to demonstrate the importance of weekday-weekend dynamics at long-term time scales.

\subsubsection{The impact of holiday season on drug consumption patterns}

The impact of holiday season on drug consumption patterns was investigated in two selected 15-days periods (21 December 2012 - 4 January 2013 and 20 December 2013-03-January 2014). The results of this research dealing with the impact of holiday season on drug consumption patterns are presented in Fig. 2-, Fig. S1 and Fig. 3. In both periods, the 1st of January (New Year) was characterized by a significantly enhanced daily mass loads of BE (224 g/day and $197 \mathrm{~g} /$ day), MDMA (62 g/day and $67 \mathrm{~g} /$ day) and AMP (42 g/day and $60 \mathrm{~g} /$ day), which confirmed an increased consumption of all major stimulating drugs in holiday seasons (Fig. 2). By contrast, the 25th of December (Christmas) was associated with an enhanced excretion of BE (166 g/day and $130 \mathrm{~g} /$ day) whereas the Christmas consumption of most amphetamine-type drugs (AMP and MDMA) was not clearly elevated. These results probably reflect the life-style differences of cocaine and amphetamine-type drug consumers within the investigated population. In both holiday season periods, a steady increase of MOR excretion towards Christmas was also observed. However this increase was not associated with the concomittant increase of 6-AM and therefore cannot be unequivocaly related to the enhanced consumption of heroin. Furthermore, unlike for stimulating drugs, z holiday-related consumption patterns could not be established for the remaining investigated drugs, such as cannabis and EDDP (Fig. 
S1). The comparison of the average mass loads during the two holiday_-season periods with the

314 average weekend and workday mass loads in the corresponding years (Fig. 3) confirmed a 315 significantly higher consumption $(p<0.05)$ of stimulating drugs $(B E, M D M A, A M P)$ during the 316 weekend $(n=19-24)$ and holiday_-season period $(n=14-15)$ as compared to workday periods ( $n$ $317=19-22$ ). The average mass loads of stimulating drugs during Christmas holiday season were 2 318 3.9-fold higher then-than during the average weekday and $1.2-1.9$-fold higher than during the 319 average weekend of the corresponding year. This is in a good agreement with previous studies 320 which indicated the enhanced consumption of stimulating drugs during the holidays, festivals, 321 tourist seasons etc. (e.g. Krizman et al., 2016; Lai et al., 2013a; Lai et al. 2013b, van Nuijs et al., 322 2009) and underlines the ability of the applied WBE approach to address the problem of relative 323 contributions of special events to the overal drug consumption in a particular yearly period.

3.2.3. The seasonal differences in drug consumption patterns

The most frequently used sampling strategy in WBE studies is based on one-week sampling scheme which includes collection of wastewater samples over a period of 7 consecutive days (e.g. Ort et al., 2014a; Thomas et al., 2012; Zuccatoet al., 2016).In this study, we compared the average daily mass loads determined in the city of Zagreb in 2 different one-week periods, early 330 spring and summer, in 2009 and 2013. The results of this comparison are presented in Fig. 4. In 331 both investigated years, the average summer mass loads of most of the investigated drug 332 biomarkers were lower than those determined in early spring (Fig. 4). However the observed 333 differences were statisticaly significant ( $p<0.05$; Mann-Whitney test) only for drug biomarkers 
334 which exhibit lower intra-week variability (e.g. MOR tot $_{\text {, }}$ THC-COOH and EDDP) whereas they were not significant for the biomarkers of stimulating drugs (BE, MDMA), probably due to the comparatively higher intra-week variability. The lower average daily mass loads determined in summer are very most likely associated with a seasonal changes in population number, which in the large continental cities, like city of Zagreb, can be characterized by a pronounceddisbalanced decrease of residential population due to outward and inward population summer tourist migrations during the summer vacation season. Namely, the contribution of tourists to the total city population is rather negligible throughout the year $\underline{1<1 \% \text {, data from Zagreb Tourist Board), whereas a significant percentage of residential }}$ population might be out of town during the peak of summer season. Unfortunately, this assumption cannot be confirmed since the precise the official data on therelated to the seasonal changesoutward migrations in of the city population size-were not available. Another possible factor which might have caused the observed differences in spring and summer mass loads is faster in-sewer drug biomarker degradation at higher temperatures (e.g. Devault et al., 2017). However, the model experiments which were performed with the wastewater from the city of Zagreb at $10^{\circ} \mathrm{C}$ and $20^{\circ} \mathrm{C}$, indicated rather higher stability of all urinary biomarkers included in this research at the both temperature conditions (Senta et al., 2016.). Since the insewer wastewater residence time in Zagreb is relatively short $(<5 \mathrm{~h})$ and a typical wastewater temperature in March and July/August is $12^{\circ} \mathrm{C}$ and $20.5^{\circ} \mathrm{C}$, respectively, it is not very likely that the observed seasonal mass load diferences were primarily caused by faster in-sewer degradation in summer. Although the reasons for the observed seasonal differences of the average mass loads are not yet fully understood, they indicated that the total drug consumption 

monthly in 2015-2016). Based on the extended scheme of the whole-year sampling carried out might be underestimated if extrapolated from the average daily mass loads determined in summer. Nevertheless, the observed seasonal differences of the average mass loads indicated that the total drug consumption might be underestimated if extrapolated from the average daily mass loads determined in summer.

\subsection{Impact of sampling strategy-scheme on the estimation of drug consumption in} multiannual studies

Most of the previously conducted multiannual WBE studies wasere based on relatively short one-week sampling periods (e.g. Kankaanpää et al., 2016; Mastroianni et al., 2017, Ort et al., 2014a; Zuccato et al. 2016), which, due to the possible week-to-week variability of daily mass loads, may be associated with z-a potential error in tracking the drug consumption on the an annual basis. In this study, a comparison was made between the representative average daily mass loads of selected drug biomarkers obtained by applying two different sampling strategiesschemes: one-week sampling scheme (March/April 2012 - 2016) and whole-year sampling scheme (Sundays and Tuesdays; sampled either bimonthlyfortnightly in 2012-2014 or

373 in 2013 and 2014, which included bimonthlyfortnightly sampling $(n=48)$, it was shown that the 374 reduction of the sample number to half (monthly sampling; $n=24$ ) did not significantly affect 375 the estimate of the mass loads ( $t$-test; $p<0.05)$. 
376 The representative daily mass loads of individual drug biomarkers determined by applying the

377 one-week and the whole-year sampling scheme are presented in Fig. 5. Apart from some

378 occassional exceptions, the application of the whole-year sampling scheme was, in principle, associated with somewhat higher day-to-day variability of daily mass loads -than the one-week sampling scheme, which is probably a result of higher intra-annual variability of drug consumption. The amphetamine-type drugs (MAMP, AMP and MDMA) exhibited the strongest day-to-day variability within the both sampling schemes, which is most probably associated with a rather irregular consumption pattern of these drugs, characterized by enhanced weekend and holiday consumption rates. Furthermore, the one-week sampling scheme was occasionally associated with relatively high day-to-day variability of AMP and MDMA. The statistical analysis of the data exhibited a significant difference $(p<0.05)$ between the representative mass loads of AMP obtained by the two applied sampling strategies schemes in all investigated years. By contrast, the differences for other investigated drug biomarkers were found to be significant ( $p$ $<0.05)$ only occasionally. The performed comparison indicated that, in the large cities like city of Zagreb, the one-week sampling scheme may provide a rather reliable base for the estimate of the annual consumption of most of the classical illicit drugs, assuming that the sampling periods exclude special events. Previous study by Ort at al. (2014b) has shown that the variability of drug consumption in smaller communities (<10 000 inhabitants) is extremely high, requiring very high sampling frequency to achieve the proper estimate of drug consumption. It was estimated that the average annual consumption calculated from 1-week sampling was subject in larger cities can be significantly smaller allowing detection of relatively small changes (20\%) of 
the drug consumption among different years. Nevertheless, although some previous studies, addressing the issue of multiannual changes, demonstrated the applicability of one-week sampling scheme (Mastroianni et al., 2017; Ort et al. 2014a, Zuccato et al., 2016), our data show that such a scheme is insufficiently reliable for the drugs exhibiting high day-to-day and intraannual variability, even in case of larger cities like the city of Zagreb-.

\subsection{Multiannual trends in drug consumption patterns and comparison with available}

\section{epidemiological data}

The back-calculations of drug consumption were made-based on representative daily mass loads determined for all samples collected within each investigated year, with the exception of those collected during the Christmas-New Year holiday seasons. The consumption was calculated for heroin, cocaine, AMP, MDMA, cannabis (THC) and methadone (MTHD). The results expressed in $\mathrm{mg} /$ day/1000 inhabitants of age 15-64 are presented in Fig. 6, whereas the results expressed in other units (e.g. mg/day/1000 inhabitants, doses/day/1000 inhabitants, g/day, kg/year, kg/year of street purity drug) are given in Electronic-Supplementary Material (Table S2). The highest illicit drug consumption rate was determined for cannabis (from 6153- $\underline{7368} \pm 1835-\underline{2197}$ $\mathrm{mg} /$ day/1000 inhabitants $15-64$ years to $16322 \underline{19544} \pm 3862 \underline{4624} \mathrm{mg} /$ day/1000 inhabitants 15-64 years), followed by heroin (from $107 \pm 104 \mathrm{mg} /$ day/1000 inhabitants $15-64$ years to $712 \pm$ $193 \mathrm{mg} /$ day/1000 inhabitants 15-64 years), cocaine (from $249 \pm 27 \mathrm{mg} /$ day/1000 inhabitants

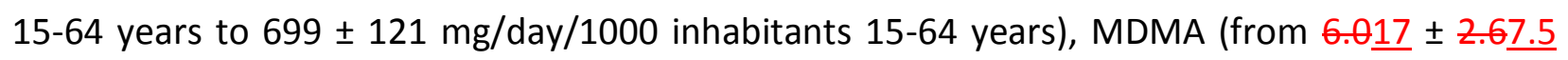
$\mathrm{mg} /$ day/1000 inhabitants $15-64$ years to $88-259 \pm 24-\underline{69} \mathrm{mg} /$ day/1000 inhabitants $15-64$ years) and AMP (from $16-\underline{13} \pm 10-\underline{8.8} \mathrm{mg} /$ day/1000 inhabitants $15-64$ years to $251 \underline{213} \pm 72 \underline{61}$ 
$419 \mathrm{mg} /$ day/100 inhabitants 15-64 years). The estimated consumption rate of the therapeutic 420 opioid methadone was in the range from $280 \pm 26 \mathrm{mg} /$ day/1000 inhabitants 15-64 years to 393

$421 \mid \pm 61 \mathrm{mg} /$ day/1000 inhabitants 15-64 years. Collectively In principle, the determined drug 422 consumption patterns and rates were rather similar to those determined in some other Mediterranean countries, like Spain and Italy (Mastroianni et al., 2017; Zuccato et al., 2016), although some differences regarding the prevalence of individual drugs as well as regarding the temporal trends were observed. For example, cannabis and cocaine were the most prevalently consumed illicit drugs in Barcelona (Spain) and investigated Italian cities, whereas a heroin consumption was reported to be much lower (Mastroianni et al., 2017; Zuccato et al., 2016). ${ }^{\prime}$ the determined drug consumption rates are of similar order of magnitude as in some other WBE studies (e.g. Mastroianni et al., 2017; Zuccato et al., 2016) although there were some differences regarding the prevalence of individual drugs as well as regarding temporal trends.

In our study, all investigated illicit drugs, except heroin, exhibited a significant increase $(p<$ 432 0.05) of the consumption rates over the investigated 8-year period (Fig. 6 and 7, Table S2). In 4332016 , the average consumption rate of pure MDMA, AMP, THC (cannabis) and cocaine, were 434 15-fold, 16-fold, 3-fold and 2-fold higher then-than in 2009, respectively. The multiannual 435 consumption patterns of pure AMP and MDMA were characterized by a rather continuing 436 increase of their consumption rates (Fig. 6) over the whole investigated time period, whereas 437 the consumption of THC (cannabis) was characterized by a significant increase in 2009-2014 438 period ( $p<0.05,3$-fold increase), and rather stable consumption rate in 2014-2016 period. By 439 contrast, the consumption rate of pure heroin dropped significantly $(p<0.05 ; 5-7$-fold) between 4402009 and 2011-2012 period, and kept at significantly lower level until $2016(p<0.05)$. However, 
441 a significant $(p<0.05)$ 2-3-fold increase in pure heroin consumption was recorded between

442 2011/2012 and 2016, which indicated a gradual recovery of heroin market in that period.

443 Interestingly, a reduction of heroin consumption in the period 2010-2012 was reported for Italy

444 as well (Zuccato et al., 2016).

Based on the estimated amounts of consumed drugs and the official data on the-purity of seized

drugs in the same periodprovided by the Office for Combating Narcotic Drug Abuse of the

Government of the Republic of Croatia (see Table S1), we calculated the amounts of the streetpurity drugs which circulated on the illegal market in Zagreb in the corresponding years (Table S2). It should be stressed that the street-drug purity of investigated drugs (heroin, 451 amphetamine, MDMA, cocaine) exhibited a pronounced temporal variability (Table S2). The 452 amounts of the most prevalent drugs present on the illegal market in Zagreb were as follows:

453 from 211 to $565 \mathrm{~kg} /$ year of heroin, from 157 to $323 \mathrm{~kg} /$ year of cocaine, from $52 \underline{44}$ to $364 \underline{309}$ $454 \mathrm{~kg} /$ year of amphetamine, from $3.5 \underline{14}$ to $43-\underline{127} \mathrm{~kg} /$ year of MDMA and from 19086-22853 to $45089-\underline{53988 \mathrm{~kg} / \text { year }}$ of cannabis.

456 Consequently, the observed multiannual trends in the consumption of pure drugs are probably 457 not impacted exclusively by the changes in drug consumption prevalence but also by the 458 changes in the street drug purity. In this context, it is interesting to note that a significant drop 459 in the heroin consumption rate between 2009 and 2011/2012 was associated with a 460 concomittant decrease of heroin street-drug purity (from $21.5 \%$ to $8.4 \%$ ) and an increase in the 461 consumption of the subpstitution theraphy drug methadone (40\%), which then kept a rather 
462 stable consumption rate in the subsequent period (2013-2016). The average number of 463 consumed methadone doses estimated in this study (e.g. $3.1 \pm 0.4$ doses/day/1000 inhabitants 464 in 2015; $80 \mathrm{mg} /$ dose) were in a rather good agreement with the amount of that drug prescibed 465 in the city of Zagreb in 2015 (11.76 DDD/TSD; DDD = 25 mg; 3.7 doses/day/1000 inhabitants for 466 the average dose of $80 \mathrm{mg} / \mathrm{L}$ ) (Draganic et al., 2017), which confirmed a reliability of WBE 467 approach for tracking the changes of the illicit drug consumption patterns.

468 The trends in population normalized number of addicts treated due to consumption of different 469 types of drugs did not, however, reflect the multiannual drug consumption trends determined 470 in this study (Fig. 7), probably due to a rather long time-gap between the initial drug 471 consumption and the involvement of the consumers in the treatment.

472 Furthermore, the drug consumption trends which were determined in the present study were 473 only partialy in agreement with the results of general population surveys performed in Croatia 474 in 2011 and 2015, which indicated a significant increase only in the consumption of cannabis 475 (2.9\% last-month prevalence in 2011; 5.0\% last-month prevalence in 2016) (Glavak Tkalic et al., 476 2013; Glavak Tkalic et al., 2016), whereas the differences in the consumption prevalence of 477 other illicit drugs were not found to be significant. Our study suggests that the outcome of 478 national population surveys on drug consumption is not necessarily representative for larger 479 cities. Given the fact that the city of Zagreb represents approximately $20 \%$ of the whole Croatian 480 population, the drug consumption trends determined in this study imply the need for specific 481 surveys focusing on larger cities. Moreover, the trends observed in the city of Zagreb might be 482 indicative an indication of some trends developing at the national level. 


\section{Conclusion}

The seveneight-year monitoring_period of drug consumption patterns in the city of Zagreb,

486 Croatia, using wastewater-based epidemiology revealed several temporal variability patterns,

487 including weekday-weekend dynamics, holiday season effects and multiannual trends. In agreement with the literature, the enhanced consumption of stimulating drugs was systematically observed during weekends and Christmas holiday season. In addition, a significant multiannual increase of cocaine (1.6-fold), THC (2.7-fold), amphetamine (16-fold) and

MDMA (15-fold) consumption with a concomitant decrease (2.3-fold) of the consumption of heroin was observed during the investigated 8-year period (2009-2016). All these variabilities should be taken into account to get a representative estimate of the average annual consumption for comparison of different years. The whole-year sampling The whole-year sampling strategyscheme showed a clear advantage over the seven-consecutive-dayone-week sampling scheme, especially for drugs showing enhanced day-to-day and intra-annual variability. which has been recently applied to study multiannual trends. Moreover, it was shown that $t$ The errors associated with day-to-day and intra-annual variability of $\mathrm{BE}(<20 \%)$ for large citiesdetermined in the city of Zagreb (>500 000 inhabitants) study were are-much smaller than-from those for thereported for small communities_(_Ort et al. 20914b), which indicated enhanced robustness of the estimates obtained for large sized cities. Our data suggest that large 
503 in drug consumption over a multi-year period. AoreovefConsequently, $t$, the trends observed in 504 the larger cities could be used as an early warning of the trends developing at the national level.

505

506

507 Acknowledgments

508 We are thankful to dr. sc. Marin Ganjto and the staff of central WWTP Zagreb for their 509 assistance with the wastewater collection. Technical assistance of Nenad Muhin is highly 510 appreciated. Epidemiological data were provided by the Croatian Institute of Public Health. The 511 data on average drug doses in Croatia were provided by Forensic Science Centre Ivan Vucetic 512 and Office for Combating Narcotic Drug Abuse of the Government of the Republic of Croatia.

513 The research was financially supported by the eity City of Zagreb, Office for Combating Narcotic 514 Drug Abuse of the Government of the Republic of Croatia and Croatian Science Foundation 515 (project COMPASS, grant number IP-2014-09-7031).

517 References

518 Bade, R., White, J.M., Gerber, C., 2018. Qualitative and quantitative temporal analysis of licit 519 and illicit drugs in wastewater in Australia using liquid chromatography coupled to mass 520 spectrometry. Anal. Bioanal. Chem. 410 (2), 529-542. 
521 Baz-Lomba, J.A., Harman, C., Reid, M., Thomas, K.V., 2017. Passive sampling of wastewater as a 522 tool for the long-term monitoring of community exposure: Illicit and prescription drug trends as 523 a proof of concept. Water Res. 121, 221-230.

524 Been, F., Lai, F.Y., Kinyua, J., Covaci, A., van Nuijs, A.L.N., 2016. Profiles and changes in stimulant 525 use in Belgium in the period of 2011-2015. Sci. Total Environ. 565, 1011-1019.

526 Bijlsma, L., Serrano, R., Ferrer, C., Tormos, I., Hernández, F., 2014. Occurrence and behavior of 527 illicit drugs and metabolites in sewage water from the Spanish Mediterranean coast (Valencia 528 region). Sci. Total Environ. 487, 703-709.

529 Bijlsma, L., Botero-Coy, A.M., Rincón, R.J., Peñuela, G.A., Hernández, F., 2016. Estimation of illicit 530 drug use in the main cities of Colombia by means of urban wastewater analysis. Sci. Total 531 Environ. 565, 984-993.

532 Bones, J., Thomas, K.V., Paull, B., 2007. Using Environmental Analytical Data to Estimate Levels 533 of Community Consumption of Illicit Drugs and Abused Pharmaceuticals. J. Environ. Monit. 9 (7), 534 701-707.

535 Castiglioni, S., Bijlsma, L., Covaci, A., Emke, E., Hernández, F., Reid, M., Ort, C., Thomas, K.V., van 536 Nuijs, A.L.N., de Voogt, P., Zuccato, E., 2013. Evaluation of uncertainties associated with the 537 determination of community drug use through the measurement of sewage drug biomarkers. 538 Environ. Sci. Technol. 47, 1452-1460. 
Devault, D.A., Nefau, T., Levi, Y., Karolak, S., 2017. The removal of illicit drugs and morphine in two waste water treatment plants (WWTPs) under tropical conditions. Environ. Sci. Pollut. Res. $\underline{24(33), 25645-25655 .}$

542 Draganic, P., Zezelic, S., Ostarcevic, S., 2017. Potrošnja lijekova u Republici Hrvatskoj 2011-2015.

543 Agencija za lijekove i medicinske proizvode - HALMED, pp. 174.

544 http://www.halmed.hr/fdsak3jnFsk1Kfa/publikacije/Potrosnja-lijekova-u-RH_2011-2015.pdf

$545 \mid$ (accessed 16.03.2018.) (in Croatian)

546 European Monitoring Centre for Drugs and Drug Addiction, 2009. Annual report on the state of

547 the drugs problem in Europe (available at) http://www.emcdda.europa.eu/publications/annual-

548 report/2009 (accessed 21st February 2018).

549 Gerrity, D., Trenholm, R.A., Snyder, S.A., 2011. Temporal variability of pharmaceuticals and illicit

550 drugs in wastewater and the effects of a major sporting event. Water Res. 45, 5399-5411.

551 Glavak Tkalic, R., Miletic, G.M., Sakoman, S., 2013. Prevalence of substance use among the 552 general population: Situation in Croatia and comparison with other European countries.

553 Drustvena Istrazivanja 22 (4), 557-578.

554 Glavak Tkalic, R., Miletic, G.M., Maricic, J., 2016. Uporaba sredstava ovisnosti u hrvatskom 555 društvu: Istraživanje na općoj populaciji. Zagreb: Institut društvenih znanosti Ivo Pilar i ured za 556 suzbijanje zlouporabe droga Vlade Republike Hrvatske. pp. 251. (in Croatian) 
557 Gracia-Lor, E., Zuccato, E., Castiglioni, S., 2016. Refining correction factors for back-calculation of 558 illicit drug use. Sci. Total Environ. 573, 1648-1659.

559 Huerta-Fontela, M., Galceran, T., Martin-Alonso, J., Ventura, F., 2008. Occurrence of 560 psychoactive stimulatory drugs in wastewaters in north-eastern Spain. Sci. Total Environ. 397, $561 \quad 39-41$.

562 Humphries, M.A., Bruno, R., Lai, F.Y., Thai, P.K., Holland, B., O'Brien, J.W., Ort, C., Mueller, J. F., 563 2016. Evaluation of monitoring schemes for wastewater-based epidemiology to identify drug 564 use trends using cocaine, methamphetamine, MDMA and methadone. Environ. Sci. Technol. 50 565 (9), 4760-4768.

566 Irvine, R.J., Kostakis, C., Felgate, P.D., Jaehne, E.J., Chen, C., White, J.M., 2011. Population drug 567 use in Australia: A wastewater analysis. Forensic Sci. Int. 210, 69-73.

568 Kankaanpää, A., Ariniemi, K., Heinonen, M., Kuoppasalmi, K., Gunnar, T., 2014. Use of illicit 569 stimulant drugs in Finland: A wastewater study in ten major cities. Sci. Total Environ. 487, 696570702.

571 Kankaanpää, A., Ariniemi, K., Heinonen, M., Kuoppasalmi, K., Gunnar, T., 2016. Current trends in 572 Finish drug abuse: Wastewater based epidemiology combined with other national indicators. 573 Sci. Total Environ. 568, 864-874. 
574

575

576

577

578

579

580

581

582 Environ. 566-567, 454-462.

591

592 49, 792-799. Zagreb, pp. 151 (in Croatian).

Jiang, J.-J., Lee, C.-L., Fang, M.-D., Tu, B.-W., Liang, Y.-J., 2015. Impacts of Emerging Contaminants on Surrounding Aquatic Environment from a Youth Festival. Environ. Sci. Technol.

Kasprzyk-Hordern, B., Dinsdale, R.M., Guwy, A., 2009. Illicit drugs and pharmaceuticals in the environment - Forensic applications of environmental data. Part 1: Estimation of the usage of drugs in local communities. Environ. Pollut. 157 (6), 1773-1777.

Khan, U., van Nuijs, A.L.N., Li, J., Maho, W., Du, P., Li, K., Hou, L., Zhang, J., Meng, X., Li, X., Covaci, A., 2014. Application of a sewage-based approach to assess the use of ten illicit drugs in four Chinese megacities. Sci. Total Environ. 487, 710-721.

Katalinic, D., Huskic, A., 2017. Report on people treated for drug abuse in Croatia in 2016. Eroatian Institute for Public Health, Zagreb.

Krizman, I., 2015. Illicit Drugs and Therapeutic Opioids in Municipal Wastewaters Biogeochemical Behavior and Estimation of Drug Abuse (PhD thesis) University of Zagreb,

Krizman, I., Senta, I., Ahel, M., Terzic, S., 2016. Wastewater-based assessment of regional and temporal consumption patterns of illicit drugs and therapeutic opioids in Croatia. Sci. Total

Lai, F.Y., Ort, C., Gartner, C., Carter, S., Prichard, J., Kirkbride, P., Bruno, R., Hall, W., Eaglesham, G., Muller, J.F., 2011. Refining the estimation of illicit drug consumptions from wastewater 
analysis: Co-analysis of prescription pharmaceuticals and uncertainty assessment. Water Res.

Lai, F.Y., Bruno, R., Leung, H. W., Thia, P.K., Ort, C., Carter, S., Thompson, K., Lam, P.K.S., Muller,

J.F., 2013a. Estimating daily and diurnal variations of illicit drug use in Hong Kong: A pilot study

Lai, F.Y., Thai, P.K., O'Brien, J., Gartner, C., Bruno, R., Kele, B., Ort, C., Prichard, J., Kirkbride, P., Hall, W., Caretr, S., Muller, J.F., 2013b. Using quantitative wastewater analysis to measure daily usage of conventional and emerging illicit drugs at an annual music festival. Drug Alcohol= Rev. 32, 594-602. Lai, F.Y., Bruno, R., Hall, W., Gartner, C., Ort, C., Kirkbride, P., Prichard, J., Thai, P.K., Carter, S., 603 Muller, J.F., 2013c. Profiles of illicit drug use during annual key holiday and control periods in 604 Australia: wastewater analysis in an urban, a semi-rural and a vacation area. Addiction 108, $605 \quad 556-565$.

606 Lai, F.Y., O'Brien, J.W., Thai, P.K., Hall, W., Chan, G., Brunod, R., Ort, C., Prichard, J., Carter, S., 607 Anuj, S., Kirkbride, P., Gartner, C., Humphries, M., Muller, J., 2016. Cocaine, MDMA and 608 methamphetamine residues in wastewater: Consumption trends (2009-2015) in South East 609 Queensland, Australia. Sci. Total Environ. 568, 803-809.

610 Mackulak, T., Škubák, J., Grabic, R., Ryba, J., Birošová, L., Fedorova, G., Špalková, V., Bodík, I., 611 2014. National study of illicit drug use in Slovakia based on wastewater analysis. Sci. Total 612 Environ. 494-495, 158-165. 
613 Mastroianni, N., López-García, E., Postigo, C., Barceló, D., Lopez de Alda, M., 2017. Five-year 614 monitoring of 19 illicit and legal substances of abuse at the inlet of a wastewater treatment 615 plant in Barcelona (NE Spain) and estimation of drug consumption patterns and trends. Sci. 616 Total Environ. 609, 916-926.

617 McCall, A.K., Bade, R., Kinyua, J., Lai, F.Y., Thai, P.K., Covaci, A., Bijlsma, L., van Nuijs, A.L.N., Ort, 618 C., 2016. Critical review on the stability of illicit drugs in sewers and wastewater samples. Water 619 Res. 88, 933-947.

620 Metcalfe, C., Tindale, K., Li, H., Rodayan, A., Yargeau, V., 2010. Illicit drugs in Canadian municipal 621 wastewater and estimates of community drug use. Environ. Pollut. 158, 3179-3185.

622 Nefau, T., Karolak, S., Castillo, L., Boireau, V., Levi, Y., 2013. Presence of illicit drugs and 623 metabolites in influents and effluents of 25 sewage water treatment plants and map of drug 624 consumption in France. Sci. Total Environ. 461-462, 712-722.

625 Ort, C., Lawrence, M.G., Rieckermann, J., Joss, A., 2010. Sampling for pharmaceuticals and 626 personal care products (PPCPs) and illicit drugs in wastewater systems: are your conclusions 627 valid? A critical review. Environ. Sci. Technol. 44, 6024-6035.

628 Ort, C., van Nuijs, A.L.N., Berset, J.D., Bijlsma, L., Castiglioni, S., Covaci, A., de Voogt, P., Emke, E., 629 Fatta-Kassinos, D., Gfiffit, P., Hernández, F., González-Mariño, I., Grabic, R., Kasprzyk-Hordern, 630 B., Mastroianni, N., Meierjohann, A., Nefau, T., Östman ,M., Pico, Y., Racamonde, I., Reid, M., 631 Slobodnik, J., Terzic, S., Thomaidis, N., Thomas, K. V., 2014a. Spatial differences and temporal 
632 changes in illicit drug use in Europe quantified by wastewater analysis. Addiction 109, 13386331352.

634 Ort, C., Eppler, J.M., Scheidegger, A., Rieckermann, J., Kinzig, M., Sörgel, F., 2014b. Challenges of 635 surveying wastewater drug loads of small populations and generalizable aspects on optimizing 636 monitoring design. Addiction 109, 472-487.

637 Postigo, C., López de Alda, M., Barceló, D., 2010. Drugs of abuse and their metabolites in the 638 Ebro River basin: Occurrence in sewageand surface water, sewage treatment plants removal 639 efficiency, and collective drug usage estimation. Environ. Int. 36, 75-84.

640 Senta, I., Krizman, I., Ahel, M., Terzic, S., 2013. Integrated procedure for multiresidue analysis of 641 dissolved and particulate drugs in municipal wastewater by liquid chromatography-tandem 642 mass spectrometry. Anal. Bioanal. Chem. 405, 3255-3268.

643 Senta, I., Krizman, I., Ahel, M., Terzic, S., 2014. Assessment of stability of drug biomarkers in 644 municipal wastewater as a factor influencing the estimation of drug consumption using sewage 645 epidemiology. Sci. Total Environ. 487, 659-665.

646 Terzic, S., Senta, I., Ahel, M., 2010. Illicit drugs in wastewater of the city of Zagreb (Croatia) 647 Estimation of drug abuse in a transition country. Environ. Pollut. 158, 2686-2693.

648 Thomas, K.V., Bijlsma, L., Castiglioni, S., Covaci, A., Emke, E., Grabic, R., Emke, E., Grabic, R., 649 Hernández, F., Karolak, S., Kasprzyk-Hordern, B., Lindberg, R., Loped de Alda, M., Meierjohann, 650 A., Ort, C., Pico, Y., Quintana, J.B., Redi, M., Rieckermann, J., Terzic, S., van Nuijs, A.L.N., de 
651 Voogt, P., 2012. Comparing illicit drug use in 19 European cities through sewage analysis. Sci. 652 Total Environ. 432, 432-439.

653 Tscharke, B.J., Chen, C., Gerber, J.P., White., J.M., 2016. Temporal trends in drug use in Adelaide, South Australia by wastewater analysis. Sci. Total. Environ. 565, 384-391.

van Nuijs, A.L.N., Pecceu, B., Theunis, L., Dubois, N., Charlier, C., Jorens, P.G., Bervoets, L., Blust,

656 R., Meulemans, H., Neels, H., Covaci, A., 2009. Can cocaine use be evaluated through analysis of 657 wastewater? A nation-wide approach conducted in Belgium. Addiction 104 (5), 734-741.

658 van Nuijs, A.L.N., Castiglioni, S., Tarcomnicu, I., Postigo, C., Lopez de Alda, M. J., Neels, H., 659 Zuccato, E., Barcelo, D., Covaci, A., 2011. Illicit drug consumption estimations derived from 660 wastewater analysis: a critical review. Sci. Total Environ. 409, 3564-3577.

661 van Nuijs, A.L.N., Abdellati, K., Bervoets, L., Blust, R., Jorens, P.G., Neels, H., Covaci, A., 2012. The 662 stability of illicit drugs and metabolites in wastewater, an important issue for sewage 663 epidemiology? J. Hazard. Mater. 234-240, 19-23.

664 van Nuijs, A.L.N., Lai, F.Y., Been, F., Andres-Costa, M.J., Barron, L., Baz-Lomba, J.A., Berset, J.D., 665 Benaglia, L., Bijlsma, L., Burgard, B., Castiglioni, S., Christophoridis, C., Covaci, A., de Voogt, P., 666 Emke, E., Fatta-Kassinos, D., Fick, J., Hernandez, F., Gerber, C., González-Mariño, I., Grabic, R. 667 Gunnar, T., Kannan, K., Karolak, S., Kasprzyk-Hordern, B., Kokot, Z., Krizman-Matasic, I., Li, A., Li, 668 X., Löve, A.S.C., Lopez de Alda, M., McCall, A.K., Meyer, M.R., Oberacher, H., O'Brien, J., 669 Quintana, J.B., Reid, M., Schneider, S., Simoes, S.S., Thomaidis, N.S., Thomas, K., Yargeau, V., 670 Ort, C., 2018. Multi-year inter-laboratory exercises for the analysis of illicit drugs and 
671 metabolites in wastewater: Development of a quality control system. Trend. Anal. Chem.€ 103, $672 \quad 34-43$

673 Zuccato, E., Chiabrando, C., Castiglioni, S., Bagnati, R., Fanelli, R., 2008. Estimating community

674 drug abuse by wastewater analysis. Environ. Health Perspect. 116 (8), 1027-1032.

675 Zuccato, E., Castiglioni, S., Senta, I., Borsotti, A., Genetti, B., Andreotti, A., Pieretti, G., Serpelloni,

676 S., 2016. Population surveys compared with wastewater analysis for monitoring illicit drug

677 consumption in Italy in 2010-2014. Drug Alcohol Depend. 161, 178-188.

678

679 
Fig.twe 1. Ratios of weekend and workday average mass loads of selected urinary drug biomarkers $\left(\mathrm{MOR}_{\mathrm{tot}}, 6-\mathrm{AM}, \mathrm{AMP}, \mathrm{MDMA}, \mathrm{BE}, \mathrm{THC}-\mathrm{COOH}, \mathrm{EDDP}\right)$ determined in the period from 2009 to 2016. Error bars represent standard deviations. Horizontal lines represent arbitrarily assumed weekend to workday mass load ratio of $1.0 \pm 0.2$.

Fig.ture 2. Mass loads of $B E, M D M A$ and $A M P$ in two different Christmas-New Year holiday periods: A) 2012/2013 and B) 2013/2014.

Fig.ure 3. Average mass loads of selected drug biomarkers determined on workdays, weekend and during two Christmas-New Year periods: A) 2012/2013 and B) 2013/2014. Error bars represent standard deviations.

Fig.ure 4. Variability of average mass loads of selected urinary drug biomarkers in Zagreb during the spring and summer sampling week in A) 2009 and B) 2013. Error bars represent standard deviations.

Fig.ture 5. Impact of the selected sampling strategy schemes (whole-year and one-week monitoring) on the determination of representative mass loads. Error bars represent standard deviations. city of Zagreb in the period 2009-2016. Error bars represent standard deviations. 
699 Fig.tue 7. Comparison of estimated drug consumption in the city of Zagreb with available 700 epidemiological data for Croatia in the period of 2009-2016. Stimulants in the epidemiological 701 figure include amphetamine-type drugs. Opiates include heroin and morphine. 
${ }^{*}$ Highlights (for review : 3 to 5 bullet points (maximum 85 characters including spaces per bullet point)

Highlights

- Drug consumption patterns were studied using wastewater-based epidemiology

- The 8-year study was performed in a large European city

- Comparison of one-week and whole-year sampling strategies was made

- Significant multiannual drug consumption changes were determined

- A comparison with epidemiological data was performed 

${ }^{*}$ Revised manuscript with no changes marked (double-spaced and continuously LINE and PAGE numbered) Click here to view linked References

1

$20 *$ Corresponding author:

21 Dr. Senka Terzic

22 Contact: terzic@irb.hr

23 Tel. +385-1-4560-940

24 Fax: +385-1-4680-242

\section{multiannual trends}
Division for Marine and Environmental Research, Rudjer Boskovic Institute, Bijenicka c. 54, 10000 Zagreb, Croatia

Ivona Krizman-Matasic, Ivan Senta, Petra Kostanjevecki, Marijan Ahel, Senka Terzic ${ }^{*}$

25 


\section{Abstract}

27 A comprehensive study aimed at monitoring of temporal variability of illicit drugs (heroin, 28 cocaine, amphetamine, MDMA, methamphetamine and cannabis) and therapeutic opiate 29 methadone in a large-sized European city using wastewater-based epidemiology (WBE) was

30 conducted in the city of Zagreb, Croatia, during an 8-year period (2009-2016). The study

31 addressed the impact of different sampling schemes on the assessment of temporal drug

32 consumption patterns, in particular multiannual consumption trends and documented the

33 possible errors associated with the one-week sampling scheme. The highest drug consumption

34 prevalence was determined for cannabis (from $59 \pm 18$ to $156 \pm 37$ doses/day/1000 inhabitants

35 15-64 years), followed by heroin (from $11 \pm 10$ to $71 \pm 19$ doses/day/1000 inhabitants 15-64

36 years), cocaine (from $8.3 \pm 0.9$ to $23 \pm 4.0$ doses/day/1000 inhabitants $15-64$ years) and

37 amphetamine (from $1.3 \pm 0.9$ to $21 \pm 6.1$ doses/day/1000 inhabitants $15-64$ years) whereas the

38 consumption of MDMA was comparatively lower (from $0.18 \pm 0.08$ to 2.7 doses \pm 0.7

39 doses/day/1000 inhabitants $15-64$ years). The drug consumption patterns were characterized by

40 clearly enhanced weekend and Christmas season consumption of stimulating drugs (cocaine,

41 MDMA and amphetamine) and somewhat lower summer consumption of almost all drugs.

42 Pronounced multiannual consumption trends were determined for most of the illicit drugs. The

43 investigated 8-year period was characterized by a marked increase of the consumption of pure 44 cocaine (1.6-fold), THC (2.7-fold), amphetamine (16-fold) and MDMA (15-fold) and a 45 concomitant decrease (2.3-fold) of the consumption of pure heroin. The heroin consumption 46 decrease was associated with an increase of methadone consumption (1.4-fold), which can be 47 linked to its use in the heroin substitution therapy. The estimated number of average 
48 methadone doses consumed in the city of Zagreb was in a good agreement with the 49 prescription data on treated opioid addicts in Croatia.

50

51 Keywords: illicit drugs, opioids, multiannual trends, wastewater-based epidemiology, Zagreb,

52 LC-MS/MS

53 


\section{Introduction}

Abuse of illicit drugs has become a major global problem with numerous negative consequences

56 including increase in crime rate, negative impacts on public health, economic damage as well as

57 costs of treatment of drug addicts (EMCDDA, 2009). Consequently, knowing the extent and patterns of drug abuse is very important for planning timely and effective actions to mitigate

59 these problems. The official data about illicit drug consumption usually include the information

60 about the amount and purity of seized drugs, number of treated drug addicts and general

61 population survey data, whose frequency in different countries may be rather different. In

62 recent years, wastewater-based epidemiology (WBE) has been used as a complementary

63 approach for the estimation of drug consumption across the world (e.g. Bijlsma et al., 2016;

64 Bones et al., 2007; Huerta-Fontela et al., 2008; Kahn et al., 2014; Kankaanpää et al., 2014;

65 Kasprzyk-Hordern et al., 2009; Irvine et al., 2011; Lai et al., 2013a, 2016; Metcalfe et al., 2010;

66 Postigo et al., 2010; Terzic et al., 2010; van Nuijs et al., 2009; Zuccato et al., 2008).

67 The main advantages of the WBE approach are objectivity and suitability for near-real-time monitoring. In order to improve and expand the WBE approach, several publications addressed

69 the problem of uncertainties associated with sample collection (Ort et al., 2010), sample 70 stability (McCall et al., 2016; van Nuijs, 2012; Senta et al., 2014) as well as back-calculation of

71 drug consumption (Castiglioni et al., 2013; Gracia-Lor et al., 2016; Lai et al., 2011). A number of

72 studies have already demonstrated the potential of WBE to provide information about the 73 spatial (Been et al., 2016; Bijlsma et al., 2016; Kankaanpää et al., 2016; Nefau et al., 2013) and 74 temporal (Bade et al., 2018; Been et al., 2016; Lai et al., 2016; Mastroianni et al., 2017; Tscharke 75 at al., 2016) drug consumption patterns, including large international comparative studies (Ort 
et al., 2014a; Thomas et al., 2012), which showed a pronounced regional and temporal varibility

77 of drug abuse accross the Europe. In several studies, the potential of this approach as a 78 complementary tool to support epidemiological and seizure data (Baz-Lomba et al., 2016; Been

79 et al., 2016; Zuccato et al., 2016) was demonstrated. The WBE approach was also successfully

80 applied to study the differences in drug consumption patterns between the large and small

81 cities (Krizman et al., 2016; van Nuijs et al., 2009), with a clear indication that large cities

82 represent communities with significantly enhanced drug consumption and, consequently, are

83 very suitable for the investigation of the drug consumption patterns.

84 Regarding temporal variability, a significant emphasis of existing studies was on short-term

85 consumption variability, especially regarding so-called recreational stimulating drugs. A number

86 of WBE studies performed in different countries confirmed an enhanced consumption of

87 stimulating illicit drugs during the weekend (e.g. Krizman et al., 2016; Terzic et al., 2010; Thomas

88 et al., 2012), large sport events (Gerritry et al., 2011), music festivals (Bijlsma et al., 2014; Jiang

89 et al., 2015; Lai et al., 2013b; Mackulak et al., 2014) and the peak of tourist season in the

90 vaccation areas (Krizman et al., 2016; Lai et al., 2013c). In contrast, only few reports addressed

91 the issue of multiannual changes in drug consumption patterns within the selected population

92 (e.g. Kankaanpää et al., 2016; Mastroianni et al., 2017; Ort et al., 2014a; Tscharke at al., 2016;

93 Zuccato et al. 2016). Most of the published multiannual studies were based on the comparison

94 of one-week wastewater sampling campaigns in a given time-period (Kankaanpää et al., 2016;

95 Mastroianni et al., 2017; Ort et al., 2014a; Zuccato et al. 2016.). In such cases, possible week-to-

96 week variability during the particular year was not taken into account, which might increase the

97 uncertainties related to the annual consumption estimates. In order to get a more accurate 
98 estimate, representative of average annual drug consumption, a recent study by Ort et al. 99 (2014b) recommended the use of stratified annual sampling to minimize the errors associated 100 with day-to-day varibility. The importance of sampling scheme for the assessment of 101 consumption was also discussed in Humphries et al. (2016).

102 In this study we investigated the multiannual trends in the consumption of 6 illicit drugs 103 (cannabis, cocaine, heroin, MDMA, amphetamine, methamphetamine) and one therapeutic 104 opioid (methadone) in the city of Zagreb in the period 2009-2016, by applying two different 105 sampling schemes (one-week sampling scheme and a whole-year sampling scheme). The city of 106 Zagreb is the capital and the largest Croatian city, representing almost 20\% of Croatia's 107 population. Furthermore, an initial WBE study conducted in Zagreb (Terzic et al., 2010) indicated 108 specific drug consumption patterns which were different from those reported for most of the 109 other European cities, in particular regarding comparatively higher prevalence of heroin 110 consumption and lower prevalence of cocaine and amphetamine drug consumption.

111 The specific goals of the present study included: a) long-term study of the weekday-related drug 112 consumption patterns; b) impact of the holiday season on drug consumption patterns; c) 113 seasonal changes in drug consumption patterns; d) testing different sampling schemes for the 114 assessment of multiannual trends; e) tracking the multiannual changes of the drug consumption 115 over a period of 8 years and comparison with the available epidemiological data.

\subsection{Selection of target compounds}


119 The selection of target compounds was based on the available data on drug consumption 120 patterns in Croatia (Glavak Tkalic et al., 2013) and in the city of Zagreb (Krizman et al., 2016;

121 Terzic et al., 2010). Selected analytes included morphine (MOR), morphine-3-glucuronide (M3G)

122 and 6-acetylmorphine (6-AM) as principal heroin-derived substances as well as benzoylecgonine

$123(\mathrm{BE})$, amphetamine (AMP), methamphetamine (MAMP), 3,4-methylendioximethamphetamine

124 (MDMA), 11-nor-9-carboxy-tetrahydrocannabinol (THC-COOH) and 2-ethylidene-1,5-dimethyl-

125 3,3-diphenylpyrrolidine (EDDP) as principal biomarkers of cocaine, amphetamine, 126 methamphetamine, MDMA, cannabis and methadone consumption, respectively.

$128 \quad$ 2.2. Chemicals and materials

129 Standard solutions of all target analytes $(1 \mathrm{~g} / \mathrm{L})$ and their deuterated analogues $(0.1 \mathrm{~g} / \mathrm{L})$ were 130 purchased from Lipomed AG (Switzerland). Mixed standard solutions of the analytes and their 131 deuterated analogues, used as surrogate standards, were prepared in methanol (MeOH) at 132 concentrations of $10 \mathrm{mg} / \mathrm{L}$ and $2 \mathrm{mg} / \mathrm{L}$, respectively, and kept in the dark at $-20{ }^{\circ} \mathrm{C}$. Aqueous 133 ammonia solution $\left(\mathrm{NH}_{3}, 25 \%\right)$ and $\mathrm{LC}-\mathrm{MS}$ grade $\mathrm{MeOH}$ were purchased from Merck AG 134 (Darmstadt, Germany). Acetic acid $\left(\mathrm{CH}_{3} \mathrm{COOH}\right)$, also LC-MS grade, formic acid (HCOOH) and 135 phosphoric acid $\left(\mathrm{H}_{3} \mathrm{PO}_{4}\right)$ were purchased from Fluka (Switzerland). Milli-Q water was obtained 136 by purifying with an Elix-Mili-Q-system (Millipore, Bedford, USA). Oasis MCX cartridges (150 mg 137 / $6 \mathrm{~mL}$ ) were purchased from Waters (Milford, MA, SAD) whereas Strata $\mathrm{NH}_{2}(200 \mathrm{mg} / 3 \mathrm{~mL}$ ) 138 cartridges as well as HPLC columns used for the chromatographic separation (Synergi Polar; 4 $139 \mu \mathrm{m}, 150 \mathrm{~mm} \times 3 \mathrm{~mm}$, Kinetex PFP; $2.6 \mu \mathrm{m}, 100 \mathrm{~mm} \times 2.1 \mathrm{~mm}$ ) were purchased from 
140 Phenomenex (Torrance, California, USA). Glass-fiber filters (GF/C) were purchased from 141 Whatman (USA).

\section{$143 \quad$ 2.3. Wastewater sampling and analysis}

144 The 24-h composite samples (from 8 a.m. of the previous day to 8 a.m. of the sample collection 145 day) of untreated wastewater were collected at the inlet of the central WWTP of the city of 146 Zagreb in the period 2009-2016, except in 2010. All collected samples were time-proportional, 147 with the sampling time interval of $15 \mathrm{~min}$. A total number of 282 samples, having an average $\mathrm{pH}$ 148 of $7.6 \pm 0.2$, was collected. Depending on the specific research goals, different sampling 149 schemes were applied to cover both short-time and long-term variability: one-week sample 150 scheme, a whole-year sampling-scheme and Christmas season sampling scheme.

151 All investigated years included at least one one-week sampling period (25 March - 2 April 2009;

15226 August - 3 September 2009, 9-15 March 2011, 17-24 March 2012, 6-12 March 2013, 24 July -

15331 August 2013, 11-18 March 2014, 17-23 March 2015, 9-15 March 2016).

154 In addition, in 2009 and further throughout the period 2012-2016, samples were also collected 155 over the whole year, two to four times per month, and uniformly covered all seasons (whole156 year sampling scheme). In principle, a whole-year sampling scheme included a collection of 157 equal number of weekend (Sunday) and weekday (Tuesday) samples. The total number of 158 samples collected within one whole-year sampling scheme varied from 21 to 46 . Special time159 periods such as Christmas holiday season and major festivals were avoided within the one-week 160 and whole-year sampling schemes. Christmas season sampling scheme included two Christmas 161 holiday seasons in the period: 21 December $2012-4$ January $2013(n=15)$ and 20 December 

2013 - 3 January $2014(n=14)$. The samples collected within the one-week sampling scheme and the Christmas holiday sampling scheme were frozen immediately after collection and kept 164 frozen until analyses, whereas all other samples were processed within a few hours after 165 collection. Since the study covers a rather long time-period, some of the data, resulting from the sampling campaigns described above, were partially used in previously published studies (e.g.

167 Krizman et al., 2016; Ort et al., 2014b; Terzic et al., 2010; Thomas et al., 2014).

168 The sample preparation and LC-MS/MS analysis were performed by applying already published and validated analytical method (Senta et al., 2013). The performance of the method was repetitively confirmed in 6 international intercalibration studies performed during the period

171 2011-2016 (van Nuijs et al., 2018). Briefly, samples of wastewater (125 mL) were spiked with

172 surrogate standards ( $120 \mathrm{ng} / \mathrm{L}$ ) and after equilibration filtered using GF/C filters. After filtration, 173 samples were enriched on Oasis MCX cartridges. The basic drugs were eluted with $6 \mathrm{~mL}$ of $0.5 \%$

$174 \mathrm{NH}_{3}$ in $\mathrm{MeOH}$ whereas $\mathrm{THC}-\mathrm{COOH}$ was eluted with methanol and additionally cleaned-up using 175 Strata $\mathrm{NH}_{2}$ cartridges. These two fractions were analyzed separately by triple-quadrupole liquid 176 chromatography tandem mass spectrometry (Quantum AM, Thermo Electron, USA). 177 Chromatographic separation of basic drug biomarkers was performed using a gradient elution 178 on Synergy $4 \mu$ POLAR-RP $80 \AA$ column (Phenomenex, $150 \times 3 \mathrm{~mm}$ ), whereas for the analyses of 179 THC-COOH, Kinetex $2.6 \mu \mathrm{m}$ PFP $100 \AA$ (Phenomenex, $100 \times 2.1 \mathrm{~mm}$ ) column was used. Eluents 180 used for the separation of basic analytes included $0.1 \%$ acetic acid in $\mathrm{H}_{2} \mathrm{O}(\mathrm{v} / \mathrm{v})$ and $0.1 \%$ acetic 181 acid in $\mathrm{MeOH}(\mathrm{v} / \mathrm{v})$, whereas $\mathrm{THC}-\mathrm{COOH}$ analyses were performed using $\mathrm{H}_{2} \mathrm{O}$ and $\mathrm{MeOH}$ as 182 eluents. THC-COOH was analyzed in negative ionization mode (NI) whereas the analyses of all 183 other analytes were performed in positive ionization mode (PI). Identification and quantification 
184 was performed using two characteristic transitions for each analyzed compound (MRM mode).

185 Quantitation of all analytes was performed using corresponding deuterated internal standards

186 for all analytes.

187

188

\subsection{Estimation of drug consumption}

189 Estimation of drug consumption was performed as described earlier by Krizman et al. (2016),

190 applying the methodology originally proposed by Zuccato et al. (2008). The representative

191 average mass loads $\left(X_{r p}\right)$ and their corresponding standard deviations $\left(S_{R P}\right)$ used for the

192 assessment of drug consumption were calculated using the following equations:

193

$$
X R P=\frac{5}{7} x(\text { workday })+\frac{2}{7} x(\text { weekend })
$$

195

$$
S R P=\sqrt{\left(\frac{5}{7} S(\text { workday })\right)^{2}+\left(\frac{2}{7} S(\text { weekend })\right)^{2}}
$$

198 in which X (workday), S (workday), X (weekend) and S (weekend) represent the average values

199 and standard deviations of workday and weekend daily mass loads. The concentration equal to 200 the half of the detection limit was applied in all cases when the analyzed urinary biomarkers 201 were not detectable.

202 The number of inhabitants as well as the number of inhabitants of age 15-64 years, served by 203 the WWTP, was based on 2011 Census data. The normalized consumption of individual drugs, 
204 expressed as the number of doses per 1000 inhabitants, was calculated using the corresponding 205 average dose size listed in Table 1.

206 The amounts of street-purity drugs which circulated on the illegal market in Zagreb were 207 calculated from the estimated annual consumption of pure drugs (expressed in $\mathrm{kg} / \mathrm{year}$ ), which 208 were divided by the corresponding drug purity presented in Table S1.

209 Most of the correction factors used in the calculation of drug consumption were taken from the 210 paper published by Gracia-Lor et al. (2016). The estimation of cocaine consumption was made 211 by using the correction factor of 3.6 (Castiglioni et al., 2013), whereas heroin consumption was

212 calculated from 6-AM mass loads, using a correction factor of 86.9 (van Nuijs et al. 2011).

\section{2.5. Statistical evaluation}

215 Statistical analysis of the data was performed using Sigma Plot 12.0 (Systat software Inc., SAD). 216 Depending on data distribution, parametric ( $t$-test, One-way ANOVA) and non-parametric tests 217 (Mann-Whitney, Kruskal-Wallis test) were applied. In order to examine differences among 218 multiple groups, One-way ANOVA and Kruskal-Wallis tests were used (with follow-up Holm219 Sidak and Dunn's method post-hoc testing, respectively) while for testing the differences 220 between two groups, $t$-test and Mann-Whitney test were used.

\section{Results and discussion}

\section{3.1. Occurrence of drug biomarkers in municipal wastewater of the city of Zagreb}

224 The analyses included selected drug biomarkers which are excreted after the consumption of 6 225 illegal drugs (cannabis, heroin, cocaine, amphetamine, MDMA and methamphetamine) and 
226 methadone which is primarily used in the treatment of heroin users. The analyses performed 227 between 2009 and 2016 showed that most of the investigated drug biomarkers were rather 228 common constituents in the wastewater of the city of Zagreb (Table 2). The most frequently 229 detected biomarkers were MOR, BE, THC-COOH and EDDP, which were determined in all 230 analyzed wastewater samples ( $n=270-282)$. Very high frequency of detection was obtained also 231 for 6-AM (98\%), M3G (97\%), AMP (96\%) and MDMA (99\%; $n=282)$, whereas MAMP was the 232 least frequently detected drug biomarker (83\%). Regarding abundances, the highest average 233 annual concentrations were determined for MOR (from $74 \pm 29 \mathrm{ng} / \mathrm{L}$ to $294 \pm 83 \mathrm{ng} / \mathrm{L}$ ), BE (from $234143 \pm 34 \mathrm{ng} / \mathrm{L}$ to $273 \pm 101 \mathrm{ng} / \mathrm{L}$ ) and EDDP (from $121 \pm 41 \mathrm{ng} / \mathrm{L}$ to $190 \pm 67 \mathrm{ng} / \mathrm{L}$ ), followed by 235 AMP (from $7.5 \pm 7.5 \mathrm{ng} / \mathrm{L}$ to $109 \pm 58 \mathrm{ng} / \mathrm{L}$ ) and MDMA (from $6.8 \pm 7.7 \mathrm{ng} / \mathrm{L}$ to $92 \pm 58 \mathrm{ng} / \mathrm{L}$ ). The 236 lowest concentrations were determined for MAMP (from $0.6 \pm 0.6 \mathrm{ng} / \mathrm{L}$ to $1.4 \pm 1.8 \mathrm{ng} / \mathrm{L}$ ), M3G 237 (from $1.6 \pm 2.2 \mathrm{ng} / \mathrm{L}$ to $9.9 \pm 6.7 \mathrm{ng} / \mathrm{L}$ ) and 6-AM (from $2.0 \pm 2.4 \mathrm{ng} / \mathrm{L}$ to $12 \pm 4.7 \mathrm{ng} / \mathrm{L}$ ).

\subsection{Drug consumption patterns}

\subsubsection{Workday/weekend drug consumption patterns}

241 Possible differences in workday to weekend consumption patterns of individual drugs have 242 been evaluated based on the ratios of weekend and workday daily mass loads of selected drug 243 biomarkers for individual years (Fig. 1). It was arbitrarily assumed that a ratio significantly 244 different from $1.0 \pm 0.2$ was a confirmation of some specific weekday-related consumption 245 pattern. It should be stressed that the ratio for MOR consumption was calculated from the 246 corresponding mass loads of the total morphine (MOR $\left.R_{\text {tot }}\right)$. The $M O R_{\text {tot }}$ mass loads were obtained 
247 by summing up the daily mass loads of MOR and M3G (taking into account the molar ratio to 248 MOR of 1.62).

249 Almost all ratios of the weekend and workday average daily mass load of stimulating drug 250 biomarkers, $\mathrm{BE}(1.5 \pm 0.3$ to $1.7 \pm 0.5), \mathrm{MDMA}(2.3 \pm 0.5$ to $4.3 \pm 3.6)$ and $\mathrm{AMP}(1.0 \pm 1.0$ to 2.2

$251 \pm 1.3$ ), were significantly (t-test) different from $1.0 \pm 0.2$. By contrast, most of the ratios for $252 \mathrm{MOR}_{\text {tot }}(0.95 \pm 0.4$ to $1.1 \pm 0.3), 6-\mathrm{AM}(0.6 \pm 0.8$ to $1.2 \pm 0.3), \mathrm{THC}-\mathrm{COOH}(0.9 \pm 0.4$ to $1.2 \pm 0.4)$ 253 and EDDP $(0.9 \pm 0.3$ to $1.1 \pm 0.3)$ indicated a rather uniform consumption of heroin, cannabis 254 and methadone throughout the week. The observed weekend-related drug consumption 255 patterns of stimulating drugs (MDMA, cocaine and AMP) documented in this study not only fully 256 support the results obtained in a number of previous studies based on 7 consecutive days 257 sampling scheme (e.g. Krizman et al., 2015; Ort et al., 2014a; Terzic et al., 2010; Thomas et al 258 2012), but also confirm the robustness of the applied whole-year sampling scheme to 259 demonstrate the importance of weekday-weekend dynamics at long-term time scales.

\subsubsection{The impact of holiday season on drug consumption patterns}

262 The results of research dealing with the impact of holiday season on drug consumption patterns 263 are presented in Fig. 2, Fig. S1 and Fig. 3. In both periods, the 1st of January (New Year) was 264 characterized by a significantly enhanced daily mass load of BE (224 g/day and $197 \mathrm{~g} / \mathrm{day})$, 265 MDMA (62 g/day and $67 \mathrm{~g} /$ day) and AMP (42 g/day and $60 \mathrm{~g} /$ day), which confirmed an 266 increased consumption of all major stimulating drugs in holiday seasons (Fig. 2). By contrast, the 267 25th of December (Christmas) was associated with an enhanced excretion of BE (166 g/day and 
$130 \mathrm{~g} /$ day) whereas the Christmas consumption of most amphetamine-type drugs (AMP and MDMA) was not clearly elevated. These results probably reflect the life-style differences of

270 cocaine and amphetamine-type drug consumers within the investigated population. In both

271 holiday season periods, a steady increase of MOR excretion towards Christmas was also

272 observed. However this increase was not associated with the concomitant increase of 6-AM and

273 therefore cannot be unequivocaly related to the enhanced consumption of heroin.

274 Furthermore, unlike for stimulating drugs, holiday-related consumption patterns could not be

275 established for the remaining investigated drugs, such as cannabis and EDDP (Fig. S1). The 276 comparison of the average mass loads during the two holiday season periods with the average

277 weekend and workday mass loads in the corresponding years (Fig. 3) confirmed a significantly 278 higher consumption $(p<0.05)$ of stimulating drugs $(\mathrm{BE}, \mathrm{MDMA}, \mathrm{AMP})$ during the weekend $(n=$ 279 19-24) and holiday season period $(n=14-15)$ as compared to workday periods $(n=19-22)$. The 280 average mass loads of stimulating drugs during Christmas holiday season were 2 - 3.9-fold 281 higher than during the average weekday and $1.2-1.9$-fold higher than during the average 282 weekend of the corresponding year. This is in a good agreement with previous studies which 283 indicated the enhanced consumption of stimulating drugs during the holidays, festivals, tourist 284 seasons etc. (e.g. Krizman et al., 2016; Lai et al., 2013a; Lai et al. 2013b, van Nuijs et al., 2009) 285 and underlines the ability of the applied WBE approach to address the problem of relative 286 contributions of special events to the overal drug consumption in a particular yearly period. 
In this study, we compared the average daily mass loads determined in the city of Zagreb in 2 different one-week periods, early spring and summer, in 2009 and 2013. The results of this

291 comparison are presented in Fig. 4. In both investigated years, the average summer mass loads 292 of most of the investigated drug biomarkers were lower than those determined in early spring 293 (Fig. 4). However the observed differences were statisticaly significant ( $p<0.05$; Mann-Whitney 294 test) only for drug biomarkers which exhibit lower intra-week variability (e.g. MOR tot, THC-COOH 295 and EDDP) whereas they were not significant for the biomarkers of stimulating drugs (BE, 296 MDMA), probably due to the comparatively higher intra-week variability. The lower average 297 daily mass loads determined in summer are most likely associated with a disbalanced outward 298 and inward population migrations during the summer vacation season. Namely, the 299 contribution of tourists to the total city population is rather negligible throughout the year $300(<1 \%$, data from Zagreb Tourist Board), whereas a significant percentage of residential 301 population might be out of town during the peak of summer season. Unfortunately, this 302 assumption cannot be confirmed since the official data related to the outward migrations of the 303 city population were not available. Another possible factor which might have caused the 304 observed differences in spring and summer mass loads is faster in-sewer drug biomarker 305 degradation at higher temperatures (e.g. Devault et al., 2017). However, the model experiments 306 which were performed with the wastewater from the city of Zagreb at $10^{\circ} \mathrm{C}$ and $20^{\circ} \mathrm{C}$, indicated 307 rather higher stability of all urinary biomarkers included in this research at the both 308 temperature conditions (Senta et al., 2016.). Since the in-sewer wastewater residence time in 309 Zagreb is relatively short ( $<5 \mathrm{~h})$ and a typical wastewater temperature in March and July/August 310 is $12^{\circ} \mathrm{C}$ and $20.5^{\circ} \mathrm{C}$, respectively, it is not very likely that the observed seasonal mass load 
311 diferences were primarily caused by faster in-sewer degradation in summer. Although the

312 reasons for the observed seasonal differences of the average mass loads are not yet fully 313 understood, they indicated that the total drug consumption might be underestimated if 314 extrapolated from the average daily mass loads determined in summer.

\subsection{Impact of sampling scheme on the estimation of drug consumption in multiannual studies}

317 Most of the previously conducted multiannual WBE studies were based on relatively short one318 week sampling periods (e.g. Kankaanpää et al., 2016; Mastroianni et al., 2017, Ort et al., 2014a; 319 Zuccato et al. 2016), which, due to the possible week-to-week variability of daily mass loads, 320 may be associated with a potential error in tracking the drug consumption on an annual basis. In

321 this study, a comparison was made between the representative average daily mass loads of 322 selected drug biomarkers obtained by applying two different sampling schemes: one-week 323 sampling scheme (March/April 2012 - 2016) and whole-year sampling scheme (Sundays and 324 Tuesdays; sampled either fortnightly in 2012-2014 or monthly in 2015-2016). Based on the 325 extended scheme of the whole-year sampling carried out in 2013 and 2014, which included 326 fortnightly sampling $(n=48)$, it was shown that the reduction of the sample number to half 327 (monthly sampling; $n=24)$ did not significantly affect the estimate of the mass loads $(t$-test; $p<$ 328 0.05).

329 The representative daily mass loads of individual drug biomarkers determined by applying the 330 one-week and the whole-year sampling scheme are presented in Fig. 5. Apart from some 331 occasional exceptions, the application of the whole-year sampling scheme was, in principle, 
332 associated with somewhat higher day-to-day variability of daily mass loads than the one-week

333 sampling scheme, which is probably a result of higher intra-annual variability of drug 334 consumption. The amphetamine-type drugs (MAMP, AMP and MDMA) exhibited the strongest 335 day-to-day variability within the both sampling schemes, which is most probably associated with 336 a rather irregular consumption pattern of these drugs, characterized by enhanced weekend and 337 holiday consumption rates. Furthermore, the one-week sampling scheme was occasionally 338 associated with relatively high day-to-day variability of AMP and MDMA. The statistical analysis 339 of the data exhibited a significant difference $(p<0.05)$ between the representative mass loads 340 of AMP obtained by the two applied sampling schemes in all investigated years. By contrast, the 341 differences for other investigated drug biomarkers were found to be significant $(p<0.05)$ only 342 occasionally. Previous study by Ort at al. (2014b) has shown that the variability of drug 343 consumption in smaller communities ( $<10000$ inhabitants) is extremely high, requiring very 344 high sampling frequency to achieve the proper estimate of drug consumption. It was estimated 345 that the average annual consumption calculated from 1-week sampling was subject to 346 approximately $60 \%$ relative error. In contrast, our study suggests that intra-annual varibilities in 347 larger cities can be significantly smaller allowing detection of relatively small changes (20\%) of 348 the drug consumption among different years. Nevertheless, although some previous studies, 349 addressing the issue of multiannual changes, demonstrated the applicability of one-week 350 sampling scheme (Mastroianni et al., 2017; Ort et al. 2014a, Zuccato et al., 2016), our data show 351 that such a scheme is insufficiently reliable for the drugs exhibiting high day-to-day and intra352 annual variability, even in case of larger cities like the city of Zagreb. 


\subsection{Multiannual trends in drug consumption patterns and comparison with available}

354 epidemiological data

The back-calculations of drug consumption were based on representative daily mass loads determined for all samples collected within each investigated year, with the exception of those collected during the Christmas-New Year holiday seasons. The consumption was calculated for heroin, cocaine, AMP, MDMA, cannabis (THC) and methadone (MTHD). The results expressed in $\mathrm{mg} /$ day/1000 inhabitants of age 15-64 are presented in Fig. 6, whereas the results expressed in other units (e.g. mg/day/1000 inhabitants, doses/day/1000 inhabitants, g/day, kg/year, kg/year of street purity drug) are given in Supplementary Material (Table S2). The highest illicit drug consumption rate was determined for cannabis (from $7368 \pm 2197$ mg/day/1000 inhabitants 1564 years to $19544 \pm 4624 \mathrm{mg} /$ day/1000 inhabitants 15-64 years), followed by heroin (from $107 \pm$ $104 \mathrm{mg} /$ day/1000 inhabitants $15-64$ years to $712 \pm 193 \mathrm{mg} /$ day/1000 inhabitants $15-64$ years), cocaine (from $249 \pm 27 \mathrm{mg} /$ day/1000 inhabitants $15-64$ years to $699 \pm 121 \mathrm{mg} /$ day/1000 inhabitants $15-64$ years), MDMA (from $17 \pm 7.5 \mathrm{mg} /$ day/1000 inhabitants $15-64$ years to $259 \pm$ $69 \mathrm{mg} /$ day/1000 inhabitants 15-64 years) and AMP (from $13 \pm 8.8 \mathrm{mg} /$ day/1000 inhabitants 15 64 years to $213 \pm 61 \mathrm{mg} /$ day/100 inhabitants $15-64$ years). The estimated consumption rate of the therapeutic opioid methadone was in the range from $280 \pm 26 \mathrm{mg} /$ day/1000 inhabitants 15 64 years to $393 \pm 61 \mathrm{mg} /$ day/1000 inhabitants $15-64$ years. In principle, the determined drug

371 consumption patterns and rates were rather similar to those determined in some other 372 Mediterranean countries, like Spain and Italy (Mastroianni et al., 2017; Zuccato et al., 2016), 373 although some differences regarding the prevalence of individual drugs as well as regarding the 374 temporal trends were observed. For example, cannabis and cocaine were the most prevalently 
375 consumed illicit drugs in Barcelona (Spain) and investigated Italian cities, whereas a heroin 376 consumption was reported to be much lower (Mastroianni et al., 2017; Zuccato et al., 2016).

377 In our study, all investigated illicit drugs, except heroin, exhibited a significant increase $(p<$ 378 0.05) of the consumption rates over the investigated 8-year period (Fig. 6 and 7, Table S2). In 3792016 , the average consumption rate of pure MDMA, AMP, THC (cannabis) and cocaine, were 380 15-fold, 16-fold, 3-fold and 2-fold higher than in 2009, respectively. The multiannual 381 consumption patterns of pure AMP and MDMA were characterized by a rather continuing 382 increase of their consumption rates (Fig. 6) over the whole investigated time period, whereas 383 the consumption of THC (cannabis) was characterized by a significant increase in 2009-2014 384 period ( $p<0.05$, 3-fold increase), and rather stable consumption rate in 2014-2016 period. By 385 contrast, the consumption rate of pure heroin dropped significantly ( $p<0.05 ; 5-7$-fold) between 3862009 and 2011-2012 period, and kept at significantly lower level until $2016(p<0.05)$. However, 387 a significant $(p<0.05) 2-3$-fold increase in pure heroin consumption was recorded between 388 2011/2012 and 2016, which indicated a gradual recovery of heroin market in that period. 389 Interestingly, a reduction of heroin consumption in the period 2010-2012 was reported for Italy 390 as well (Zuccato et al., 2016).

391 Based on the estimated amounts of consumed drugs and the official data on purity of seized 392 drugs provided by the Office for Combating Narcotic Drug Abuse of the Government of the 393 Republic of Croatia (see Table S1), we calculated the amounts of the street-purity drugs which 394 circulated on the illegal market in Zagreb in the corresponding years (Table S2). It should be 395 stressed that the street-drug purity of investigated drugs (heroin, amphetamine, MDMA, 
cocaine) exhibited a pronounced temporal variability (Table S2). The amounts of the most

397 prevalent drugs present on the illegal market in Zagreb were as follows: from 211 to 565 $398 \mathrm{~kg} /$ year of heroin, from 157 to $323 \mathrm{~kg} /$ year of cocaine, from 44 to $309 \mathrm{~kg} /$ year of amphetamine, 399 from 14 to $127 \mathrm{~kg} /$ year of MDMA and from 22853 to $53988 \mathrm{~kg} /$ year of cannabis.

400 Consequently, the observed multiannual trends in the consumption of pure drugs are probably 401 not impacted exclusively by the changes in drug consumption prevalence but also by the 402 changes in the street drug purity. In this context, it is interesting to note that a significant drop 403 in the heroin consumption rate between 2009 and 2011/2012 was associated with a 404 concomitant decrease of heroin street-drug purity (from $21.5 \%$ to $8.4 \%$ ) and an increase in the 405 consumption of the substitution therapy drug methadone (40\%), which then kept a rather 406 stable consumption rate in the subsequent period (2013-2016). The average number of 407 consumed methadone doses estimated in this study (e.g. $3.1 \pm 0.4$ doses/day/1000 inhabitants 408 in 2015; $80 \mathrm{mg} /$ dose) were in a rather good agreement with the amount of that drug prescibed 409 in the city of Zagreb in 2015 (11.76 DDD/TSD; DDD = 25 mg; 3.7 doses/day/1000 inhabitants for 410 the average dose of $80 \mathrm{mg} / \mathrm{L}$ ) (Draganic et al., 2017), which confirmed a reliability of WBE 411 approach for tracking the changes of the illicit drug consumption patterns.

412 The trends in population normalized number of addicts treated due to consumption of different 413 types of drugs did not, however, reflect the multiannual drug consumption trends determined 414 in this study (Fig. 7), probably due to a rather long time-gap between the initial drug 415 consumption and the involvement of the consumers in the treatment. 
416 Furthermore, the drug consumption trends which were determined in the present study were

417 only partialy in agreement with the results of general population surveys performed in Croatia

418 in 2011 and 2015, which indicated a significant increase only in the consumption of cannabis

419 (2.9\% last-month prevalence in 2011; 5.0\% last-month prevalence in 2016) (Glavak Tkalic et al.,

420 2013; Glavak Tkalic et al., 2016), whereas the differences in the consumption prevalence of

421 other illicit drugs were not found to be significant. Our study suggests that the outcome of

422 national population surveys on drug consumption is not necessarily representative for larger

423 cities. Given the fact that the city of Zagreb represents approximately $20 \%$ of the whole Croatian

424 population, the drug consumption trends determined in this study imply the need for specific

425 surveys focusing on larger cities. Moreover, the trends observed in the city of Zagreb might be

426 an indication of some trends developing at the national level.

\section{5. Conclusion}

429 The eight-year monitoring period of drug consumption patterns in the city of Zagreb, Croatia, 430 using wastewater-based epidemiology revealed several temporal variability patterns, including 431 weekday-weekend dynamics, holiday season effects and multiannual trends. In agreement with 432 the literature, the enhanced consumption of stimulating drugs was systematically observed 433 during weekends and Christmas holiday season. In addition, a significant multiannual increase of 434 cocaine (1.6-fold), THC (2.7-fold), amphetamine (16-fold) and MDMA (15-fold) consumption 435 with a concomitant decrease (2.3-fold) of the consumption of heroin was observed during the 436 investigated 8-year period (2009-2016). The whole-year sampling scheme showed a clear 
437 advantage over the one-week sampling scheme, especially for drugs showing enhanced day-to438 day and intra-annual variability. The errors associated with day-to-day and intra-annual 439 variability of $B E(<20 \%)$ determined in the city of Zagreb (>500 000 inhabitants) study were 440 much smaller from those reported for small communities (Ort et al. 2014b), which indicated 441 enhanced robustness of the estimates obtained for large sized cities. Our data suggest that large 442 sized cities can provide a basis for a reliable detection of relatively small changes in drug 443 consumption over a multi-year period. Consequently, the trends observed in the larger cities 444 could be used as an early warning of the trends developing at the national level.

\section{Acknowledgments}

448 We are thankful to dr. sc. Marin Ganjto and the staff of central WWTP Zagreb for their 449 assistance with the wastewater collection. Technical assistance of Nenad Muhin is highly 450 appreciated. Epidemiological data were provided by the Croatian Institute of Public Health. The 451 data on average drug doses in Croatia were provided by Forensic Science Centre Ivan Vucetic 452 and Office for Combating Narcotic Drug Abuse of the Government of the Republic of Croatia.

453 The research was financially supported by the City of Zagreb, Office for Combating Narcotic 454 Drug Abuse of the Government of the Republic of Croatia and Croatian Science Foundation 455 (project COMPASS, grant number IP-2014-09-7031). 
458 Bade, R., White, J.M., Gerber, C., 2018. Qualitative and quantitative temporal analysis of licit 459 and illicit drugs in wastewater in Australia using liquid chromatography coupled to mass 460 spectrometry. Anal. Bioanal. Chem. 410 (2), 529-542.

461 Baz-Lomba, J.A., Harman, C., Reid, M., Thomas, K.V., 2017. Passive sampling of wastewater as a 462 tool for the long-term monitoring of community exposure: Illicit and prescription drug trends as 463 a proof of concept. Water Res. 121, 221-230.

464 Been, F., Lai, F.Y., Kinyua, J., Covaci, A., van Nuijs, A.L.N., 2016. Profiles and changes in stimulant 465 use in Belgium in the period of 2011-2015. Sci. Total Environ. 565, 1011-1019.

466 Bijlsma, L., Serrano, R., Ferrer, C., Tormos, I., Hernández, F., 2014. Occurrence and behavior of 467 illicit drugs and metabolites in sewage water from the Spanish Mediterranean coast (Valencia 468 region). Sci. Total Environ. 487, 703-709.

469 Bijlsma, L., Botero-Coy, A.M., Rincón, R.J., Peñuela, G.A., Hernández, F., 2016. Estimation of illicit 470 drug use in the main cities of Colombia by means of urban wastewater analysis. Sci. Total 471 Environ. 565, 984-993.

472 Bones, J., Thomas, K.V., Paull, B., 2007. Using Environmental Analytical Data to Estimate Levels 473 of Community Consumption of Illicit Drugs and Abused Pharmaceuticals. J. Environ. Monit. 9 (7), $474 \quad 701-707$.

475 Castiglioni, S., Bijlsma, L., Covaci, A., Emke, E., Hernández, F., Reid, M., Ort, C., Thomas, K.V., van 476 Nuijs, A.L.N., de Voogt, P., Zuccato, E., 2013. Evaluation of uncertainties associated with the 
477 determination of community drug use through the measurement of sewage drug biomarkers.

478 Environ. Sci. Technol. 47, 1452-1460.

479 Devault, D.A., Nefau, T., Levi, Y., Karolak, S., 2017. The removal of illicit drugs and morphine in 480 two waste water treatment plants (WWTPs) under tropical conditions. Environ. Sci. Pollut. Res. $48124(33), 25645-25655$.

482 Draganic, P., Zezelic, S., Ostarcevic, S., 2017. Potrošnja lijekova u Republici Hrvatskoj 2011-2015. 483 Agencija za lijekove i medicinske proizvode - HALMED, pp. 174. 484 http://www.halmed.hr/fdsak3jnFsk1Kfa/publikacije/Potrosnja-lijekova-u-RH_2011-2015.pdf 485 (accessed 16.03.2018.) (in Croatian)

486 European Monitoring Centre for Drugs and Drug Addiction, 2009. Annual report on the state of 487 the drugs problem in Europe (available at) http://www.emcdda.europa.eu/publications/annual488 report/2009 (accessed 21st February 2018).

489 Gerrity, D., Trenholm, R.A., Snyder, S.A., 2011. Temporal variability of pharmaceuticals and illicit 490 drugs in wastewater and the effects of a major sporting event. Water Res. 45, 5399-5411.

491 Glavak Tkalic, R., Miletic, G.M., Sakoman, S., 2013. Prevalence of substance use among the 492 general population: Situation in Croatia and comparison with other European countries. 493 Drustvena Istrazivanja 22 (4), 557-578. 
494 Glavak Tkalic, R., Miletic, G.M., Maricic, J., 2016. Uporaba sredstava ovisnosti u hrvatskom 495 društvu: Istraživanje na općoj populaciji. Zagreb: Institut društvenih znanosti Ivo Pilar i ured za 496 suzbijanje zlouporabe droga Vlade Republike Hrvatske. pp. 251. (in Croatian)

497 Gracia-Lor, E., Zuccato, E., Castiglioni, S., 2016. Refining correction factors for back-calculation of 498 illicit drug use. Sci. Total Environ. 573, 1648-1659.

499 Huerta-Fontela, M., Galceran, T., Martin-Alonso, J., Ventura, F., 2008. Occurrence of 500 psychoactive stimulatory drugs in wastewaters in north-eastern Spain. Sci. Total Environ. 397, $501 \quad 39-41$.

502 Humphries, M.A., Bruno, R., Lai, F.Y., Thai, P.K., Holland, B., O'Brien, J.W., Ort, C., Mueller, J. F., 503 2016. Evaluation of monitoring schemes for wastewater-based epidemiology to identify drug 504 use trends using cocaine, methamphetamine, MDMA and methadone. Environ. Sci. Technol. 50 505 (9), 4760-4768.

506 Irvine, R.J., Kostakis, C., Felgate, P.D., Jaehne, E.J., Chen, C., White, J.M., 2011. Population drug 507 use in Australia: A wastewater analysis. Forensic Sci. Int. 210, 69-73.

508 Kankaanpää, A., Ariniemi, K., Heinonen, M., Kuoppasalmi, K., Gunnar, T., 2014. Use of illicit 509 stimulant drugs in Finland: A wastewater study in ten major cities. Sci. Total Environ. 487, 696510702. 
511 Kankaanpää, A., Ariniemi, K., Heinonen, M., Kuoppasalmi, K., Gunnar, T., 2016. Current trends in

512 Finish drug abuse: Wastewater based epidemiology combined with other national indicators.

513 Sci. Total Environ. 568, 864-874.

514 Jiang, J.-J., Lee, C.-L., Fang, M.-D., Tu, B.-W., Liang, Y.-J., 2015. Impacts of Emerging

515 Contaminants on Surrounding Aquatic Environment from a Youth Festival. Environ. Sci. Technol.

$516 \quad 49,792-799$.

517 Kasprzyk-Hordern, B., Dinsdale, R.M., Guwy, A., 2009. Illicit drugs and pharmaceuticals in the 518 environment - Forensic applications of environmental data. Part 1: Estimation of the usage of 519 drugs in local communities. Environ. Pollut. 157 (6), 1773-1777.

520 Khan, U., van Nuijs, A.L.N., Li, J., Maho, W., Du, P., Li, K., Hou, L., Zhang, J., Meng, X., Li, X., 521 Covaci, A., 2014. Application of a sewage-based approach to assess the use of ten illicit drugs in 522 four Chinese megacities. Sci. Total Environ. 487, 710-721.

523 Krizman, I., 2015. Illicit Drugs and Therapeutic Opioids in Municipal Wastewaters 524 Biogeochemical Behavior and Estimation of Drug Abuse (PhD thesis) University of Zagreb, 525 Zagreb, pp. 151 (in Croatian).

526 Krizman, I., Senta, I., Ahel, M., Terzic, S., 2016. Wastewater-based assessment of regional and 527 temporal consumption patterns of illicit drugs and therapeutic opioids in Croatia. Sci. Total 528 Environ. 566-567, 454-462. 
529 Lai, F.Y., Ort, C., Gartner, C., Carter, S., Prichard, J., Kirkbride, P., Bruno, R., Hall, W., Eaglesham,

530 G., Muller, J.F., 2011. Refining the estimation of illicit drug consumptions from wastewater 531 analysis: Co-analysis of prescription pharmaceuticals and uncertainty assessment. Water Res.

$53245,4437-4448$

533 Lai, F.Y., Bruno, R., Leung, H. W., Thia, P.K., Ort, C., Carter, S., Thompson, K., Lam, P.K.S., Muller, 534 J.F., 2013a. Estimating daily and diurnal variations of illicit drug use in Hong Kong: A pilot study 535 of using wastewater analysis in an Asian metropolitan city. Forensic. Sci. Int. 233, 126-132.

536 Lai, F.Y., Thai, P.K., O'Brien, J., Gartner, C., Bruno, R., Kele, B., Ort, C., Prichard, J., Kirkbride, P., 537 Hall, W., Caretr, S., Muller, J.F., 2013b. Using quantitative wastewater analysis to measure daily 538 usage of conventional and emerging illicit drugs at an annual music festival. Drug Alcohol Rev. $53932,594-602$.

540 Lai, F.Y., Bruno, R., Hall, W., Gartner, C., Ort, C., Kirkbride, P., Prichard, J., Thai, P.K., Carter, S., 541 Muller, J.F., 2013c. Profiles of illicit drug use during annual key holiday and control periods in 542 Australia: wastewater analysis in an urban, a semi-rural and a vacation area. Addiction 108, $543556-565$.

544 Lai, F.Y., O'Brien, J.W., Thai, P.K., Hall, W., Chan, G., Brunod, R., Ort, C., Prichard, J., Carter, S., 545 Anuj, S., Kirkbride, P., Gartner, C., Humphries, M., Muller, J., 2016. Cocaine, MDMA and 546 methamphetamine residues in wastewater: Consumption trends (2009-2015) in South East 547 Queensland, Australia. Sci. Total Environ. 568, 803-809. 
548 Mackulak, T., Škubák, J., Grabic, R., Ryba, J., Birošová, L., Fedorova, G., Špalková, V., Bodík, I., 549 2014. National study of illicit drug use in Slovakia based on wastewater analysis. Sci. Total 550 Environ. 494-495, 158-165.

551 Mastroianni, N., López-García, E., Postigo, C., Barceló, D., Lopez de Alda, M., 2017. Five-year 552 monitoring of 19 illicit and legal substances of abuse at the inlet of a wastewater treatment 553 plant in Barcelona (NE Spain) and estimation of drug consumption patterns and trends. Sci. 554 Total Environ. 609, 916-926.

555 McCall, A.K., Bade, R., Kinyua, J., Lai, F.Y., Thai, P.K., Covaci, A., Bijlsma, L., van Nuijs, A.L.N., Ort, 556 C., 2016. Critical review on the stability of illicit drugs in sewers and wastewater samples. Water 557 Res. 88, 933-947.

558 Metcalfe, C., Tindale, K., Li, H., Rodayan, A., Yargeau, V., 2010. Illicit drugs in Canadian municipal 559 wastewater and estimates of community drug use. Environ. Pollut. 158, 3179-3185.

560 Nefau, T., Karolak, S., Castillo, L., Boireau, V., Levi, Y., 2013. Presence of illicit drugs and 561 metabolites in influents and effluents of 25 sewage water treatment plants and map of drug 562 consumption in France. Sci. Total Environ. 461-462, 712-722.

563 Ort, C., Lawrence, M.G., Rieckermann, J., Joss, A., 2010. Sampling for pharmaceuticals and 564 personal care products (PPCPs) and illicit drugs in wastewater systems: are your conclusions 565 valid? A critical review. Environ. Sci. Technol. 44, 6024-6035. 
Ort, C., van Nuijs, A.L.N., Berset, J.D., Bijlsma, L., Castiglioni, S., Covaci, A., de Voogt, P., Emke, E.,

567 Fatta-Kassinos, D., Gfiffit, P., Hernández, F., González-Mariño, I., Grabic, R., Kasprzyk-Hordern, 568 B., Mastroianni, N., Meierjohann, A., Nefau, T., Östman ,M., Pico, Y., Racamonde, I., Reid, M., 569 Slobodnik, J., Terzic, S., Thomaidis, N., Thomas, K. V., 2014a. Spatial differences and temporal 570 changes in illicit drug use in Europe quantified by wastewater analysis. Addiction 109, 13385711352.

572 Ort, C., Eppler, J.M., Scheidegger, A., Rieckermann, J., Kinzig, M., Sörgel, F., 2014b. Challenges of 573 surveying wastewater drug loads of small populations and generalizable aspects on optimizing 574 monitoring design. Addiction 109, 472-487.

575 Postigo, C., López de Alda, M., Barceló, D., 2010. Drugs of abuse and their metabolites in the 576 Ebro River basin: Occurrence in sewageand surface water, sewage treatment plants removal 577 efficiency, and collective drug usage estimation. Environ. Int. 36, 75-84.

578 Senta, I., Krizman, I., Ahel, M., Terzic, S., 2013. Integrated procedure for multiresidue analysis of 579 dissolved and particulate drugs in municipal wastewater by liquid chromatography-tandem 580 mass spectrometry. Anal. Bioanal. Chem. 405, 3255-3268.

581 Senta, I., Krizman, I., Ahel, M., Terzic, S., 2014. Assessment of stability of drug biomarkers in 582 municipal wastewater as a factor influencing the estimation of drug consumption using sewage 583 epidemiology. Sci. Total Environ. 487, 659-665.

584 Terzic, S., Senta, I., Ahel, M., 2010. Illicit drugs in wastewater of the city of Zagreb (Croatia) 585 Estimation of drug abuse in a transition country. Environ. Pollut. 158, 2686-2693. 
Thomas, K.V., Bijlsma, L., Castiglioni, S., Covaci, A., Emke, E., Grabic, R., Emke, E., Grabic, R., 587 Hernández, F., Karolak, S., Kasprzyk-Hordern, B., Lindberg, R., Loped de Alda, M., Meierjohann, 588 A., Ort, C., Pico, Y., Quintana, J.B., Redi, M., Rieckermann, J., Terzic, S., van Nuijs, A.L.N., de Voogt, P., 2012. Comparing illicit drug use in 19 European cities through sewage analysis. Sci. Total Environ. 432, 432-439.

591 Tscharke, B.J., Chen, C., Gerber, J.P., White., J.M., 2016. Temporal trends in drug use in 592 Adelaide, South Australia by wastewater analysis. Sci. Total Environ. 565, 384-391.

593 van Nuijs, A.L.N., Pecceu, B., Theunis, L., Dubois, N., Charlier, C., Jorens, P.G., Bervoets, L., Blust, 594 R., Meulemans, H., Neels, H., Covaci, A., 2009. Can cocaine use be evaluated through analysis of 595 wastewater? A nation-wide approach conducted in Belgium. Addiction 104 (5), 734-741. van Nuijs, A.L.N., Castiglioni, S., Tarcomnicu, I., Postigo, C., Lopez de Alda, M. J., Neels, H., 597 Zuccato, E., Barcelo, D., Covaci, A., 2011. Illicit drug consumption estimations derived from 598 wastewater analysis: a critical review. Sci. Total Environ. 409, 3564-3577. 600 stability of illicit drugs and metabolites in wastewater, an important issue for sewage 601 epidemiology? J. Hazard. Mater. 234-240, 19-23. 603 Benaglia, L., Bijlsma, L., Burgard, B., Castiglioni, S., Christophoridis, C., Covaci, A., de Voogt, P., 604 Emke, E., Fatta-Kassinos, D., Fick, J., Hernandez, F., Gerber, C., González-Mariño, I., Grabic, R. 605 Gunnar, T., Kannan, K., Karolak, S., Kasprzyk-Hordern, B., Kokot, Z., Krizman-Matasic, I., Li, A., Li, 
606 X., Löve, A.S.C., Lopez de Alda, M., McCall, A.K., Meyer, M.R., Oberacher, H., O'Brien, J., 607 Quintana, J.B., Reid, M., Schneider, S., Simoes, S.S., Thomaidis, N.S., Thomas, K., Yargeau, V., 608 Ort, C., 2018. Multi-year inter-laboratory exercises for the analysis of illicit drugs and 609 metabolites in wastewater: Development of a quality control system. Trend. Anal. Chem. 103, $610 \quad 34-43$.

611 Zuccato, E., Chiabrando, C., Castiglioni, S., Bagnati, R., Fanelli, R., 2008. Estimating community 612 drug abuse by wastewater analysis. Environ. Health Perspect. 116 (8), 1027-1032.

613 Zuccato, E., Castiglioni, S., Senta, I., Borsotti, A., Genetti, B., Andreotti, A., Pieretti, G., Serpelloni, 614 S., 2016. Population surveys compared with wastewater analysis for monitoring illicit drug 615 consumption in Italy in 2010-2014. Drug Alcohol Depend. 161, 178-188.

616

617 
620 Fig. 1. Ratios of weekend and workday average mass loads of selected urinary drug biomarkers $621\left(\mathrm{MOR}_{\text {tot }}, 6-\mathrm{AM}, \mathrm{AMP}, \mathrm{MDMA}, \mathrm{BE}, \mathrm{THC}-\mathrm{COOH}, \mathrm{EDDP}\right)$ determined in the period from 2009 to 622 2016. Error bars represent standard deviations. Horizontal lines represent arbitrarily assumed 623 weekend to workday mass load ratio of $1.0 \pm 0.2$.

624 Fig. 2. Mass loads of BE, MDMA and AMP in two different Christmas-New Year holiday periods: 625 A) $2012 / 2013$ and B) $2013 / 2014$.

626 Fig. 3. Average mass loads of selected drug biomarkers determined on workdays, weekend and 627 during two Christmas-New Year periods: A) 2012/2013 and B) 2013/2014. Error bars represent 628 standard deviations.

629 Fig. 4. Variability of average mass loads of selected urinary drug biomarkers in Zagreb during the 630 spring and summer sampling week in A) 2009 and B) 2013. Error bars represent standard 631 deviations.

632 Fig. 5. Impact of the selected sampling schemes (whole-year and one-week monitoring) on the 633 determination of representative mass loads. Error bars represent standard deviations.

634 Fig. 6. Consumption of cocaine, heroin, MDMA, amphetamine, THC and methadone in the city 635 of Zagreb in the period 2009-2016. Error bars represent standard deviations. 
636 Fig. 7. Comparison of estimated drug consumption in the city of Zagreb with available 637 epidemiological data for Croatia in the period of 2009-2016. Stimulants in the epidemiological 638 figure include amphetamine-type drugs. Opiates include heroin and morphine. 
Table 1. Selected drug biomarkers and data used for estimation of drug consumption.

\begin{tabular}{|c|c|c|c|c|c|}
\hline Drug & $\begin{array}{l}\text { Biomarker for } \\
\text { estimation of } \\
\text { consumption }\end{array}$ & $\begin{array}{l}\text { Percentage of drug } \\
\text { doses excreted as } \\
\text { drug biomarker }\end{array}$ & $\begin{array}{l}\text { Molar } \\
\text { ratio }\end{array}$ & $\begin{array}{l}\text { Correction } \\
\text { factor }\end{array}$ & Dose (mg) \\
\hline Heroin & 6-AM & 1.3 & 1.13 & $86.9^{\mathrm{a}}$ & $10^{d}$ \\
\hline Cocaine & $\mathrm{BE}$ & 29 & 1.05 & $3.6^{\mathrm{b}}$ & $30^{d}$ \\
\hline Amphetamine & AMP & 36 & 1.00 & $2.8^{c}$ & $10^{c}$ \\
\hline MDMA & MDMA & 22.5 & 1.00 & $4.4^{c}$ & $97^{d}$ \\
\hline THC (Cannabis) & $\mathrm{THC}-\mathrm{COOH}$ & 0.5 & 0.91 & $182^{\mathrm{C}}$ & $125^{c}$ \\
\hline Methadone & EDDP & 25 & 1.12 & 3.6 & $80^{e}$ \\
\hline
\end{tabular}

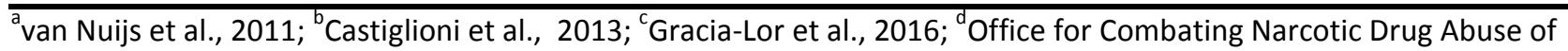
the Government of the Republic of Croatia, data for 2013; ${ }^{~}$ Croatian Institute of Public Health, data for Zagreb for 2010. 
Click here to download Table: Table 2 R1.doc

Table 2. Mass loads of urinary biomarkers (MOR tot, MOR, M3G, 6-AM, MAMP, AMP, MDMA, BE, MDMA, THC-COOH, EDDP) in raw wastewater of the city of Zagreb (Croatia) in the period 2009 - 2016.

\begin{tabular}{|c|c|c|c|c|c|c|c|}
\hline $\begin{array}{l}\text { Urinary drug } \\
\text { biomarker }\end{array}$ & Year & $n^{a}$ & $F^{b}$ & $\begin{array}{c}\text { Concentration } \\
\text { range } \\
\text { (ng/L) }\end{array}$ & $\begin{array}{c}\text { Average } \pm \text { SD } \\
\text { (ng/L) }\end{array}$ & $\begin{array}{c}\text { Mass load } \\
\text { range } \\
\text { (g/day) } \\
\end{array}$ & $\begin{array}{c}\text { Average } \pm \text { SD } \\
\text { (g/day) }\end{array}$ \\
\hline \multirow{7}{*}{$\mathrm{MOR}_{\text {tot }}$} & 2009 & 39 & 100 & $161-476$ & $294 \pm 83$ & $45-106$ & $75 \pm 15$ \\
\hline & 2011 & 7 & 100 & $130-160$ & $142 \pm 10.8$ & $30-36$ & $32 \pm 2.4$ \\
\hline & 2012 & 54 & 100 & $26-183$ & $95 \pm 37$ & $11-61$ & $27 \pm 12$ \\
\hline & 2013 & 72 & 100 & $33-167$ & $90 \pm 32$ & $17-50$ & $28 \pm 6.8$ \\
\hline & 2014 & 54 & 100 & $25-129$ & $80 \pm 28$ & $17-62$ & $28 \pm 7.5$ \\
\hline & 2015 & 30 & 100 & $45-144$ & $94 \pm 23$ & $16-39$ & $30 \pm 5.2$ \\
\hline & 2016 & 26 & 100 & $49-147$ & $97 \pm 22$ & $18-44$ & $35 \pm 6.2$ \\
\hline \multirow{7}{*}{ MOR } & 2009 & 39 & 100 & $160-476$ & $294 \pm 83$ & $45-106$ & $75 \pm 15$ \\
\hline & 2011 & 7 & 100 & $109-135$ & $120 \pm 9.3$ & $25-31$ & $27 \pm 2.1$ \\
\hline & 2012 & 54 & 100 & $19-183$ & $94 \pm 37$ & $11-61$ & $27 \pm 12$ \\
\hline & 2013 & 72 & 100 & $26-166$ & $86 \pm 32$ & $15-50$ & $27 \pm 7.0$ \\
\hline & 2014 & 54 & 100 & $22-127$ & $74 \pm 29$ & $13-61$ & $26 \pm 7.3$ \\
\hline & 2015 & 30 & 100 & $41-141$ & $91 \pm 22$ & $16-38$ & $29 \pm 5.0$ \\
\hline & 2016 & 26 & 100 & $42-143$ & $91 \pm 23$ & $17-41$ & $32 \pm 5.7$ \\
\hline \multirow{7}{*}{ M3G } & 2009 & 0 & NA & NA & NA & NA & NA \\
\hline & 2011 & 7 & 100 & $3.3-5.5$ & $4.7 \pm 0.7$ & $0.7-1.3$ & $1.1 \pm 0.2$ \\
\hline & 2012 & 54 & 85 & $<0.2-10.5$ & $1.6 \pm 2.2$ & $<0.03-6.8$ & $0.5 \pm 1.1$ \\
\hline & 2013 & 72 & 100 & $<0.3-19$ & $6.6 \pm 4.9$ & $<0.1-8.9$ & $2.3 \pm 2.0$ \\
\hline & 2014 & 54 & 100 & $<0.3-29$ & $8.5 \pm 6.7$ & $<0.1-15$ & $3.4 \pm 3.3$ \\
\hline & 2015 & 30 & 100 & $<0.3-16$ & $3.9 \pm 4.2$ & $<0.1-6.5$ & $1.2 \pm 1.5$ \\
\hline & 2016 & 26 & 100 & $<0.3-24$ & $9.9 \pm 6.7$ & $<0.1-11$ & $3.9 \pm 3.0$ \\
\hline \multirow{7}{*}{ 6-AM } & 2009 & 39 & 100 & $3.3-28$ & $12 \pm 4.7$ & $0.7-6.0$ & $3.1 \pm 1.2$ \\
\hline & 2011 & 7 & 100 & $2.3-4.2$ & $3.3 \pm 0.6$ & $0.5-0.96$ & $0.8 \pm 0.1$ \\
\hline & 2012 & 54 & 91 & $<0.1-16$ & $2.0 \pm 2.4$ & $<0.01-3.7$ & $0.5 \pm 0.6$ \\
\hline & 2013 & 72 & 100 & $0.1-14$ & $3.1 \pm 1.9$ & $0.1-3$ & $1.1 \pm 0.5$ \\
\hline & 2014 & 54 & 100 & $0.1-7.0$ & $3.1 \pm 1.04$ & $0.1-2.3$ & $1.2 \pm 0.4$ \\
\hline & 2015 & 30 & 93 & $<0.1-7.6$ & $3.4 \pm 1.8$ & $<0.04-1.9$ & $1.1 \pm 0.5$ \\
\hline & 2016 & 26 & 100 & $2.2-16$ & $5.0 \pm 2.9$ & $0.7-4.1$ & $1.7 \pm 0.7$ \\
\hline \multirow{7}{*}{ MAMP } & 2009 & 0 & NA & NA & NA & NA & NA \\
\hline & 2011 & 0 & NA & NA & NA & NA & NA \\
\hline & 2012 & 54 & 83 & $<0.2-4.0$ & $0.7 \pm 0.9$ & $<0.1-0.96$ & $0.2 \pm 0.2$ \\
\hline & 2013 & 72 & 78 & $<0.2-3.8$ & $1.1 \pm 1.0$ & $<0.1-2$ & $0.4 \pm 0.5$ \\
\hline & 2014 & 54 & 78 & $<0.2-2.8$ & $0.63 \pm 0.66$ & $<0.1-1.9$ & $0.25 \pm 0.3$ \\
\hline & 2015 & 30 & 100 & $<0.4-5.9$ & $1.4 \pm 1.8$ & $<0.1-1.7$ & $0.4 \pm 0.5$ \\
\hline & 2016 & 26 & 89 & $<0.2-12$ & $1.3 \pm 2.3$ & $<0.1-3.7$ & $0.5 \pm 0.7$ \\
\hline \multirow{7}{*}{ AMP } & 2009 & 39 & 72 & $<1.3-35$ & $7.5 \pm 7.5$ & $<0.3-7.6$ & $1.9 \pm 1.8$ \\
\hline & 2011 & 7 & 100 & $32-62$ & $42 \pm 10.3$ & $7.2-13$ & $9.5 \pm 2.1$ \\
\hline & 2012 & 54 & 100 & $7.2-58$ & $27 \pm 15$ & $2.3-17$ & $7.5 \pm 4.1$ \\
\hline & 2013 & 72 & 100 & $6.3-235$ & $45 \pm 38$ & $2.7-63$ & $13 \pm 8.4$ \\
\hline & 2014 & 54 & 100 & $14-149$ & $51 \pm 26$ & $6.1-74$ & $18 \pm 12$ \\
\hline & 2015 & 30 & 100 & $34-320$ & $100 \pm 70$ & $12-111$ & $32 \pm 23$ \\
\hline & 2016 & 26 & 100 & $25-295$ & $109 \pm 58$ & $15-89$ & $38 \pm 19$ \\
\hline \multirow{4}{*}{ MDMA } & 2009 & 39 & 79 & $<1.1-33$ & $6.8 \pm 7.7$ & $<0.2-7.4$ & $1.7 \pm 1.7$ \\
\hline & 2011 & 7 & 100 & $5.3-16$ & $9.4 \pm 4.6$ & $1.2-3.6$ & $2.1 \pm 1.0$ \\
\hline & 2012 & 54 & 98 & $<0.1-96$ & $26 \pm 22$ & $<0.03-21$ & $7.1 \pm 4.9$ \\
\hline & 2013 & 72 & 100 & $3.4-260$ & $30 \pm 40$ & $1.8-62$ & $8.5 \pm 8.7$ \\
\hline
\end{tabular}




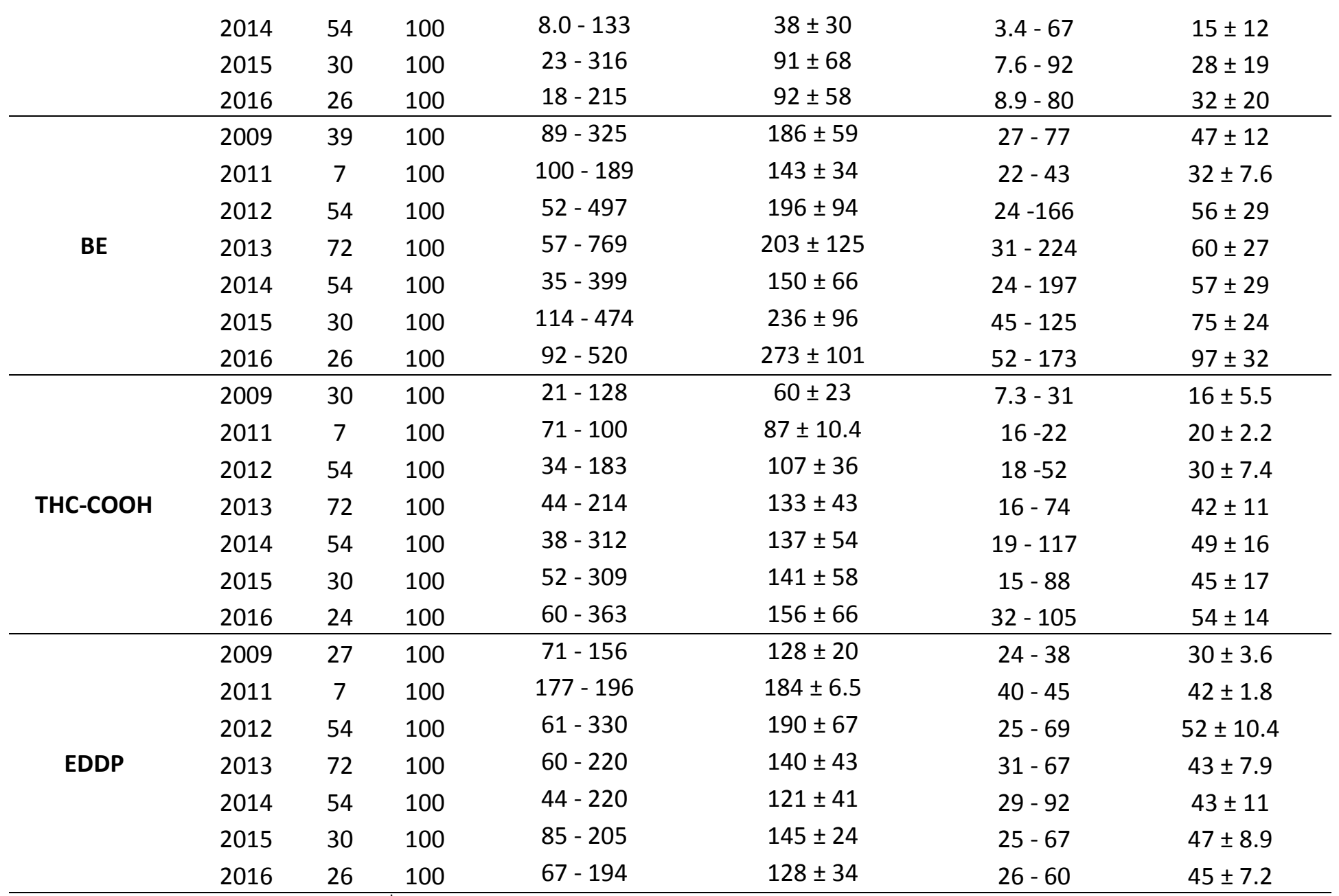

${ }^{a}$ Number of analyzed samples; ${ }^{b}$ Frequency of detection; NA - not applicable 

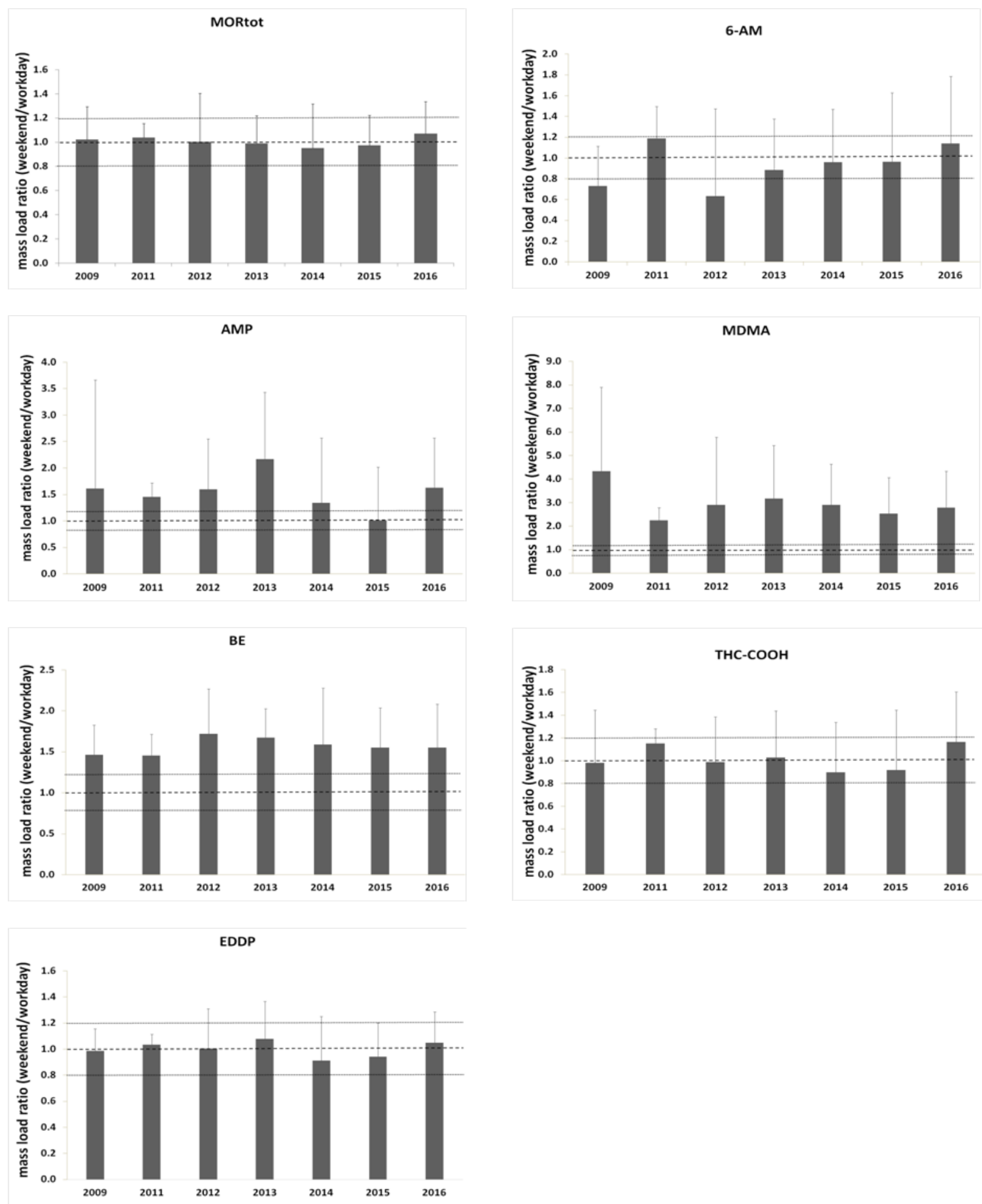

Figure 1. Ratios of weekend and workday average mass loads of selected urinary drug biomarkers (MORtot, 6-AM, AMP, MDMA, BE, THC-COOH, EDDP) determined in the period from 2009 to 2016. Error bars represent standard deviations. Horizontal lines represent arbitrarily assumed weekend to workday mass load ratio of $1.0 \pm 0.2$. 
A)

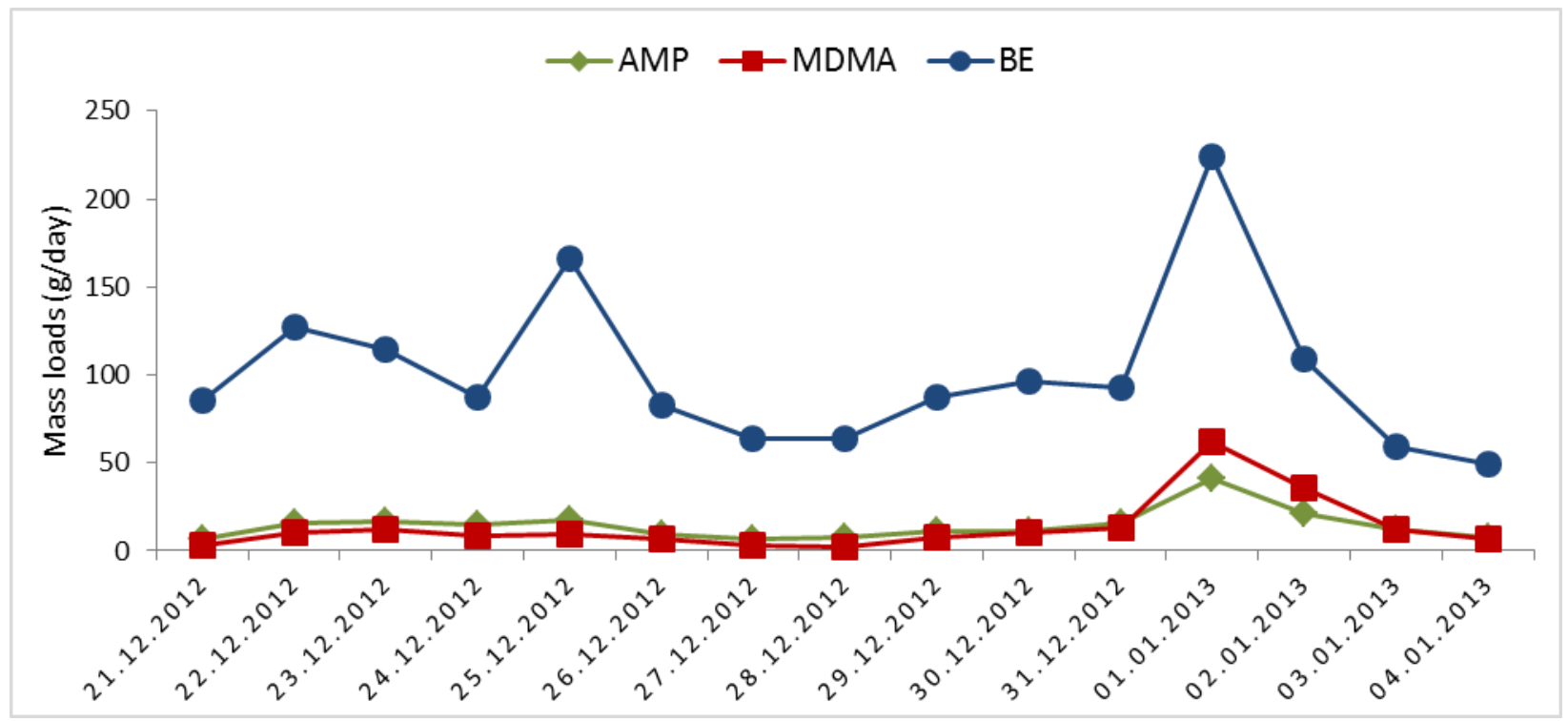

B)

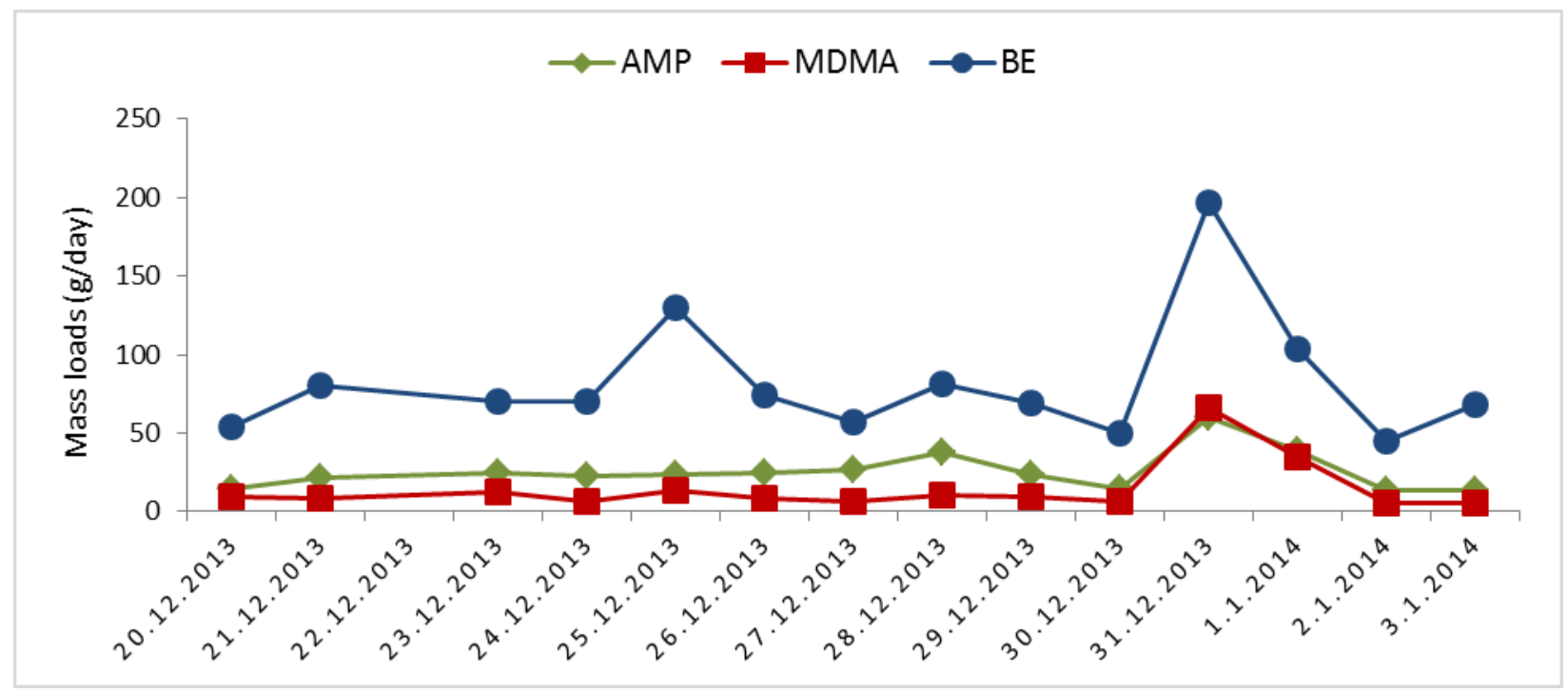

Fig. 2. Mass loads of BE, MDMA and AMP in two different Christmas-New Year holiday periods: A) 2012/2013 and B) 2013/2014. 
(A)

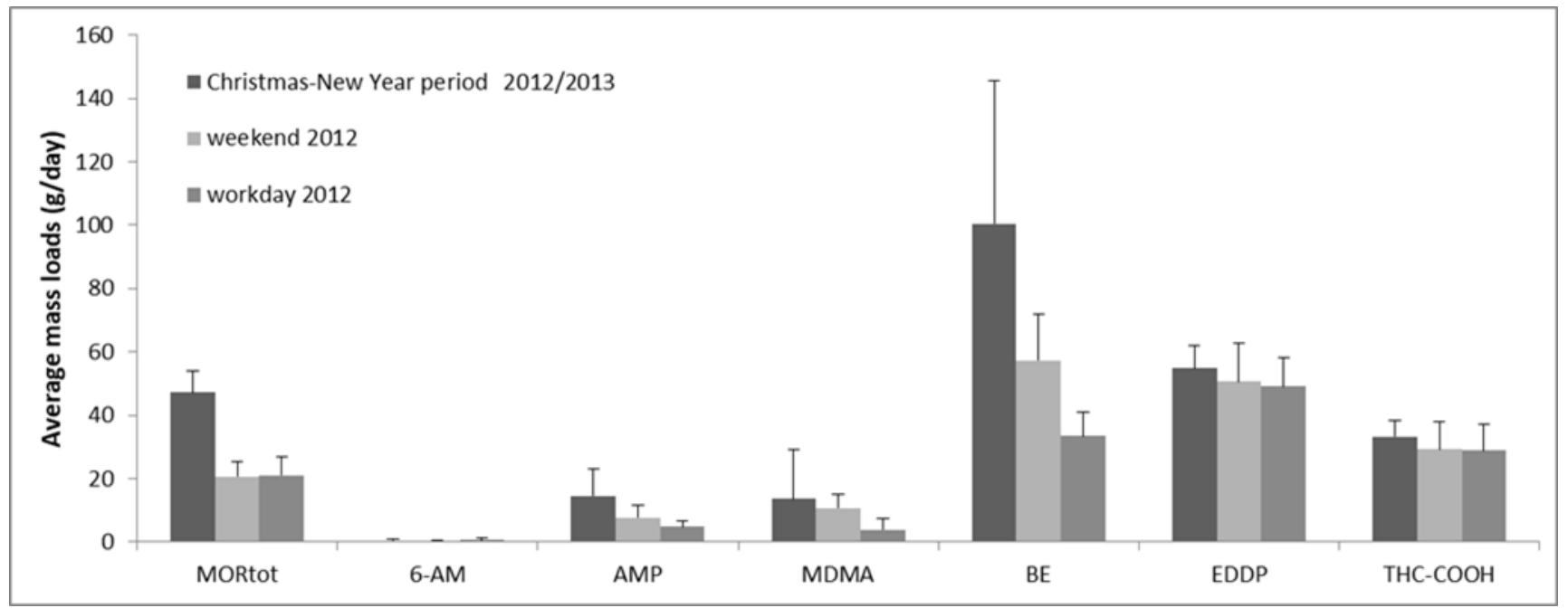

(B)

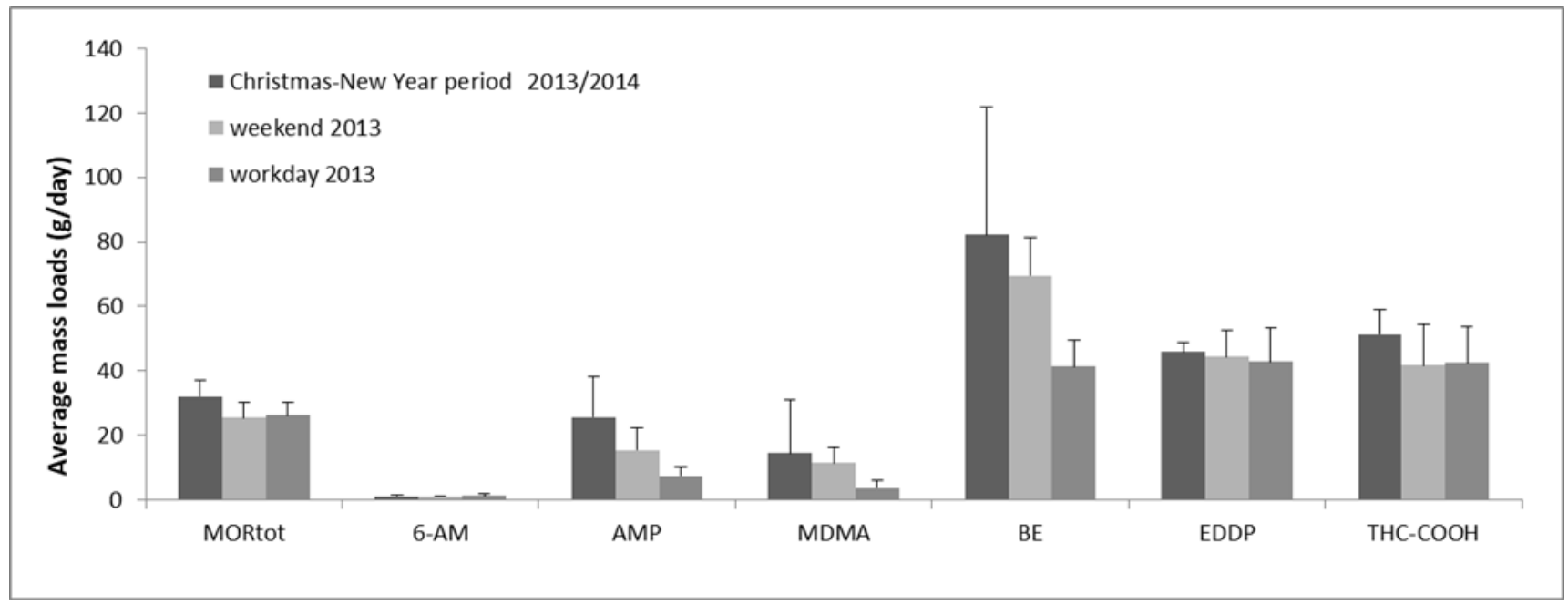

Fig. 3. Average mass loads of selected drug biomarkers determined on workdays, weekend and during two Christmas-New Year periods: A) 2012/2013 and B) 2013/2014. Error bars represent standard deviations. 

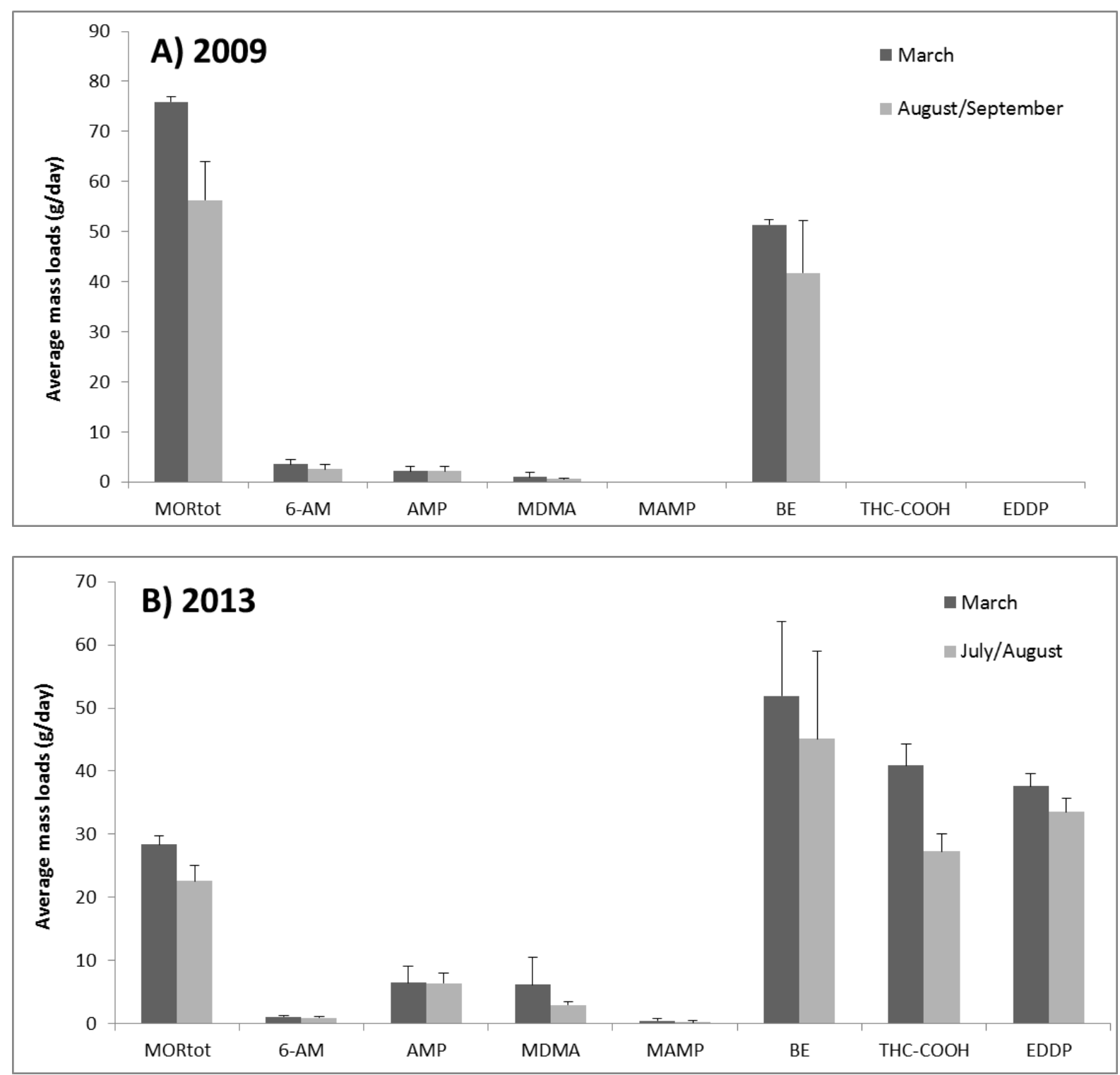

Fig. 4. Variability of average mass loads of selected urinary drug biomarkers in Zagreb during the spring and summer sampling week in A) 2009 and B) 2013. Error bars represent standard deviations. 


\section{Figure 5}

Click here to download Figure: Fig 5_R1.doc
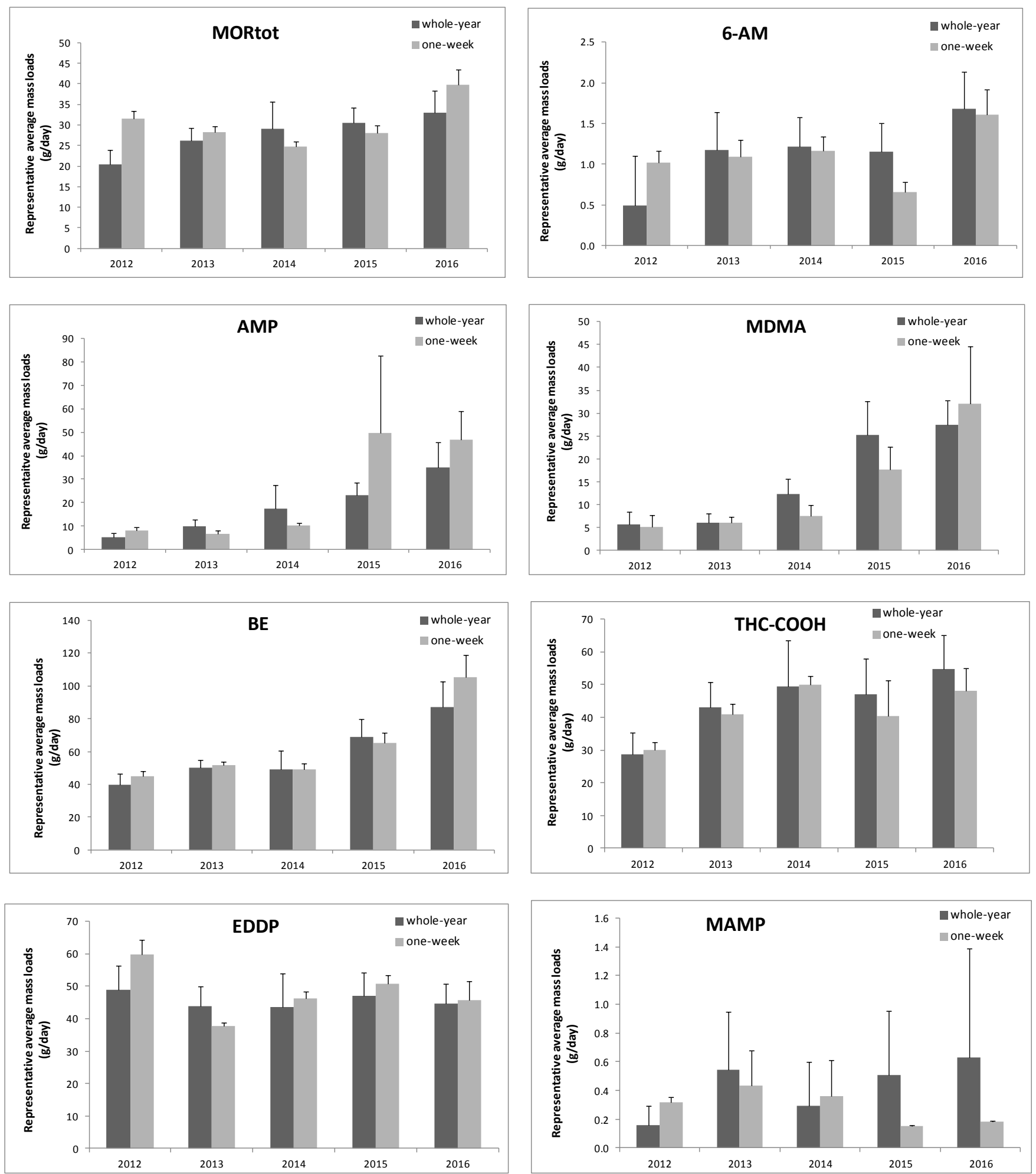

Figure 5. Impact of the selected sampling strategy (whole-year and one-week monitoring) on the determination of representative mass loads. 

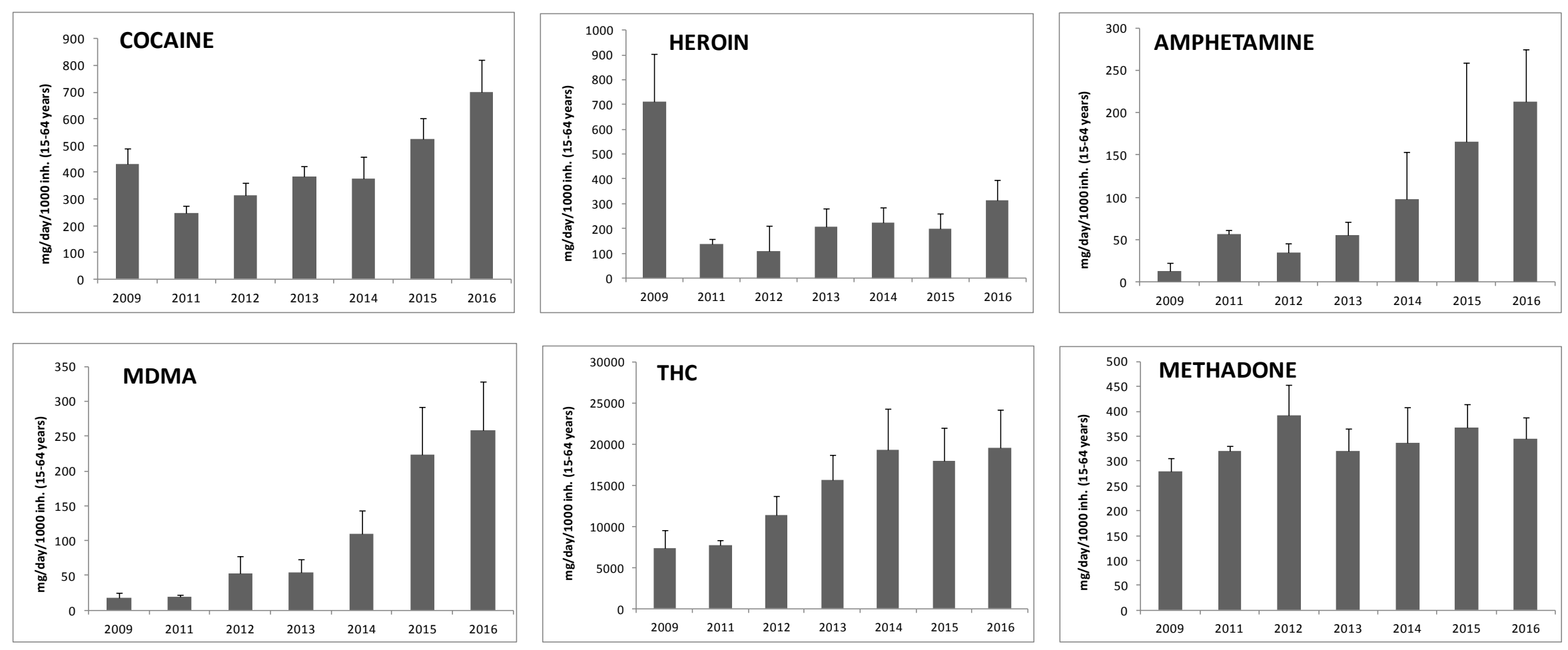

Fig. 6. Consumption of cocaine, heroin, MDMA, amphetamine, THC and methadone in the city of Zagreb in the period 2009-2016. Error bars represent standard deviations. 

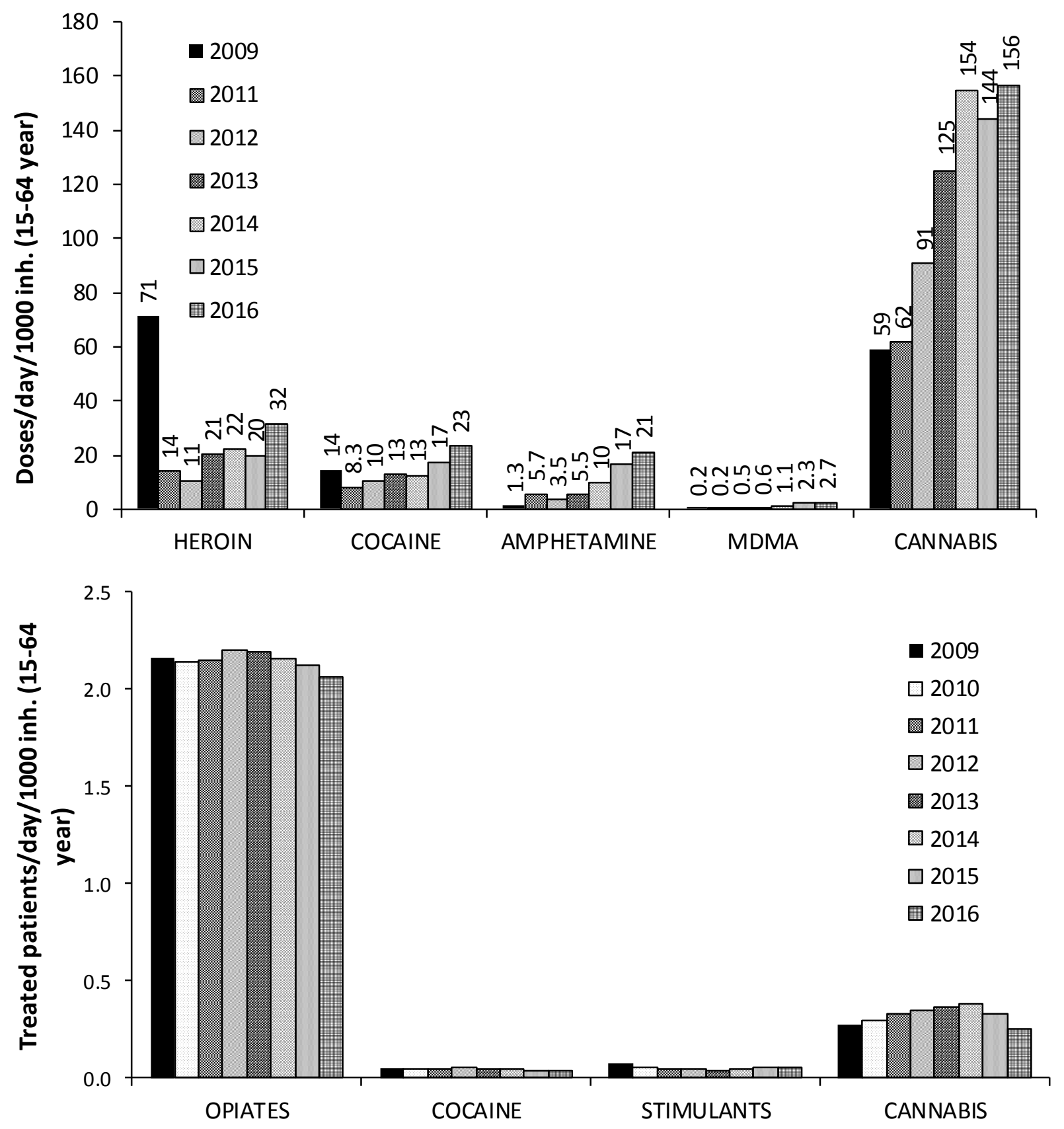

Fig. 7. Comparison of estimated drug consumption in the city of Zagreb with available epidemiological data for Croatia in the period of 2009-2016. Stimulants in the epidemiological figure include amphetamine-type drugs. Opiates include heroin and morphine. 

Supplementary material for on-line publication only
Click here to download Supplementary material for o

Click here to download Supplementary material for on-line publication only: Krizman et al_Supplementary material_R1.doc 